

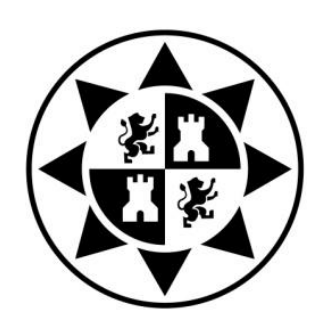

UNIVERSIDAD POLITÉCNICA DE CARTAGENA

Departamento de Producción Vegetal

\section{Effects of aeration of the nutrient solution and application of PGPR on the production and quality of baby leaf vegetables grown in floating system}

Autora:

Diana Niñirola Campoy

Dirigida por:

Juan A. Fernández Hernández

Catalina Egea Gilabert 

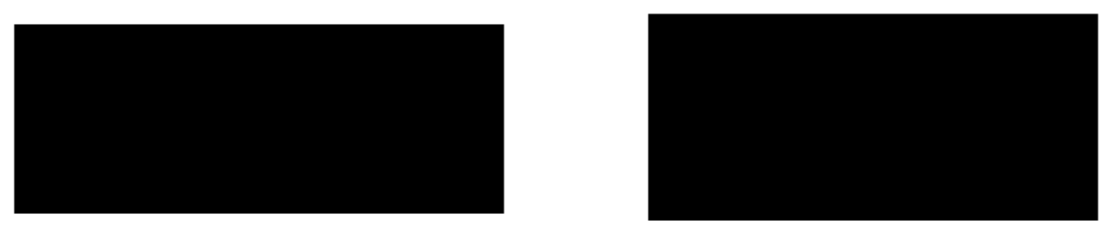
- 


\section{AGRADECIMIENTOS}

A Juan y Caty por confiar en mí desde el principio, darme la oportunidad de conocer el mundo de la investigación y hacer posible esta tesis.

A Encarna por ser el apoyo, la profesora y la amiga.

A mis compañeras y amigas: Adriana, Raquel, Almudena, Marina, Mayra y Eli, por todo.

A los maestros de la finca: Francisco, Jose, Pedro, Fini y Vicente.

A mis profesores: Juan Antonio, Eva, Marcos, Julia y a todo el departamento de Producción Vegetal.

A Virginia, Victoria, María, Mª Ángeles, Juan, Nacho, Eva, Lucía, María y Elena por su ayuda.

A Silvana, por el trato especial.

A mis amigos de Turín: Giuseppe, Manuela, Alessio, Paolo, Guido, Serenella y Francesca.

A mis amigas turcas Hale y Funda.

A mis hermanas, porque no hay mejores.

A mis padres, por apoyarme en mis estudios y en la vida.

Y a Eduardo y Claudia por ser mi piedra angular. 


\section{RECONOCIMIENTOS}

Este trabajo se encuadra dentro de las actividades del Departamento de Producción Vegetal de la Universidad Politécnica de Cartagena en el proyecto de investigación MCINN "Optimización de la tecnología de producción de hortalizas de hoja pequeña (baby leaf) en bandejas flotantes para su uso como producto mínimamente procesado de alta calidad" (AGL2010-17680).

Los resultados de la presente tesis doctoral han sido publicados en:

\section{Revistas científicas:}

- L. J. Lara, C. Egea-Gilabert, D. Niñirola, E. Conesa, J. A. Fernández. 2011. Effect of aeration of the nutrient solution on the growth and quality of purslane (Portulaca oleracea). Journal of Horticultural Science \& Biotechnology, 86 (6): 603-610.

- D. Niñirola, J. A. Fernández, E. Conesa, J. A. Martínez, C. EgeaGilabert. 2014. Combined effects of growth cycle and different levels of aeration in nutrient solution on productivity, quality, and shelf life of watercress (Nasturtium officinale R. Br.) Plants. Hortscience, 49(5): $567-573$.

- D. Niñirola, G. Pignata, M. Casale, P. E. Lo Turco, C. Egea-Gilabert, J. A. Fernández, S. Nicola. Inherent quality and safety of watercress (Nasturtium officinale $\mathrm{R}$. Br.) grown in a floating system using plant growth-promoting rhizobacteria (PGPR). Horticultural Science. (enviado)

- D. Niñirola, J. A. Fernández, C. Egea-Gilabert, E. Conesa. Nutrient solution aeration and growing cycles affect quality and yield of freshcut baby leaf red lettuce. Journal of the Science of Food and Agriculture. (enviado)

\section{Congresos:}

- V. Balanza, J.A. Martínez, E. Conesa, C. Egea-Gilabert, D. Niñirola, J. López, J.A. Fernández. Effect of PGPR application and nitrogen 
doses on baby leaf lettuce grown in a floating system. GreenSys 2011: Advances, technologies and management towards sustainable greenhouse ecosystems. Halkidiki 2011. Acta Horticulturae, 952, ISHS 2012.

- D. Niñirola, C. Egea-Gilabert, E. Conesa, F. Artés-Hernández, J.A. Martínez, F. Artés, J.A. Fernández. Influence of aeration of the nutrient solution on quality changes of two baby leaf lettuce cultivars grown in a floating system at harvest and during shelf life as fresh-cut product. II ISHS International Conference on quality management of fresh cut produce: Convenience food for a tasteful life. Torino 2011.

- D. Niñirola, C. Egea-Gilabert, J.A. Martínez, E. Conesa, Gutiérrez, L, J.A. Fernández. Efecto de la aireación de la solución nutritiva sobre el crecimiento y la calidad de berros cultivados en bandejas flotantes. XIII Congreso SECH. Almería, 2012.

- S. Nicola, C. Egea-Gilabert, D. Niñirola, E. Conesa, G. Pignata, E. Fontana, J.A. Fernández. Nitrogen and aeration levels of the nutrient solution in soilless cultivation systems as important growing conditions affecting inherent quality of baby leaf vegetables: a review. Second Symposium on Horticulture in Europe. Angers, France, 2012.

- D. Niñirola, C. Egea-Gilabert, J.A. Martínez, J. López-Marín, E. Conesa y J.A. Fernández. 2014. Influencia de la aireación de la solución nutritiva y de la fecha de cosecha en la producción y calidad de lechuga "babyleaf". VII Congreso Ibérico de Agroingeniería y Ciencias Hortícolas: Innovar y Producir para el Futuro (F. G. UPM, ed.): 2023-2028, Madrid. 
ABSTRACT 
The floating system is one of the easiest and cheapest hydroponic methods used to produce baby leaf vegetables, a product which has grown in popularity in recent years as a ready-to-eat vegetable included in salads or as a single products.

The aim of this thesis was to assess the influence of three levels of aeration of the nutrient solution, the growing cycle or the application of plant growth promoting rhizobacteria (PGPR) on yield, on quality and on shelf life as a fresh-cut product of different species of baby leaf vegetables.

In the experiments of aeration of the nutrient solution, three levels [no aeration (NA), low aeration (LA) or high aeration (HA)] were studied in three different species (purslane, watercress and lettuce).

The study of three levels of aeration of the nutrient solution on the growth and quality of two cultivars of purslane (Portulaca oleracea L.) over four crop cycles showed that purslane exhibited little sensitivity to oxygen depletion in the rooting medium, since it was able to adapt to a gradual reduction in oxygen content. Under such conditions, purslane plants created an aerenchyma tissue that helped to maintain growth. Under conditions in which no aeration was provided, there was a slight decrease in plant growth. The final quality of the product was improved because leaf nitrate concentrations were reduced compared with the high aeration treatment, and the content of functional phytochemicals and chlorophyll contents were increased.

The study of the effects of nutrient solution aeration and growing cycle (spring vs. winter) on yield, quality and on shelf life as a fresh-cut product of watercress (Nasturtium officinale $\mathrm{R}$. Br.) showed that in the spring cycle, the plants had significantly higher yield and antioxidant capacity and lower specific leaf area, total root length, root diameter, length of 0 to $0.5 \mathrm{~mm}$ diameter root, and oxalate content than in the winter cycle. The absence of aeration increased the antioxidant capacity and vitamin $\mathrm{C}$ content in both cycles. Several adventitious roots developed exogenously from the watercress stem at the nodes as a morphological adaptation to oxygen depletion, particularly in NA conditions. The nitrate, oxalate, $\mathrm{Ca}^{2+}, \mathrm{K}^{+}$ contents, and microbial populations were affected by both the cycle and the aeration conditions. Hue angle of the leaves was affected by both the cycle and storage time, and chromaticity and lightness were affected by the three factors (cycle, aeration, and storage time). The global quality was significantly higher ( 7.8 over 9 points hedonic scale) in the spring cycle than in winter, the score reflecting their 
marketable value ( 7.0 over 9 points). The mild dehydration problems observed in the winter cycle that led to a slightly lower overall product quality that could be the result of the development of thinner leaves and also the differences in the respiration rates compared with the spring cycle. In general, the spring cycle led to higher productivity, antioxidant capacity, and $\mathrm{Ca}^{2+}$ and $\mathrm{K}^{+}$contents and lower oxalate content. Aeration slightly affected the quality of the final product, the plants grown in non-aerated conditions being richer in vitamin $\mathrm{C}$ and antioxidants and with lower nitrate content.

The study of the effects of nutrient solution aeration and growing cycle (autumn, winter and summer) on yield, quality, and on shelf life as a fresh-cut product of a red lettuce (Lactuca sativa L.) showed that the specific leaf area was lowest in winter. Yield was affected only by the growing cycle, showing the highest value in autumn. Lack of aeration produced shorter total root length but did not affect the root diameter. The percentage of dry matter and the nitrate content were affected by growing cycle and aeration, total phenolics and mesophilic microorganism by both aeration and storage time, hue angle and chromacity by growing cycle and storage time, and antioxidant capacity, vitamin $\mathrm{C}$, lightness and psychrophilic microorganisms were affected by all three factors. NA conditions increased the antioxidant capacity in summer and vitamin $\mathrm{C}$ content in winter. After 7 days of storage at $5{ }^{\circ} \mathrm{C}$, the antioxidant capacity, total phenolics, vitamin $\mathrm{C}$ and nitrate content decreased. The leaves were redder (higher Hue angle) in autumn and winter. The lowest mesophilic and psychrophilic count was observed in autumn.

The last two chapters relate to the use of plant growth promoting rhizobacteria (PGPR) to improve the quality and yield of baby leaf vegetables grown in floating system.

Regarding to the effect of application of two PGPR (Bacillus subtilis and Bacillus velezensis) and two concentrations of nitrogen (4 and $12 \mathrm{mM}$ ) in the nutrient solution on yield, quality and nitrate content of two baby leaf lettuce cultivars the results showed that in both cultivars and crop cycles plant height was affected by the level of $\mathrm{N}$ and the PGPR application, while leaf area, fresh and dry weight were only affected by the level of $\mathrm{N}$. The use of the nutrient solution containing $12 \mathrm{mM}$ of nitrogen increased the accumulation of nitrate in leaves. The application of $B$. velezensis in the nutrient solution provoked a decrease of nitrate 
content in red lettuce leaves respect to control. Finally, root growth was not affected by neither nutritive solution nor bacterial inoculants in both cultivars.

Finally, the study of the effect of applying a PGPR (Bacillus subtilis) on the yield, quality and safety of watercress considering two factors: substrate disinfection and inoculation with B. subtilis showed that substrate disinfection had a positive effect on plant development because it increased the shoot antioxidant capacity and general plant growth and decreased the colony-forming units of moulds. In turn, inoculation with $B$. subtilis increased the antioxidant capacity but decreased the chlorophyll $a$, chlorophyll $b$ and carotenoid contents and did not affect the rest of parameters measured. 

INDEX 

INTRODUCTION

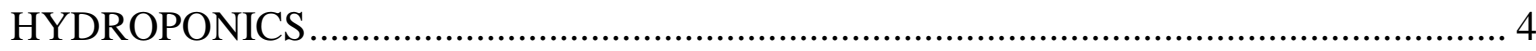

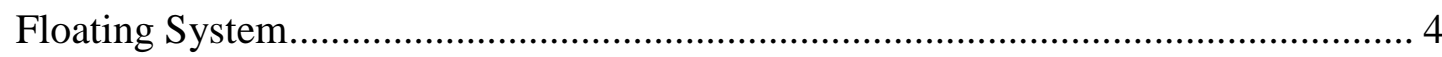

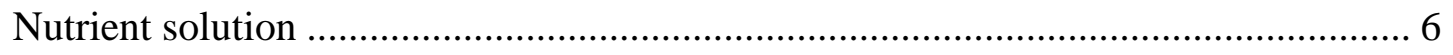

AERATION OF THE NUTRIENT SOLUTION AND RESPONSE TO HYPOXIA............ 8

PLANT GROWTH PROMOTING RHIZOBACTERIA (PGPR) ……………………….... 9

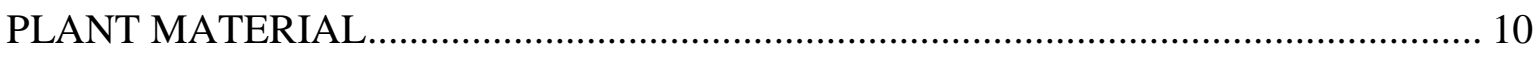

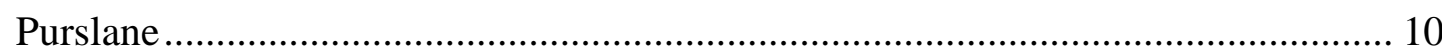

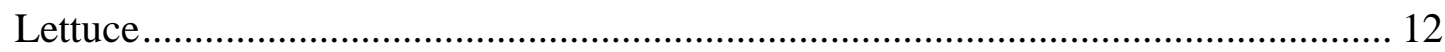

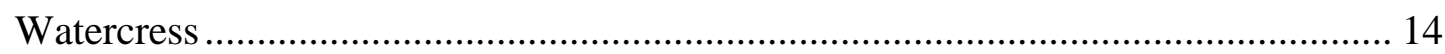

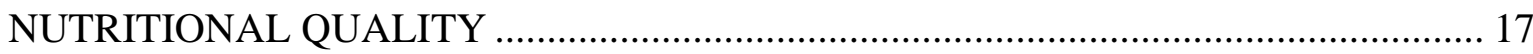

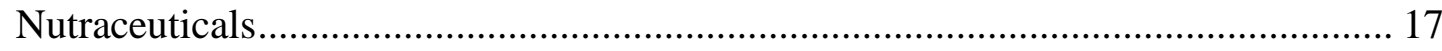

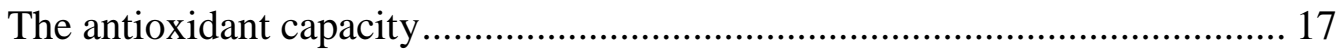

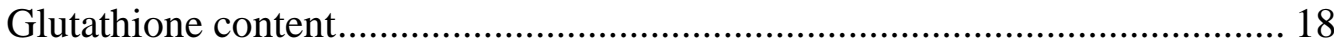

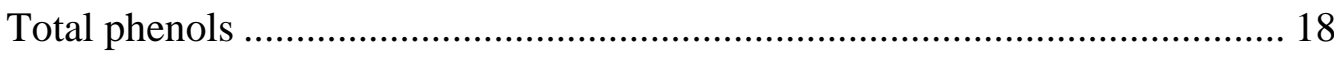

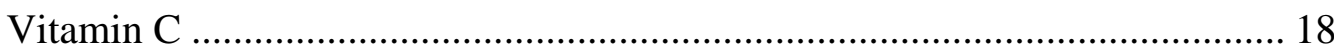

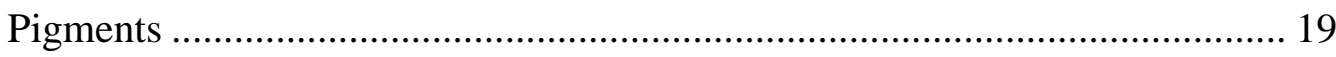

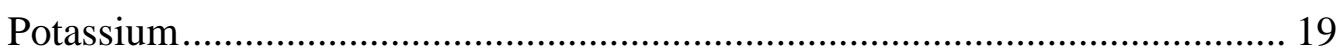

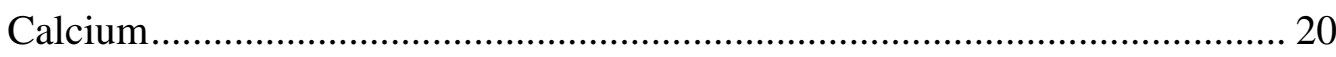

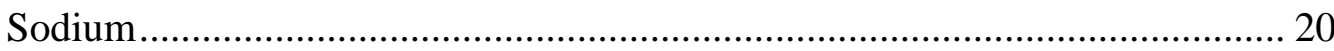

Antinutritional compounds ..................................................................................... 20

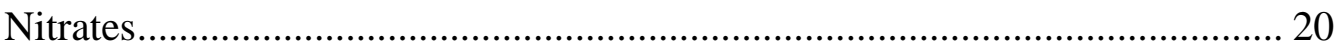

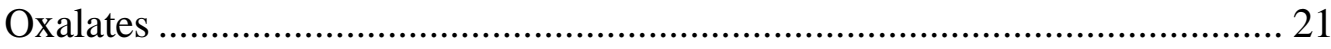

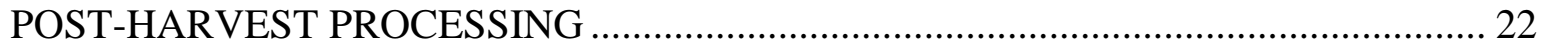

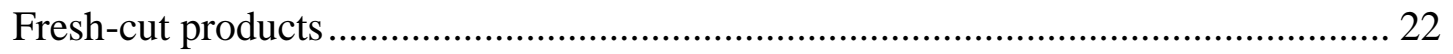

Factors involved in Fresh-Cut Produce ................................................................... 23

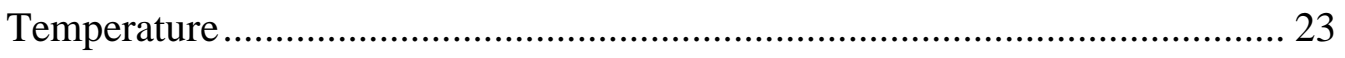


Atmosphere

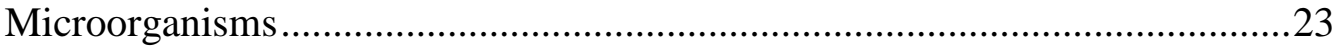

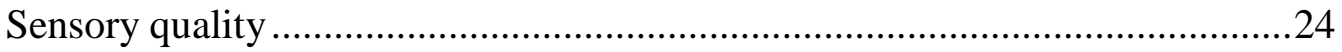

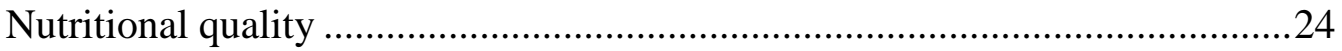

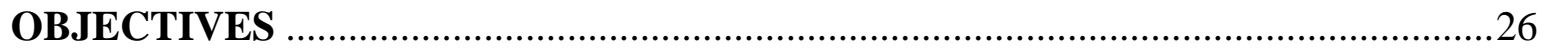

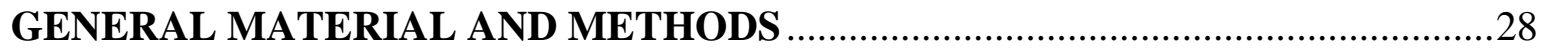

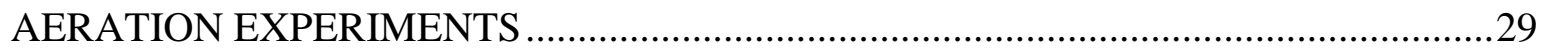

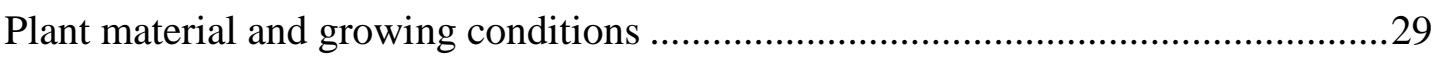

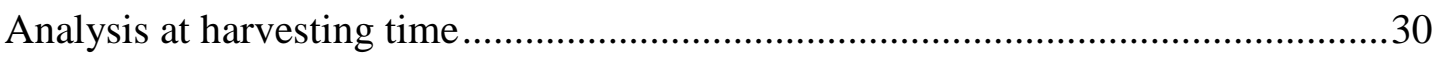

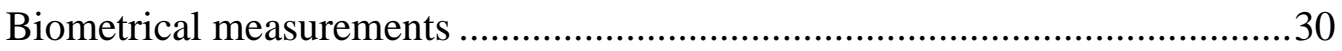

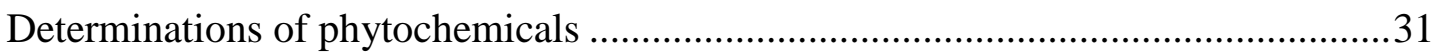

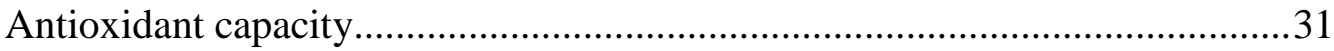

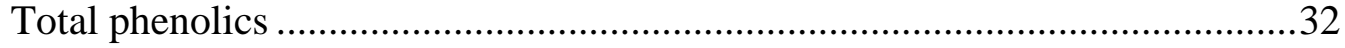

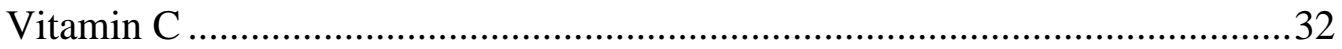

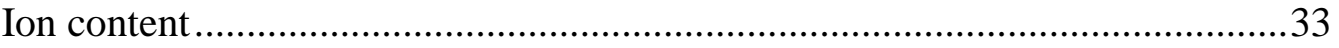

Postharvest product management ……...................................................................3

Postharvest was performed in the watercress and lettuce assays.....................33

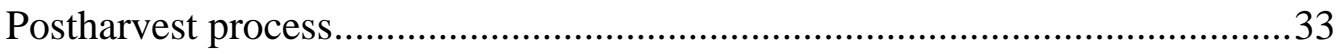

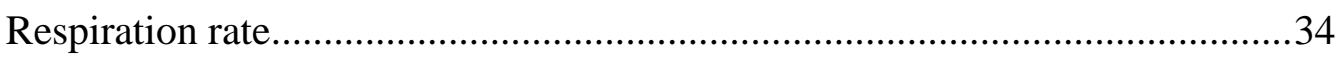

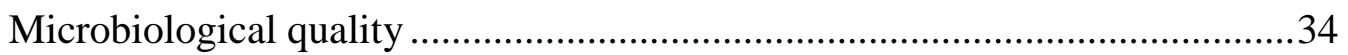

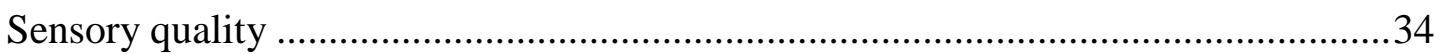

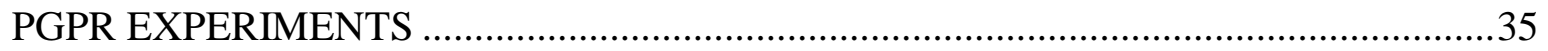

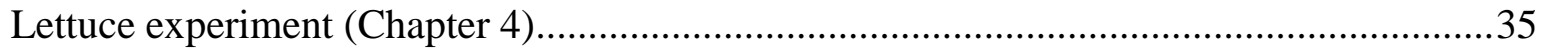

Plant material and growing conditions .................................................................

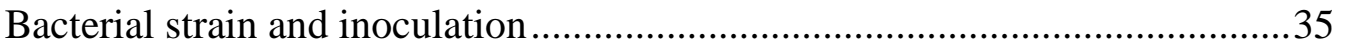

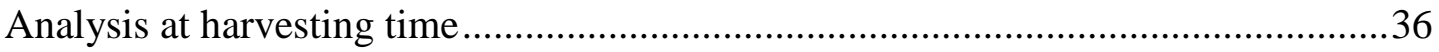

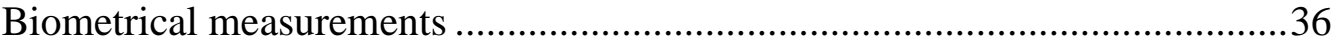




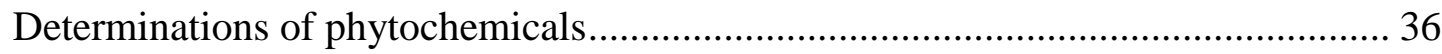

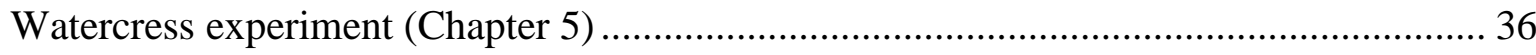

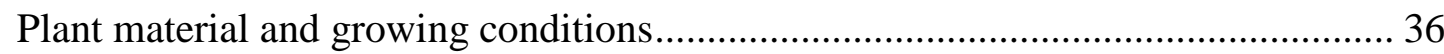

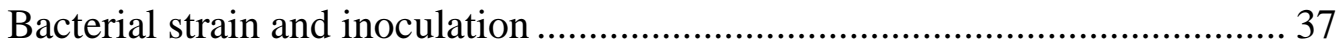

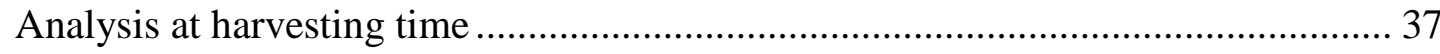

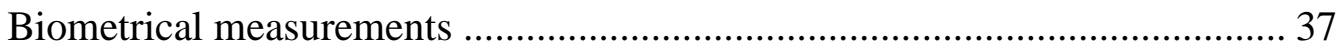

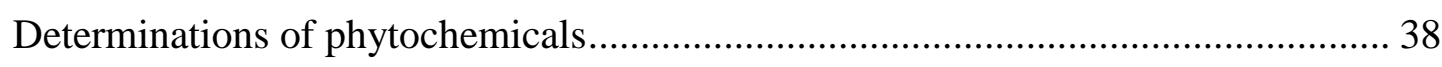

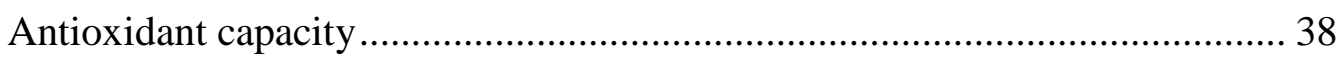

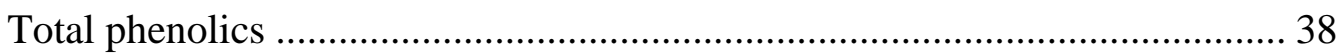

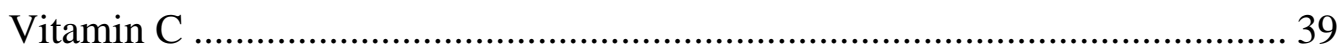

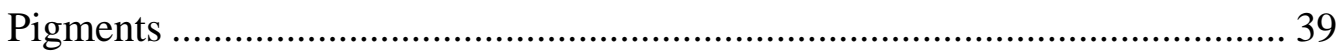

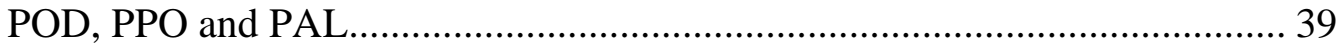

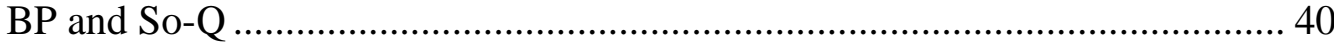

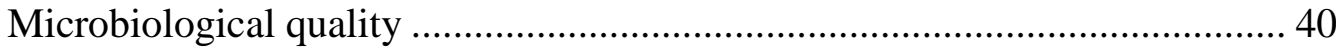

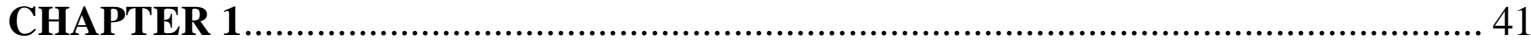

EFFECT OF AERATION OF NUTRIENT SOLUTION ON THE GROWTH AND QUALITY OF PURSLANE (Portulaca oleracea) ................................................. 42

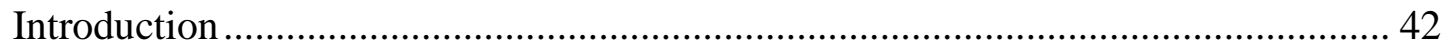

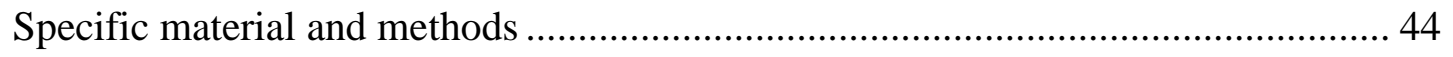

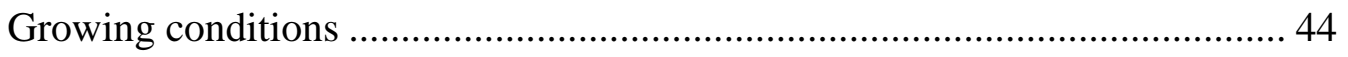

Plant growth measurements .............................................................. 45

Determinations of phytochemical contents ................................................ 46

Experimental design and statistical analysis ............................................. 46

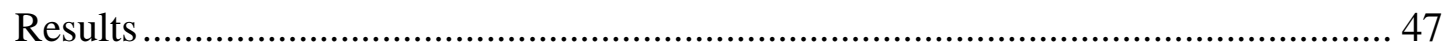

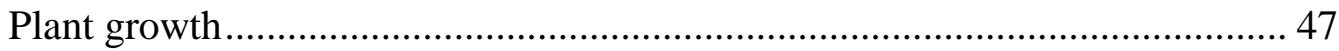

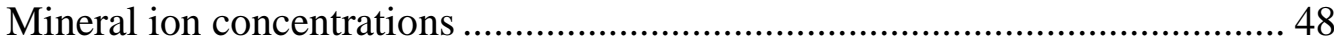

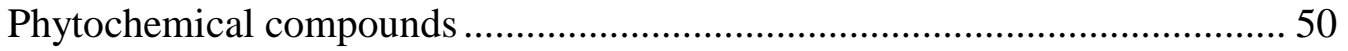


Discussion .50

CHAPTER 2 .56

COMBINED EFFECTS OF GROWTH CYCLE AND DIFFERENT LEVELS OF AERATION IN NUTRIENT SOLUTION ON PRODUCTIVITY, QUALITY, AND SHELF LIFE OF WATERCRESS (Nasturtium officinale R. BR.) PLANTS ............57

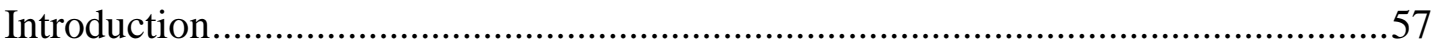

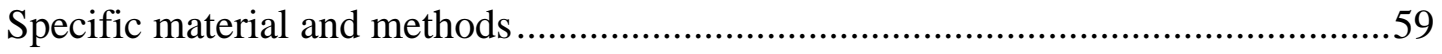

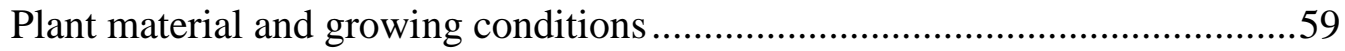

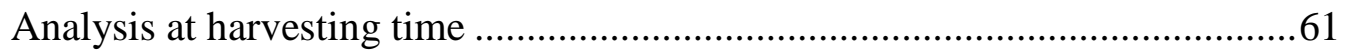

Postharvest product management and analysis ............................................61

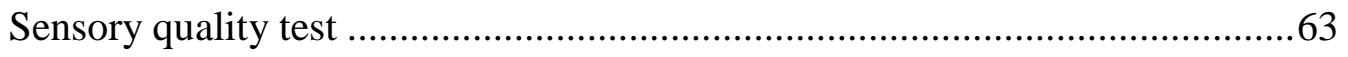

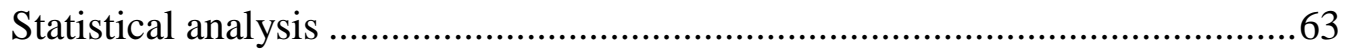

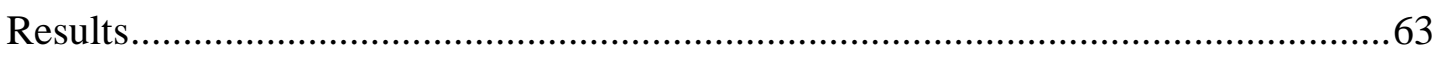

Temperature and dissolved oxygen in the nutrient solution...........................63

Growth, yield, and quality characteristics of watercress at harvesting time .....64

Visual and microbiological quality of fresh-cut product.................................66

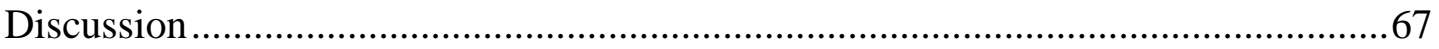

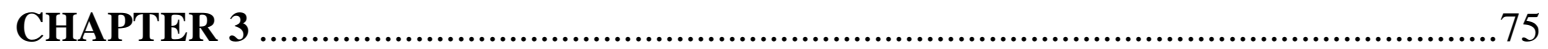

NUTRIENT SOLUTION AERATION AND GROWING CYCLES AFFECT QUALITY AND YIELD OF FRESH-CUT BABY LEAF RED LETTUCE …..........................76

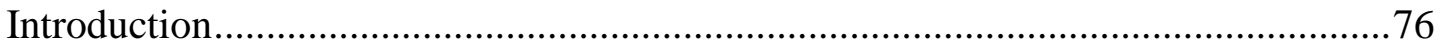

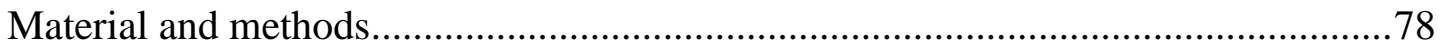

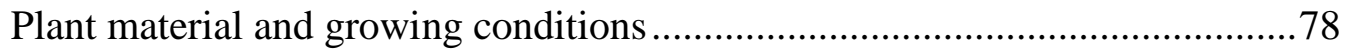

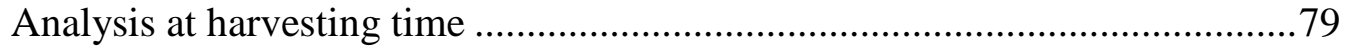

Postharvest product management and analysis ............................................ 80

Experimental design and statistical analysis .............................................. 80

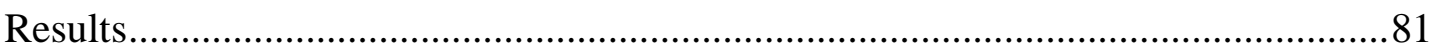

Monitoring of dissolved oxygen and temperature of the nutrient solution .......81 
Growth parameters and yield at harvesting time 81

Quality characteristics of fresh cut lettuce .................................................. 83

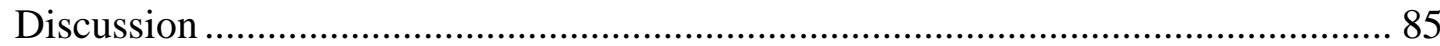

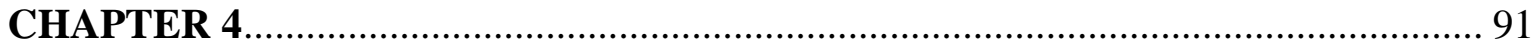

EFFECT OF PGPR APPLICATION AND NITROGEN DOSES ON BABY LEAF LETTUCE GROWN IN A FLOATING SYSTEM ............................................. 92

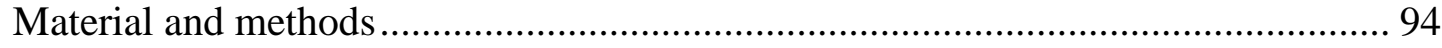

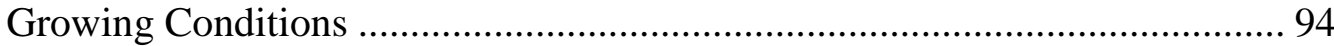

Plant Growth and Nitrate Measurements ...................................................... 95

Experimental Design and Statistical Analysis ............................................ 95

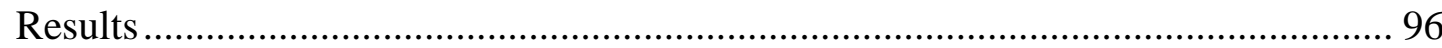

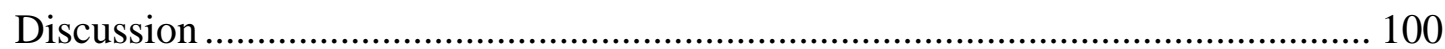

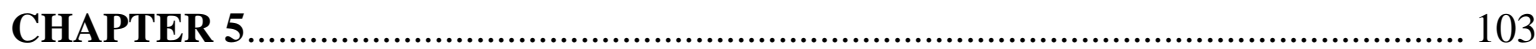

INHERENT QUALITY AND SAFETY OF WATERCRESS (Nasturtium officinale R.

BR.) GROWN IN A FLOATING SYSTEM USING PLANT GROWTHPROMOTING RHIZOBACTERIA (PGPR) ...................................................... 104

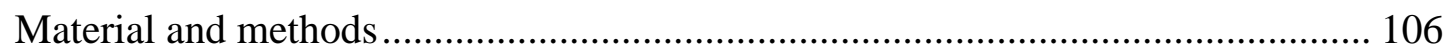

Plant material and growing conditions ................................................... 106

Bacterial strain and inoculation ............................................................. 107

Biometrical measurements and phytochemicals analyses ........................... 108

Microbiological analysis...................................................................... 109

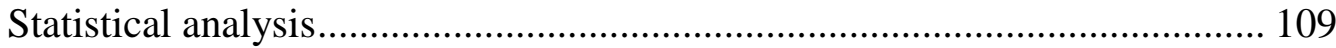

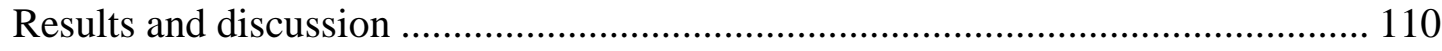

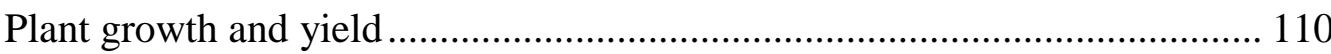

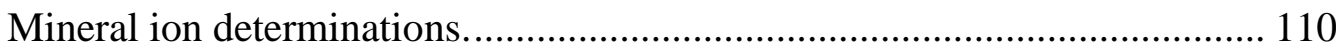

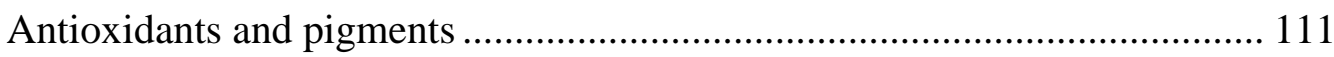

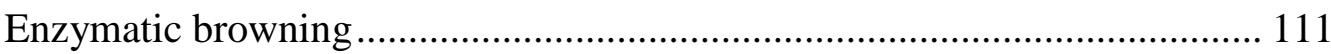

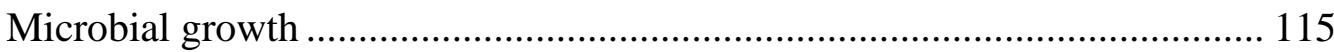




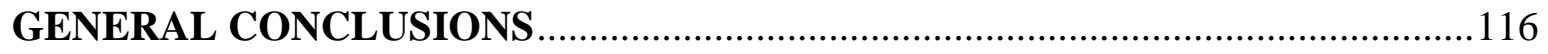

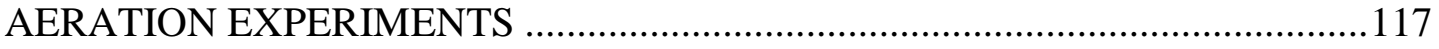

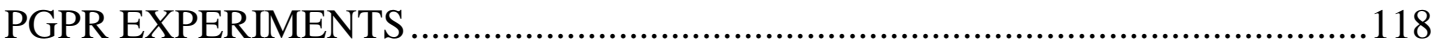

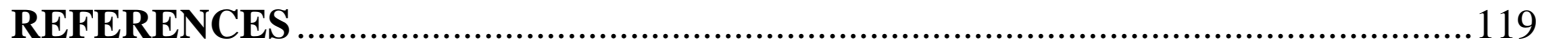

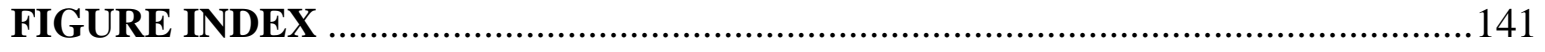

TABLE INDEX

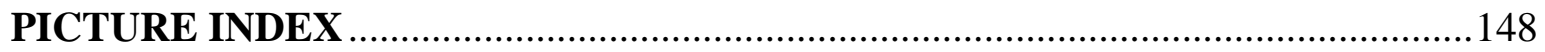


INTRODUCTION 

In recent decades, social changes relating to families, incorporation of women into the workplace, etc., have significantly affected the way in which we eat. Abandoning traditional recipes and formats for quick and easy to prepare or ready to eat products with a high fat content and low nutritional quality are affecting people's health. As a consequence the Spanish Agency for Food and Nutrition (AESAN in its Spanish abbreviation) and the Alimentum Foundation have developed a plan to promote healthy lifestyles in the Spanish population. With promotional campaigns encouraging healthy eating and regular physical activity, these bodies propose light, balanced and healthy meals without losing sight of consumer needs concerning the lack of time for, and perhaps interest in, cooking. In the modern diet, too, vegetables are tending to lose the characteristic role that they once had to becoming possible alternatives to meat and fish (Meletti, 2006).

In light of the above, arose a new concept for consuming fruit and vegetables, but always respecting the most rigorous quality and safety controls, both from a food and environmental point of view, offering a product with certain added value that consumers would find attractive and for which they would be willing to pay a little more.

In order to meet consumer demands, industries processing fruit and vegetables, and even growers, have had to make adjustments, including the incorporation of new farming systems, equipment and new species better adapted to the new food ranges being demanded. The latter includes the incorporation of new crops to protected cultivation, the modification of horticultural cycles in the case of out-of-season production, the intense application of technology in both irrigation and pest and disease control, the replacement of soil by artificial soil material supports, the use of species with beneficial health effects, etc. Such kinds of complex systems can be adapted to the continuous innovation that the market demands for minimally processed products. 


\section{HYDROPONICS}

Hydroponics refers to crops grown on the water. Interest in this technology has grown all over the world, from developed countries, where it is used for vegetable production with high added value, to developing countries for its ability to adapt to different social and economic realities. Hydroponic systems allow the production of clean fruits and leaves, facilitating and postharvest handling in processing industries, and enabling growth factors to be controlled (Fontana et al., 2003).

There are six basic types of hydroponic growing systems:

- Ebb and flow. Plants grow in culture trays on growing beds that are temporarily filled with nutrient solution. After a time, the nutrient solution is drained, in a process that can be repeated several times a day.

- Recirculation or NFT (Nutrient Film Technique). In this system, the nutrient solution is maintained in continuous recirculation of a series of PVC channels. The channels are provided with holes in the top where the plants are placed.

- Wick culture. In this system, plants are grown in an inert substrate and an absorbent wick connects the substrate with the nutrient solution tank.

- Drip - the most used technique. This hydroponic method is based on a nutrient solution dripping slowly onto an inert medium in which the plants grow.

- Aeroponics. In this system, the roots are open to the air inside a spray chamber that provides the darkness and humidity they need. The nutrient solution is provided regularly through a nebulizer system.

- Floating System. Plants are grown in holes in polystyrene trays floating on the nutrient solution, with the roots dipped in the same.

\section{Floating System}

The floating system is an irrigation system based on a series of trays that float on a film of water or nutrient solution of approximately $5-10 \mathrm{~cm}$. This technique reduces crop cycles with respect to soil culture being of great interest for its low installation and manpower costs, absence of weeds and quick and 
straightforward harvesting. The ability to program each of the phases of the crop allows continuous production throughout the year (Cros et al. 2003).

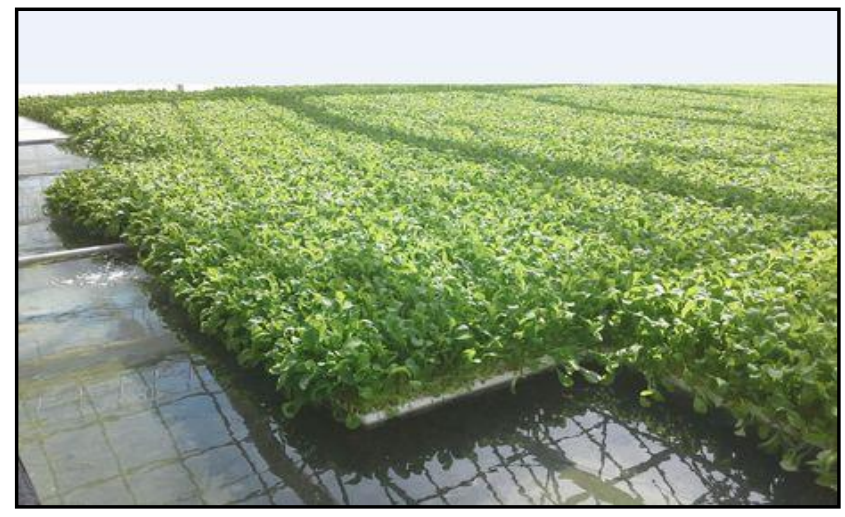

Picture 1: Floating raft system. (Zea, 2014. www hortidaily.com)

Crop cycles change their duration depending on the species and the season. In the climate of south-eastern Spain, crops can be harvested from 20 days in a summer, e.g. purslane (Fernández et al., 2007), or from 56 days in winter, e.g. bladder campion (Conesa et al., 2009a).

Floating system allows the intensive cultivation of plants, providing an abundant yield and preventing evaporation losses. This system also enables efficient fertilizer use, the rapid correction of nutritional deficiencies and control of important anti-nutritional compounds, such as nitrates, which tend to accumulate in some species (Santamaria et al., 1997). Moreover, this culture technique results in more efficient water use and greenhouse space (Galloway et al., 2000). Furthermore, the spread of fungal leaf diseases is negligible due to the total lack of leaf wetness, so that the finished product is clean and ready for bagging and marketing.

Currently this system is used both to produce seedlings for transplanting and vegetables, such as iceberg lettuce.

The essential elements of these systems are expanded polystyrene trays or other water-repellent materials of low volumetric weight, and closed beds to contain the water and fertilizer, with a depth of $10-25 \mathrm{~cm}$.

Styrofloat trays are widely used, in which holes have been replaced by pyramidal-trunk fissures of little volume, minimising the use of substrate, which is only necessary to support the seed. 


\section{Nutrient solution}

The main parameters which characterize the nutrient solution are $\mathrm{pH}$, electrical conductivity, competition between ions, temperature and dissolved oxygen (Favela et al., 2006).

The base of a nutrient solution is water, and so its composition must be taken into account by carrying out a preliminary analysis. Once this is known, the nutrient solution is made up through the addition of macronutrients and micronutrients, taking into account the nutritional needs of plants. A basic nutrient solution would be composed of nitrogen, phosphorus, potassium, calcium, magnesium and sulphur, complemented with micronutrients (iron, boron, manganese, zinc, etc.) (Trejo-Tellez and Gómez-Merino, 2012). The concentration of these nutrients may vary depending on the crop species, the climatic conditions and the initial conditions of the water.

The $\mathrm{pH}$ of a nutrient solution is a property that is inherent to its composition and cannot be varied independently (Steiner, 1961). The availability of some plant nutrients is greatly affected by $\mathrm{pH}$. The best range for nutrients to be absorbed in soilless culture is between 5.5 and 6.8, since this is the range in which the most of the nutrients are available (Baixauli and Aguilar, 2002). Furthermore, with a $\mathrm{pH}$ below 5 , nitrogen $(\mathrm{N})$, potassium $(\mathrm{K})$, calcium $(\mathrm{Ca})$, magnesium $(\mathrm{Mg})$ deficiencies may occur, while above 8 the availability of iron $(\mathrm{Fe})$, boron $(\mathrm{B})$, zinc $(\mathrm{Zn})$, magnesium $(\mathrm{Mg})$ and copper $(\mathrm{Cu})$ is decreased. After initial adjustment of the nutrient solution $\mathrm{pH}$, plant root activities continuously modify this value (Spinu et al.,1997) so that continuous adjustment of the $\mathrm{pH}$ is required during the crop cycle.

The electrical conductivity is a measure of the total salts dissolved in the hydroponic nutrient solution. This is a very important factor because it adversely affects plant development. High levels of electrical conductivity may cause salt stress, giving rise water absorption problems due to the increase of osmotic pressure in the root zone, or to the phytotoxicity of ions such as sodium. In addition plants grown under salt stress are characterized by reduced growth and yield (Lazof and Bernstein, 1999; Tarakcioglu and Inal, 2002).

Ionic competition is a feature of active ion uptake by the roots of plants. This competition may manifest itself as an antagonistic interaction of ions, 
producing insoluble precipitates by high affinity charges or as direct competition to be taken up by plants. There may also be synergistic interactions, in which case ions "help each other" to be taken up by plants.

Temperature is a factor affecting the solubility of gases and salts, and the development of any organisms present in the water. The oxygen concentration in water is inversely proportional to temperature but this relationship may be altered because of photosynthesis and respiration processes. Generally, in aqueous solutions, the electrical conductivity increases by $2-3 \%$ for every increase of $1{ }^{\circ} \mathrm{C}$.

In the case of dissolved oxygen, the quantity present in water may be affected by abiotic factors such as temperature, salinity, turbulence and atmospheric pressure. As stated above, temperature influences the dissolved oxygen in the water, being $14.60 \mathrm{mg} / \mathrm{L}$ at $0{ }^{\circ} \mathrm{C}$ and $7.04 \mathrm{mg} / \mathrm{L}$ at $35{ }^{\circ} \mathrm{C}$ at sea level air pressure (Lind, 1974). Salinity also reduces the concentration of oxygen in water due to a more effective competition of the salts for intermolecular spaces due to their ionic charges with respect to oxygen (Wilson, 2009). Oxygen transfer through the air-water interface is facilitated by increasing the surface area exposed to the atmosphere. The movement of water by waves, waterfalls or bubbling increases the surface exposed to the atmosphere, thereby facilitating oxygen exchange. An increase in both altitude and atmospheric pressure causes a decrease in the oxygen dissolved in water. At a temperature of $25{ }^{\circ} \mathrm{C}$ the dissolved oxygen ranges from $8.24 \mathrm{mg} / \mathrm{L}$ at 0 metres $(760 \mathrm{~mm} \mathrm{Hg})$ to $6.66 \mathrm{mg} / \mathrm{L}$ at 1829 metres (614 mm Hg) (Campbell Scientific, Instruction manual CS512, 2006). 


\section{AERATION OF THE NUTRIENT SOLUTION AND RESPONSE TO HYPOXIA}

Plants growing in a floating system may suffer hypoxia because roots gradually consume the dissolved oxygen in the nutrient solution. The negative effects of hypoxia generally affect the growth, development and physiology of plants. The stress experienced by oxygen deficiency (hypoxia) or total absence (anoxia) can result in the death of crops and wild flora, hurting both the economy and the environment (Vartapetian, 2006). For this reason, to ensure the functionality of the root it is necessary to maintain an adequate concentration of oxygen in the root zone, since the lack of oxygen reduces water and mineral uptake by the plant, with repercussions on root and shoots growth, and, consequently, on final crop yield (Tesi et al. 2003a). To avoid the negative impact on performance, growers aerate nutrient solutions in order to enrich them with oxygen. There are significant differences in sensitivity to oxygen deficiency in the rooting medium among plant species, even among cultivars (Veen, 1988).

Some plants at low oxygen concentrations may undergo anatomical and morphological adaptations that facilitate oxygen transport, forming a specific tissue called aerenchyma, whose channels internally diffuse gases from the aerial part to the roots (Evans, 2003). Another adaptation caused by the lack of oxygen is the proliferation of adventitious roots, which are located on leaf axils, and whose origin is exogenous (Kaskey and Tindall, 1979). In addition, recent knowledge concerning the activation of genes in response to oxygen deprivation has provided additional information on the processes of response and acclimation to hypoxia (Bailey-Serres and Chang, 2005). However, the tolerance of and ability to adapt to the lack of oxygen depend on the species and cultivated variety. 


\section{PLANT GROWTH PROMOTING RHIZOBACTERIA (PGPR)}

Plant growth-promoting rhizobacteria (PGPR) are soil bacteria inhabiting around or on the root surface and which are directly or indirectly involved in promoting plant growth and development via the production and secretion of various regulatory chemicals near the rhizosphere (Ahemad and Kibret, 2014). The interactions between bacteria and plants can be neutral, negative or positive (Whipps, 2001). PGPR promote plant growth due to the positive interaction with the plant through increasing nitrogen fixation, promoting free-living nitrogenfixing bacteria, increasing the supply of other nutrients, producing plant hormones, enhancing other beneficial bacteria and fungi, and controlling diseases, nematodes and insect pests (Reddy, 2013). Among strains with PGPR activity, species belonging to genera Pseudomonas and Bacillus are the most extensively studied (Kumar et al., 2011).

Bacillus is the most abundant genus in the rhizosphere and the PGPR activity of some of these strains has been known for many years, resulting in a broad knowledge of the mechanisms involved (Sivasakthi et al., 2013).

Bacillus subtilis is a plant-beneficial Gram-positive bacterium widely used as a biofertilizer (Beauregard et al., 2013). It is a ubiquitous bacterium commonly found in various ecological niches including soil, water and air, which does not have a history of pathogenicity from contact in the environment. Bacillus velezensis is also a Gram-positive aerobic bacterium, which may control Fusarium wilt in strawberries (Nam et al., (2009).

B. subtilis and B. velezensis have been assessed as being of great potential for use in agriculture and have been used in the formulation of commercial products for agricultural use in several countries. In Spain, products include Larminar® (Agrimor), Serenade ${ }^{\circledR}$ Max (Bayer), Botrybel (Probelte) or Cilus (Ithec) that work like PGPR or biological control agents. 


\section{PLANT MATERIAL}

One type of vegetable perfectly adapted to cultivation in floating systems is known as baby leaf. Baby leaf species are small and young shoots, which are harvested when they measure between 8 and $12 \mathrm{~cm}$. Their production cycles are short, and they are ready to harvest between 15 to 50 days after sowing. Currently, their growing process is totally mechanized, existing specialized machines for sowing and harvesting. The concept of baby leaf is applicable to species included in this work, such as purslane, lettuce and watercress, but also to other species such as, lamb lettuce, spinach, rocket salad, bladder campion, etc.

\section{Purslane}

The origin of purslane does not seem to be clear: some authors place it in Asia (Hernandez-Leon, 1994) and others in North Africa (Chapman et al., 1974). Purslane belongs to the Portulacaceae family and has wide variety of common names (in English; purslane, pursley, etc., in Spanish; verdolaga, buglosa, porcelana, etc.). Portulaca comes from the Latin "portula" meaning Little door, referring to how their capsules open, while its scientific name is Portulaca oleracea.

Purslane is a spontaneous grass very widespread in the Mediterranean area, where it is eaten raw in salads or cooked. It was used as a medicinal plant in ancient Egypt, but it was during the Middle Ages when numerous references to this vegetable by Hispano-Arabic authors can be found. These authors recognize a certain intraspecific variability, citing the demands of its culture and calling it soft, fatuous and blessed.

From the sixteenth century, the cultivation of purslane was lost in Spain and it began to be treated as weed. In many Latin American countries into which its cultivation was introduced, purslane remains highly estimated (HernandezLeon, 1994).

Purslane is rich in vitamin $\mathrm{C}, \alpha$-tocopherol, $\beta$-carotene, glutathione, folate, essential amino acids and $\alpha$-linolenic acid, an essential $\omega$-3 fatty acid with 
beneficial effects on coronary heart disease (Table 1). As a medicinal plant it is valued for its antiscorbutic and diuretic properties.

Table 1: Nutritional content of purslane. Source: Purslane raw. USDA National Nutrient Database for Standard Reference (2015).

\begin{tabular}{|lcc|}
\hline Nutrient & Unit & Value per \\
Water & $\mathrm{g}$ & 92.86 \\
Energy & $\mathrm{kcal}$ & 20 \\
Protein & $\mathrm{g}$ & 2.03 \\
Total lipid (fat) & $\mathrm{g}$ & 0.36 \\
Carbohydrate, by difference & $\mathrm{g}$ & 3.39 \\
Minerals & & \\
Calcium, Ca & $\mathrm{mg}$ & 65 \\
Iron, Fe & $\mathrm{mg}$ & 1.99 \\
Magnesium, Mg & $\mathrm{mg}$ & 68 \\
Phosphorus, P & $\mathrm{mg}$ & 44 \\
Potassium, K & $\mathrm{mg}$ & 494 \\
Sodium, Na & $\mathrm{mg}$ & 45 \\
Zinc, Zn & $\mathrm{mg}$ & 0.17 \\
Vitamins & & \\
Vitamin C, total ascorbic acid & $\mathrm{mg}$ & 21 \\
Thiamin & $\mathrm{mg}$ & 0.047 \\
Riboflavin & $\mathrm{mg}$ & 0.112 \\
Niacin & $\mathrm{mg}$ & 0.48 \\
Vitamin B-6 & $\mathrm{mg}$ & 0.073 \\
Folate, DFE & $\mathrm{mg}$ & 12 \\
Vitamin B-12 & $\mu \mathrm{I}$ & 0 \\
Vitamin A, IU & $\mathrm{mg}$ & 0 \\
Vitamin D (D2 + D3) & & \\
Vitamin D & & \\
Lipids & & \\
Cholesterol & & \\
Other & & \\
Caffeine & & \\
\hline
\end{tabular}

Despite its high nutritional value, its acceptance as a leafy vegetable may be limited due to the accumulation of oxalic acid in large quantities (Palaniswamy et al., 2002), making it potentially harmful to people prone to kidney stone formation. The amount of oxalic acid and $\alpha$-linolenic acid vary with the culture conditions and the age of the plant (Palaniswamy et al., 2004).

Currently, it is grown worldwide and, in Europe, it is grown in the United Kingdom, Holland and Spain, among other countries. In Spain, the most common way to eat purslane is in a salad with endive, cucumber and tomato, for example, 
although also in other recipes it is cooked with chicken or pork. In Mexico, it is frequently eaten with egg for breakfast, and in Turkey in salad with yogurt and walnuts.

Purslane appears to be an excellent candidate for inclusion in saline drainage water reuse systems (Grieve and Suarez, 1997). It is highly tolerant of both chlorides and sulphates, a moderate accumulator of selenium and a valuable vegetable crop for human consumption (Bianco et al., 1998) and livestock fodder. It is also a source of a gum with emulsifying properties, which can be used in the food industry (Garti et al., 1999).

\section{Lettuce}

The origin of the lettuce is located in India, although its wild ancestor, Lactuca scariola, grows in most temperate areas of the world, so their geographical origin are unclear (Mallar, 1978). Lettuce (Lactuca sativa) belongs to the Asteraceae family. Its name comes from the Latin "lac-tis" (milk) in reference to the white sap that exudes when it is cut. The first description of its cultivation goes back to Theophrastus (300 BC) and Pliny and Columella, who detailed the existence of four types of lettuce. Christopher Columbus introduced it into America and there are references to its cultivation in Brazil (1650) and Haiti (1865) (Bianco, 1990).

Lettuce is an annual herbaceous plant. The plant has a very short stem of 2 to $5 \mathrm{~cm}$ (practically acaule) where the leaves are inserted. These may or may not form a head, and vary in shape, number, size and colour, according to the botanical variety and cultivar.

Most lettuces grow heads, either tightly closed crisp heads or loose leaf heads. Cos, or romaine lettuces, have a long, oval head of tightly packed crisp leaves; the Batavia lettuce has thick, crunchy leaves, while crisp head lettuces, also known as iceberg, produce very round, crunchy, pale green heads and the French lettuce has a round head, fine leaves, buttery texture, and a delicate and intense flavour.

Currently, lettuce is consumed almost all over the world, throughout the year and usually fresh. It is appreciated for its nutritional quality and it is a basic component in almost every low calorie diet. Characterized by having few calories 
and a substantial content of vitamin $\mathrm{C}$ and calcium (Table 1), make it a recurring ingredient in recipes for salads, as decoration or garnish in many dishes.

Spain is Europe's largest consumer of lettuce with $19 \mathrm{~kg}$ per capita/year, followed by Italy with $14 \mathrm{~kg}$ per capita/year.

Table 2: Nutritional content of red and green lettuce. Source: Lettuce green and red leaf raw. USDA National Nutrient Database for Standard Reference (2015).

\begin{tabular}{|c|c|c|c|}
\hline Nutrient & Unit & $\begin{array}{c}\text { Red leaf } \\
100 \mathrm{~g}\end{array}$ & $\begin{array}{c}\text { Green leaf } \\
100 \mathrm{~g}\end{array}$ \\
\hline Water & g & 95.64 & 94.98 \\
\hline Energy & kcal & 16 & 15 \\
\hline Protein & $\mathrm{g}$ & 1.33 & 1.36 \\
\hline Total lipid (fat) & $\mathrm{g}$ & 0.22 & 0.15 \\
\hline Carbohydrate, by difference & g & 2.26 & 2.87 \\
\hline Fiber, total dietary & $\mathrm{g}$ & 0.9 & 1.3 \\
\hline Sugars, total & $\mathrm{g}$ & 0.48 & 0.78 \\
\hline \multicolumn{4}{|l|}{ Minerals } \\
\hline Calcium, $\mathrm{Ca}$ & $\mathrm{mg}$ & 33 & 36 \\
\hline Iron, $\mathrm{Fe}$ & $\mathrm{mg}$ & 1.2 & 0.86 \\
\hline Magnesium, Mg & $\mathrm{mg}$ & 12 & 13 \\
\hline Phosphorus, $\mathrm{P}$ & $\mathrm{mg}$ & 28 & 29 \\
\hline Potassium, K & $\mathrm{mg}$ & 187 & 194 \\
\hline Sodium, $\mathrm{Na}$ & $\mathrm{mg}$ & 25 & 28 \\
\hline Zinc, Zn & $\mathrm{mg}$ & 0.2 & 0.18 \\
\hline \multicolumn{4}{|l|}{ Vitamins } \\
\hline Vitamin $\mathrm{C}$, total ascorbic acid & $\mathrm{mg}$ & 3.7 & 9.2 \\
\hline Thiamin & $\mathrm{mg}$ & 0.064 & 0.07 \\
\hline Riboflavin & $\mathrm{mg}$ & 0.077 & 0.08 \\
\hline Niacin & $\mathrm{mg}$ & 0.321 & 0.375 \\
\hline Vitamin B-6 & $\mathrm{mg}$ & 0.1 & 0.09 \\
\hline Vitamin A, RAE & $\mu \mathrm{g}$ & 375 & 370 \\
\hline Vitamin A, IU & $\mathrm{IU}$ & 7492 & 7405 \\
\hline Vitamin E (alpha-tocopherol) & $\mathrm{mg}$ & 0.15 & 0.22 \\
\hline Vitamin K (phylloquinone) & $\mu \mathrm{g}$ & 140.3 & 126,13 \\
\hline Folate, DFE & $\mu \mathrm{g}$ & 0 & 38 \\
\hline \multicolumn{4}{|l|}{ Lipids } \\
\hline Fatty acids, total saturated & $\mathrm{g}$ & no data & 0.02 \\
\hline Fatty acids, total saturated & $\mathrm{g}$ & no data & 0.02 \\
\hline Fatty acids, total monounsaturated & $\mathrm{g}$ & no data & 0.006 \\
\hline Fatty acids, total polyunsaturated & $\mathrm{g}$ & no data & 0.082 \\
\hline
\end{tabular}

The largest lettuce producer in the world is China, followed by USA and India. Spain, with 868,436 t, is in fourth place (Source: FAOSTAT, 2013). 


\section{Watercress}

Watercress belongs to the Brassicaceae family, genus Nasturtium and species officinale. Its botanical name is Nasturtium officinale $\mathrm{R}$. Br. It is also known as "mastuerzo de agua" or "berro" in Spanish, "cresson" or "cressonfontaine "in French or "agrião de agua" or "agrião das fontes" in Portuguese. Nasturtium comes from the Latin nasus = "nose" and tortus = "twisted" because of its spicy smell. It is a semi-aquatic plant found on the edge of creeks and streams of clear water. It is native to Europe and Central Asia and has long been used in folk medicine to alleviate respiratory problems and skin complaints.

It is a perennial, aquatic or semi-aquatic plant, creeping or floating, glabrous and 10 to $60 \mathrm{~cm}$ tall. It tends to cluster in large colonies. The ascending stems are hollow and branched, with fleshy roots on internodes. The leaves are dark green, glabrous, bipinnate, with 3-11 ovate to orbicular leaflets, the largest being the terminal leaflet. The flowers are small, yellow or white, forming clusters of inflorescences or panicled and terminal axillaries. The fruits are straight or curved pods, which are cylindrical and about the same length as pedicel pods. The root is fibrous.

Watercress contains a relatively large amount of vitamins $\mathrm{C}$ and provitamin A, folic acid, iodine, iron, protein, and, especially, calcium and sulphur compounds, which influence its characteristic odour, but also add to its nutritional benefits (Rose et al., 2000).

The consumption of watercress can reduce cholesterol, triglycerides and low-density lipoprotein (LDL-C), which is attributed to its high antioxidant potential (Yazdanparast et al., 2008)

Another positive effect watercress has on human health is that, like all Brassicas, it is rich in glucosinolates, which are glycosides containing a sulphur and which can be hydrolysed, enzymatically or not, resulting in isocyanates and/or nitriles. Isocyanates are very important because they are the main inducers of carcinogen detoxification enzymes (Williams et al., 2009). One of the two most potent inducers found in watercress is labelled 2-fenetilglucosinolate, also known as PEITC (Alwi et al., 2010) or gluconasturtiin. 
Table 3: Nutritional content of watercress. Source: Watercress raw. USDA National Nutrient Database for Standard Reference (2015).

\begin{tabular}{|c|c|c|}
\hline Nutrient & Unit & $\begin{array}{c}\text { Watercress } \\
100 \mathrm{~g}\end{array}$ \\
\hline Water & $\mathrm{g}$ & 95.11 \\
\hline Energy & kcal & 11 \\
\hline Protein & $\mathrm{g}$ & 2.3 \\
\hline Total lipid (fat) & $\mathrm{g}$ & 0.1 \\
\hline Carbohydrate, by difference & $\mathrm{g}$ & 1.29 \\
\hline Fiber, total dietary & $\mathrm{g}$ & 0.5 \\
\hline Sugars, total & $\mathrm{g}$ & 0.2 \\
\hline \multicolumn{3}{|l|}{ Minerals } \\
\hline Calcium, $\mathrm{Ca}$ & $\mathrm{mg}$ & 120 \\
\hline Iron, $\mathrm{Fe}$ & $\mathrm{mg}$ & 0.2 \\
\hline Magnesium, Mg & $\mathrm{mg}$ & 21 \\
\hline Phosphorus, $\mathrm{P}$ & $\mathrm{mg}$ & 60 \\
\hline Potassium, K & $\mathrm{mg}$ & 330 \\
\hline Sodium, $\mathrm{Na}$ & $\mathrm{mg}$ & 41 \\
\hline Zinc, Zn & $\mathrm{mg}$ & 0.11 \\
\hline \multicolumn{3}{|l|}{ Vitamins } \\
\hline Vitamin $\mathrm{C}$, total ascorbic acid & $\mathrm{mg}$ & 43 \\
\hline Thiamin & $\mathrm{mg}$ & 0.09 \\
\hline Riboflavin & $\mathrm{mg}$ & 0.12 \\
\hline Niacin & $\mathrm{mg}$ & 0.2 \\
\hline Vitamin B-6 & $\mathrm{mg}$ & 0.129 \\
\hline Folate, DFE & $\mu \mathrm{g}$ & 9 \\
\hline Vitamin B-12 & $\mu \mathrm{g}$ & 0 \\
\hline Vitamin A, RAE & $\mu \mathrm{g}$ & 160 \\
\hline Vitamin A, IU & IU & 3191 \\
\hline Vitamin E (alpha-tocopherol) & $\mathrm{mg}$ & 1 \\
\hline Vitamin D (D2 + D3) & $\mu \mathrm{g}$ & 0 \\
\hline Vitamin D & IU & 0 \\
\hline Vitamin K (phylloquinone) & $\mu \mathrm{g}$ & 250 \\
\hline \multicolumn{3}{|l|}{ Lipids } \\
\hline Fatty acids, total saturated & $\mathrm{g}$ & 0.027 \\
\hline $\begin{array}{l}\text { Fatty acids, total } \\
\text { monounsaturated }\end{array}$ & $\mathrm{g}$ & 0.008 \\
\hline $\begin{array}{l}\text { Fatty acids, total } \\
\text { polyunsaturated }\end{array}$ & $\mathrm{g}$ & 0.035 \\
\hline Cholesterol & $\mathrm{mg}$ & 0 \\
\hline
\end{tabular}

In contrast, watercress, as an aquatic plant, may accumulate high levels of heavy metals such as zinc and copper, and, to a lesser extent, nickel (Kara, 2006). It is also capable of accumulating in its leaves large amounts arsenic, an inorganic compound used in industry and agriculture, and may be found in different oxidation states in water (Ozturk et al., 2010). 
The cultivation of watercress is important locally in the developed world but there are few statistics on its production and trade. The annual output of UK is about $2500 \mathrm{t}$, but is now declining. In France, the production is about $10000 \mathrm{t}$ and in Africa it is grown on a small scale throughout the continent.

Watercress is consumed in many different ways. It can be added to cooked dishes, salads, sandwiches, soups, stews, stir-fries, pasta, smoothies, or be the principal ingredient of pesto, etc. The most common way to consume watercress is in salads, since it not only combines well with many leafy vegetables, but can also be mixed with cheese, meat, beans, couscous, fruits, etc. 


\section{NUTRITIONAL QUALITY}

\section{Nutraceuticals}

The term nutraceutical comes from the words nutrition and pharmaceutical. It was coined in 1989 in the United States by Dr. Stephen DeFelice (Escaff et al., 2006), who defined it as a food or part of a food such as a dietary supplement that has a medical or health benefit including the prevention and treatment of disease. Today there is growing concern about the relationship between our health and the food we eat, a fact that has not gone unnoticed by the food industry.

Among nutraceuticals, we focus in this doctoral thesis on antioxidants, analysing their antioxidant capacity, the glutathione content, total phenolic and vitamin $\mathrm{C}$ content, and cation content such as calcium, magnesium and potassium.

\section{The antioxidant capacity}

Numerous epidemiological studies indicate that a diet rich in fruits and vegetables may reduce the risk of diseases such as cancer and cardiovascular and neurodegenerative diseases (Balsano and Alisi, 2009). Antioxidants have a well known ability to remove excess free radicals produced as a result of cellular oxidation, thus avoiding harmful effects caused by oxidative stress.

The principal free radicals are reactive oxygen and nitrogen species (ROS and RNS) such as superoxide $\left(\mathrm{O}_{2}^{-}\right)$, hydrogen peroxide $\left(\mathrm{H}_{2} \mathrm{O}_{2}\right)$, hydroxyl radical $\left(\mathrm{OH}^{*}\right)$, and nitric oxide (NO).

The action mechanisms of antioxidants involve direct interaction with the reactive species to prevent the cellular harmful and to protect the cell.

Among antioxidants that enter the body through the diet are vitamins (ascorbic acid), carotenoids (lycopene), polyphenols (flavonoids and nonflavonoids) and others as glucosinolates and organosulphates.

Natural antioxidants found in plants respond to environmental signals and, since environmental factors can be manipulated to a greater or lesser extent in commercial production systems, it is possible to improve the nutritional quality of 
plant products by increasing their antioxidant content (Benavides-Mendoza et al. 2009).

\section{Glutathione content}

Glutathione is an important antioxidant in plants, animals, fungi and some bacteria and archaea, preventing damage to important cellular components caused by reactive oxygen species (Pompella et al., 2003). Glutathione is involved in many processes in the body, including tissue building and repair, making chemicals and proteins needed in the body, and for the immune system. Glutathione is an important compound for controlling biotic and abiotic stress in plants. It is a pivotal component of the glutathione-ascorbate cycle, a system that reduces poisonous hydrogen peroxide (Noctor and Foyer, 1998). Avocados, asparagus, raw spinach, cauliflower, okra, broccoli, tomatoes, squash and potatoes are vegetables particularly high in glutathione (Peiper, 2007).

\section{Total phenols}

Phenolic compounds have been extensively studied due to their influence on food quality. They are antioxidants and are a large group of chemicals with different chemical structures and activities, which include more than 8000 different compounds (Martinez-Valverde, 2000).

Phenols are considered secondary plant metabolites, some of which are essential for their physiological functions and others are useful to defend against stress (water, saline, diseases, pests, etc.). On the other hand, when the phenols are oxidized, they give rise to quinones, which impart a brown colour that is often undesirable for consumption or sale (Gimeno, 2004).

\section{Vitamin C}

The discovery of vitamin $\mathrm{C}$ is associated with scurvy, a disease that was first discovered among who made long journeys by sea. Little by little, it became clear that scurvy attacked only those who did not consume fresh foods, a finding that led to the introduction of fresh food, especially citrus fruits, in the diets of sailors.

Plants and most animals can synthesize their own L-ascorbic acid (vitamin C), but a mutation in the gene for L-gulono- $\gamma$-lactone oxidase in the primate 
lineage means that human beings need to acquire this essential compound in their diet (Jain and Nessler, 2000).

Vitamin $\mathrm{C}$ is a water-soluble vitamin derivative of the glucose metabolism. It acts as reducing agent and is required for the synthesis of collagen fibres through the process of hydroxylation of proline and lysine. The main role of ascorbate is to protect tissues from oxidative harmful products and maintain certain enzymes in the reduced forms in which they are required (Padh, 1990). Ascorbate, which is available for energetically favourable oxidation, reacts with the unpaired electron of the reactive oxygen species leading to monodehydroascorbate first and then to dehydroascorbate. This results in the reduction of reactive oxygen species in water and oxidized forms of ascorbate, which are stable and non-reactive. (source: www.acidoascorbico.com)

Views on human needs differ greatly. Some people keep themselves healthy with $10 \mathrm{mg}$ per day, although $25 \mathrm{mg}$ for adults, $30 \mathrm{mg}$ for adolescents, 35 $\mathrm{mg}$ during pregnancy and $45 \mathrm{mg}$ during lactation appear to be reasonable amounts (Latham, 2002). Foods with high levels of vitamin C include kiwi fruit, tomatoes, potatoes and citrus fruits such as limes, oranges and lemons (Valdes, 2006).

\section{Pigments}

Chlorophyll is a green photosynthetic pigment which helps plants to obtain energy from light. This energy is then used by plants to combine carbon dioxide and water into carbohydrate to sustain their life process (Shibghatallah et $a l ., 2013)$. Most investigators agree that the ratio between chlorophyll $a$ and $b$ is 3:1 but these values vary as a function of plant growth, development, cultivar and environmental factors (Bojović and Stojanović, 2005).

\section{Potassium}

Potassium is essential for photosynthesis, activates enzymes to metabolize carbohydrates for the manufacture of amino acids and proteins, facilitates cell division and growth by helping to move starches and sugars between plant parts, increases stalk and stem stiffness, enhances disease resistance, increases drought tolerance, regulates the opening and closing of stomata, gives plumpness to grain and seed, improves firmness, texture, size and colour of fruit crops and increases the oil content of oil crops (Tucker, 1999). 
Among the many plant mineral nutrients, potassium stands out as a cation with a strong influence on the quality attributes that determine fruit marketability, consumer preference, and the concentration of critically important human-health associated phytonutrients (Lester et al., 2010).

\section{Calcium}

Calcium is a constituent of the cell walls and is involved in the production of new growing points and root tips. It provides elasticity and expansion of cell walls, which prevents growing points from becoming rigid and brittle. It is immobile within plants and remains in the older tissue throughout the growing season. It acts as a base for neutralizing the organic acids generated during the growing process and aids in carbohydrate translocation and nitrogen absorption (Tucker, 1999). Furthermore, according to Poovaiah (1986), there is considerable evidence that the rate of senescence of fruit and vegetables is influenced by the calcium content of the tissue.

\section{Sodium}

Although sodium has not been shown to be an essential nutrient for most plants, there is a high degree of sodium utilization in many plants and some degree of the same in most, if not all, plants (Subbarao et al., 2003), particularly when potassium is deficient (Maathuis, 2014). The uptake of sodium ions is desirable as a way to build osmotic potential, absorb water and sustain turgor, although an excess of sodium ions may be toxic (Pardo and Quintero, 2002).

\section{Antinutritional compounds}

Some vegetables consumed for their leaves contain substances called antinutrients that affect the ability to assimilate certain nutrients. In their raw state plant sources contain a wide variety of antinutrients, which are potentially toxic. However, being an antinutritional factor is not an intrinsic characteristic of a compound but depends upon the digestive process of the ingesting animal (Aberoumand, 2011). This is the case of nitrates and oxalates.

\section{Nitrates}

Nitrates themselves are relatively non-toxic; rather, their toxicity is determined by the reduction of nitrate to nitrite in the human body which, in high 
concentrations, can cause methemoglobinemia, whose most characteristic sign is cyanosis. Nitrate can be converted to nitrite by bacterial reduction in food (during processing and storage) and in the body itself (in saliva and the gastrointestinal tract). Nitrites oxidize the iron in blood haemoglobin, impeding oxygen transport. Moreover, nitrates react with amino acids from food in the stomach, causing nitrosamines and nitrosamides, substances that have a proven carcinogenic effect. The Spanish Agency for Food Safety and Nutrition (AESAN) recommends that certain leafy vegetables should not be introduced in the diet of babies, at least the first few year of life, to prevent methemoglobinemia.

This has led the nitrate content of leafy vegetables to be considered as a characteristic of quality. For example, the European Union has passed legislation on the content of nitrates in vegetables like spinach, salad rocket and lettuce, establishing limits between 2000 and $7000 \mathrm{mg} \mathrm{NO} / \mathrm{kg}$ depending on the time of collection and whether they are grown in the greenhouse or outdoors (EC, 2011).

The nitrate concentration of plants depends on the differences between the rate of absorption and assimilation. Thus, all processes that affect nitrate absorption, assimilation and translocation in the plant can modify its contents. In addition to genotypic differences, light intensity, photoperiod, temperature and any change in the supply of $\mathrm{N}$ (quantity, source, application) can affect the nitrate concentration in leaves (Burns et al., 2011). The accumulation of such compounds can be prevented using soilless systems, which can provide high quality vegetables in less time and with low nitrate contents (Fontana and Nicola, 2004).

\section{Oxalates}

Another component of vegetable dangerous to human health is oxalate, since it reduces the absorption of other minerals such as $\mathrm{Ca}, \mathrm{Fe}, \mathrm{Mg}$, etc., and can form kidney stones in the form of calcium oxalate (Libert and Franceschi, 1987). It is possible to reduce the oxalate content in plants by controlling nitrogen inputs, substituting the nitrate ion in the nutrient solution by ammonia, as demonstrated by Palaniswamy et al. (2000) in the cultivation of purslane. 


\section{POST-HARVEST PROCESSING}

\section{Fresh-cut products}

Products derived from fresh leafy vegetables are often included in the socalled fresh-cut line of products. This refers to products, fresh fruits and vegetables without heat treatment, prepared, washed and packaged that have been cut, with no manipulation that affects their physical integrity or ready to eat or cook and intended for human consumption. Although they are called very differently around the world (Fourth Range, ready to eat, etc.) the most reliable way of naming the product, based on their method of preparation, is minimally processed products (Artés and Artés-Hernandez, 2000).

Minimally processed products such as vegetables consumed as whole leaves have to undergo certain basic phases after harvesting such as precooling, selection, washing and disinfection, rinsing, drying, weighing, packaging, quality control, cold storage and, finally, refrigerated transport and marketing before they are finally consumed (Artés-Hernandez and Artés, 2005).

The packaging used for products such as leafy vegetables are made of materials such as polyethylene (PE), polystyrene (PS) or polyamide (PA), both in their simple forms and in complex films, which can satisfy a large number of requirements. Product presentation is usually in bags, coated trays or pots with lids. The objective is to match the packaging and atmosphere to the product type to allow longer life. This can be achieved by using gas mixtures, known as modified atmosphere packaging, or films that allow suitable oxygen transmission rates (OTR).

The leader in the consumption of fresh-cut products is the United States, accounting for $85 \%$ of global sales compared to $7 \%$ in Europe, where the UK and French fresh-cut products markets account for $8 \%$ of total sales of horticultural products (Source: www.ainiadisal.com, 2008). In Spain, the market for fresh-cut products moves around 300 million Euros per year, with lettuce, salads and spinach being the best selling products. Spanish per capita consumption of these 
products is around $2 \mathrm{~kg}$ per year, far from the $6 \mathrm{~kg}$ to $30 \mathrm{~kg}$ in France and the USA (Lobo and Gonzalez, 2006).

\section{Factors involved in Fresh-Cut Produce}

\section{Temperature}

Temperature is the factor that most significantly affects the appearance, firmness, texture and vitamin content (Watada and Qi, 1999). Postharvest, the product should be kept refrigerated, while during washing the water temperature should be as low as possible and always adapted to the characteristics of the product. Once packed, the storage temperature should be appropriate to the species or product, thus preventing any increase in the respiration rate and corresponding deterioration: In this respect, low temperatures are essential for maintaining good quality (Wataba and Qi, 1999).

\section{Atmosphere}

When the product is at the indicated temperature, it is packaged. Modified atmosphere packaging (MAP) prolongs the shelf life of fresh-cut products by decreasing $\mathrm{O}_{2}$ and increasing $\mathrm{CO}_{2}$ concentrations in the package atmosphere, which is accomplished by the interaction between respiratory $\mathrm{O}_{2}$ uptake and $\mathrm{CO}_{2}$ evolution of the produce, and gas transfer through the package films (Beaudry, 2007).

An important factor is that the packaging material should be appropriate for the product in question. For example, lettuce tolerates a minimum of $2 \%$ oxygen and a maximum of $2 \%$ carbon dioxide (Kader et al., 1989). In addition to the appropriate temperature and packaging, possible damage should be minimized during postharvest handling (Garrett, 1998).

\section{Microorganisms}

Recent food safety alerts in Europe and USA have led to increased consumer concern in this area, especially with respect to fresh produce.

This type of food must comply with regulations, such as regulation on the hygiene of foodstuffs (EC, 2004) and regulation on the microbiological criteria applicable to foodstuffs (EC, 2007), which includes many categories both in terms of process hygiene criteria and in terms of food safety criteria. Regulation 
on the microbiological criteria applicable to foodstuffs, regulates the number of colony forming units (cfu) of Listeria monocytogenes and E. coli, that should not be exceeded during the shelf life of products and before the food has left the immediate control of the food producing company (EC, 2007).

The postharvest control of microorganisms includes quantification of mesophilic and psychrophilic microorganisms. Aerobic mesophilic bacteria are organisms whose optimum growth temperature is between 15 and $35^{\circ} \mathrm{C}$. In this group are included all bacteria, moulds and yeasts capable of growing at $30^{\circ} \mathrm{C}$. This count estimates the total microflora without specifying the types of microorganism in question. Values higher than $10^{6}-10^{7} \mathrm{cfu} / \mathrm{g}$ are a sign of product decomposition (Pascual and Calderón, 2000). Psychrophilic organisms are fungi and bacteria that require low temperatures. They show optimal growth between 12 and $15{ }^{\circ} \mathrm{C}$, but are able to grow at temperatures near $0^{\circ} \mathrm{C}$. Psychrophilics are found in species of the genera Pseudomonas, Enterobacter, Escherichia, Bacillus, Streptococcus, etc. The quantification of mesophilic and psychrophilic microorganism reflects the health quality of tested products and indicates the hygienic conditions of the raw and processed material.

\section{Sensory quality}

The attributes that are most frequently considered by consumers are, first, visual appearance and then the aroma, taste and texture (Beaulieu, 2011). To maintain the sensory quality it is important to control dehydration, browning and other features of the product through pre and postharvest treatments.

Enzymatic browning is a widespread colour reaction occurring in fruits and vegetables, which involves the interaction of oxygen, phenolic compounds and polyphenol oxidases. The phenomenon is particularly detrimental in the quality maintenance of the fresh-cut fruit and vegetables (He and Luo, 2007). According to Degl'Innocenti et al. (2005), in response to cutting, the phenylalanine ammonia lyase (PAL) produces phenols, which are then oxidized by the action of polyphenol oxidase (PPO) and peroxidase (POD) to quinones, which, in turn, spontaneously polymerize to form brown pigments.

\section{Nutritional quality}

Nutritional value is an extremely important quality factor, which can be regarded as a hidden attribute. This quality factor is becoming increasingly 
valued by consumers, scientists, and the medical profession as phytonutrients, functional foods and antioxidants become more appreciated (Beaulieu, 2011). Therefore, the study of the antioxidant capacity and the glutathione, vitamin C, mineral and pigment contents at the time when the product is to be consumed is interesting from the point of view of consumers, producers and postharvest treatment. 


\section{OBJECTIVES}


The main objectives of this work are described below:

For oxygenation experiments with purslane, watercress and red lettuce:

- $\quad$ Evaluation of the specific capacity of hypoxia toleration by the species growing in floating system.

- $\quad$ Studying the effect of aeration on the accumulation of nitrate and oxalate in leaves.

- Studying the effect of aeration on the increase in functional elements.

- $\quad$ Studying the effect of aeration on the shelf-life of fresh-cut product.

For plant growth promoting rhizobacteria (PGPR) experiments with watercress and lettuce:

- $\quad$ Studying the effect of PGPR for increasing yield.

- Reducing the concentration of nutritionally undesirable compounds using PGPR.

- $\quad$ Studying the effect of PGPR for increasing functional elements in leaves. 


\section{GENERAL MATERIAL AND METHODS}




\section{AERATION EXPERIMENTS}

\section{Plant material and growing conditions}

The experiments were conducted at the "Tomás Ferro" Experimental

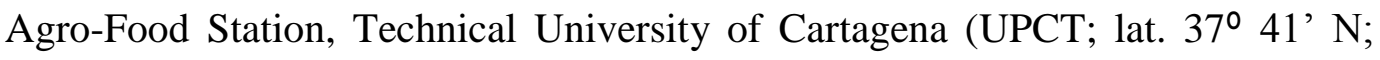
long. $\left.0^{\circ} 57^{\prime} \mathrm{W}\right)$.

The plant material used in the different experiments is listed below:

- Two cultivars of purslane (P. oleracea L.), namely "Golden" (Tozer Seeds Co., Cobham, UK) and the local Spanish accession, C-215, provided by the germplasm bank of UPCT, in chapter 1;

- A commercial cultivar of watercress (Nasturtium officinale R. Br.) "Large leaf" (Tozer Seeds Co., Cobham, U.K.), in chapters 2 and,

- A commercial cultivar of red baby leaf lettuce (Lactuca sativa L.), var. 'Diveria' (Rijz Zwaan Seeds Company, De Lier, Netherland), in chapter 3.

The plant material for each experiment was cultivated in a floating system in an unheated $145 \mathrm{~m}^{2}$ greenhouse covered with thermal polyethylene. Sowing was carried out manually into "styrofloat" trays (Europak S.p.A, Vazzola, Italy) containing peat that it was a balanced mix of blonde and black peat (Floragard Vertriebs GmbH, Oldenburg, Germany). The trays of $60 \times 41 \mathrm{~cm}$ have pyramidal-trunk $172 \mathrm{~mm}$ long fissures $20 \mathrm{~mm}$ apart and grouped in three for a total of 42 fissures per tray; fissures measure $10 \mathrm{~mm}$ on the top and $2.5 \mathrm{~mm}$ on the bottom, leading to a volume of $32.4 \mathrm{~cm}^{3}$ per fissure. After sowing the trays were then transferred to flotation beds floating on fresh tap water. Then aeration was provided at three levels using a blow pump connected to a pipe trellis positioned at the bottom of each flotation bed. The pipes were perforated with holes at 0,6 , or 36 holes $\mathrm{m}^{-2}$ to provide the different levels of aeration to be tested (no aeration, low, or high aeration, respectively). Each level of treatment was carried out in a stainless steel flotation bed with dimensions $1.35 \times 1.25 \times$ 0.2 m covered with PVC liner. 
One week after sowing, the tap water in the beds was replaced with a nutrient solution ( $\mathrm{pH}$ of 5.8 to 5.6 and EC around $2.8 \mathrm{dS} / \mathrm{m}$ ), containing the following elements in mol/L: $\mathrm{NO}_{3}^{-}, 7200 ; \mathrm{NH}_{4}^{+}, 4800 ; \mathrm{H}_{2} \mathrm{PO}_{4}^{-}, 2000 ; \mathrm{K}^{+}, 6000$; $\mathrm{Mg}^{2+}, 1500 ; \mathrm{Ca}^{2+}, 2000$. A commercial mixture of microelements at a concentration of $0.02 \mathrm{~g} \mathrm{~L}^{-1}$ (Nutromix, Biagro S.L., Valencia, Spain) and $\mathrm{Fe}$ chelate at a concentration of $0.02 \mathrm{~g} \mathrm{~L}^{-1}$ (Sequestrene, Syngenta AG, Basel, Switzerland) were added to the solution.

The EC and temperature of the nutrient solution were monitored during the growing cycles using Campbell CS547 sensors (Campbell Scientific Inc., Logan, UT, USA) and the oxygen concentrations were also monitored using Campbell CS512 sensors located in each bed and how measure each minute and it was made the average every hour.

Each culture was harvested at the optimum time of consumption, depending on the species.

\section{Analysis at harvesting time}

\section{Biometrical measurements}

At harvest, 20 plants per tray were taken and shoot and root were separated to perform the following measures:

- Shoot fresh weight, from which the yield is calculated.

- Dry matter content (\%) that is the ratio between dry and fresh weight. Dry weight was determined by drying in an oven between $50-60{ }^{\circ} \mathrm{C}$ until constant weight.

- Leaf area using a leaf area meter (LICOR-3100 C; LICOR Biosciences Inc., Lincoln, NE, USA). Specific leaf area was obtained by dividing leaf area per plant by leaf weight per plant.

- Relative chlorophyll content measured with a chlorophyll meter (Minolta SPAD-502; Konica- Minolta Sensing Inc., Osaka, Japan).

- The colour parameters in leaves were determined using a tristimulus colorimeter $\left(\mathrm{L}^{*} \mathrm{a}^{*} \mathrm{~b}^{*}\right.$ colour space) (Minolta CR-10; Konica- Minolta Sensing Inc., Osaka, Japan) and calculating the hue angle $\left(\mathrm{H}^{*}\right)$ as $\mathrm{H}^{*}=$ $\tan ^{-1}\left(b^{*} / a^{*}\right)$ and chromacity $\left(C^{*}\right)$ as $C^{*}=\left(a^{* 2}+b^{* 2}\right)^{1 / 2}$. 
- Root length, root length per diameter, root diameter, root area, root volume and the number of root branches were determined using a Winrhizo LA 1600 root counter (Regent Inc., Quebec, Canada).

- Number of adventitious roots developing exogenously from the stem at the nodes in the case of watercress.

- Percentage of aerenchyma tissue: root sections were obtained from tap roots $1.0 \mathrm{~cm}$ from the root collar of portulaca and watercress. Fresh sections were fixed, dehydrated, stained, embedded using a JB4 Plus Embedding Kit (Electron Microscopy Sciences, Hatfield, PA), and observed by optical microscopy to calculate the percentage of aerenchyma tissue from digitalised photomicrographs using the AutoCAD software (Autodesk Inc., San Rafael, CA, USA).

\section{Determinations of phytochemicals}

All the phytochemical determinations were performed at harvest time and at the end of storage in watercress and lettuces assays.

\section{Extraction and analysis of total phenolic content and total antioxidant capacity}

Methanolic extracts were prepared for the estimation of phenolic compounds and antioxidant capacity. Triplicate samples $(0.5 \mathrm{~g})$ of shoot were weighed into Falcon tubes together with $3 \mathrm{~mL}$ of pure methanol and homogenised (Ultra-Turrax T25, IKA-Labortechnik, Staufen, Germany) for 1 min. Afterwards the Falcon tubes were placed in ice and shaken on an orbital shaker (SSL1, Stuart, Stone, UK) at $200 \mathrm{rpm}$ for $60 \mathrm{~min}$ at $9{ }^{\circ} \mathrm{C}$. Samples were then transferred to Eppendorf tubes and centrifuged at $1200 \times g$ for $15 \mathrm{~min}$ at $4{ }^{\circ} \mathrm{C}$ (Heraeus Fresco 21, Thermo Scientific, Osterode, Germany).

\section{Antioxidant capacity}

The antioxidant capacity of shoot samples was evaluated in terms of their free radical-scavenging capacity according to Brand-Williams et al. (1995). Briefly, a solution of $0.7 \mathrm{mmol} \mathrm{L}^{-1}$ 2,2-diphenyl-1 picryhydrazyl (DPPH) radical in methanol was prepared daily. A $0.1 \mathrm{~mL}$ aliquot of the extract supernatant was added to $0.9 \mathrm{~mL}$ of DPPH stock solution. The homogenate was shaken vigorously 
and kept in darkness for $40 \mathrm{~min}$ at room temperature. The absorption of samples at $515 \mathrm{~nm}$ was measured in a spectrophotometer (HP 8453, Hewlett Packard) against a blank of methanol. The measurement was compared with a standard curve of ascorbic acid concentrations and expressed as $\mathrm{mg}$ ascorbic acid equivalent antioxidant capacity (AAE)/kg FW.

\section{Total phenolics}

The total phenolic content of shoot samples was determined by the FolinCiocalteu colorimetric method, based on the procedure of Singleton and Rossi (1965). A $0.1 \mathrm{~mL}$ aliquot of the extract supernatant was mixed with $0.15 \mathrm{~mL}$ of Folin-Ciocalteu's reagent (diluted 1:1 v/v with Milli Q water) and $1 \mathrm{~mL} \mathrm{~L} \mathrm{of} 4 \mathrm{~g}$

$\mathrm{L}^{-1} \mathrm{NaOH} / 20 \mathrm{~g} \mathrm{~L}^{-1} \mathrm{Na}_{2} \mathrm{CO}_{3}$. The solution was incubated at room temperature for $1 \mathrm{~h}$ in darkness, after which its absorption at $750 \mathrm{~nm}$ was measured (HP 8453, Hewlett Packard). The measurement was compared with a standard curve of chlorogenic acid concentrations and expressed as mg chlorogenic acid equivalent (CAE)/Kg FW.

\section{Vitamin C}

The content of vitamin $\mathrm{C}$, measured as ascorbic acid (AA) and dehydroascorbic acid, was measured in shoots using high-performance liquid chromatography.

Three gram of frozen samples were crushed and then homogenized with 6 $\mathrm{mL}$ of an extraction solution of $0.1 \mathrm{M}$ anhydrous citric acid, $0.05 \% \mathrm{NaF}$ and 4 $\mathrm{mM}$ EDTA in 5\% aqueous methanol for $2 \mathrm{~min}$ at high speed in an Ultraturrax blender. The homogenate was filtered through cheesecloth and the $\mathrm{pH}$ was adjusted to 2.3-2.4. Then the filtrate was centrifuged for $10 \mathrm{~min}$ at $11950 \mathrm{x} \mathrm{g}$ and $2{ }^{\circ} \mathrm{C}$ in a Sorvall RC-SB centrifuge. Later the sample was passed through a SepPak Cl8 cartridge (Waters Assoc.) which had been preconditioned with $10 \mathrm{~mL}$ HPLC-grade methanol and $10 \mathrm{~mL}$ of ultrapure water. The first $1 \mathrm{~mL}$ of eluent was discarded and the next $3 \mathrm{~mL}$ retained for analysis. As specified by Zapata and Dufour (1992), $37 \mathrm{~min}$ before injection onto the HPLC system $1 \mathrm{~mL}$ of 1,2phenylenediamine $(3.33 \mathrm{mg} / \mathrm{mL})$ in methanol/water $(5: 95, \mathrm{v} / \mathrm{v})$ was added. The mixture was immediately passed through a $0.45-\mathrm{mm}$ filter (Acrodisc. Gelman Sciences, Ann Arbor, MI) into an amber sample vial and sealed. 
The HPLC system consisted of a Shimadzu equipped with a degasser, DGU-20A, autosampler SIL-30AC, column oven CTO- 10AS, communications module CMB-20A, and diode array detector SPDM-20. A Waters PBondapakCl 8 reversed-phase column, $30 \mathrm{~cm}$ x $3.9 \mathrm{~mm}$ i.d. was used for separation, with a Bio-Rad Bio-sil Micro-Guard ODS-5S $4.6 \mathrm{~mm}$ x $3 \mathrm{~cm}$ i.d. guard column. The eluent was methanol/water $(5: 95, \mathrm{v} / \mathrm{v})$ containing $5 \mathrm{mM}$ hexadecyltrimethylammonium bromide and $50 \mathrm{mM}$ potassium dihydrogen phosphate. The flow rate was $1.8 \mathrm{~mL} / \mathrm{min}$. Detection was at $261 \mathrm{~nm}$ for reduced L-ascorbate and at $348 \mathrm{~nm}$ for L-dehydroascorbate. Standards of L-ascorbate, and dehydroascorbate were supplied by Sigma-Aldrich Chemical Company.

\section{Ion content}

Nitrate, oxalate, potassium, sodium and calcium ions were extracted from 3 samples of $0.2 \mathrm{~g}$ dry matter of ground shoot. Extraction was carried out using $50 \mathrm{~mL}$ of distilled water in an orbital shaker (Stuart SSL1, Stone, UK) for $45 \mathrm{~min}$ at $110 \mathrm{rpm}$ at $50^{\circ} \mathrm{C}$. The concentrations of ions were determined by ion chromatography using a Metrosep A SUPP 5 column (Metrohm AG, Zofingen, Switzerland) at a flow rate of $0.7 \mathrm{~mL} / \mathrm{min}$ for anions and a Metrosep C 2-250 column at a flow rate of $1.0 \mathrm{~mL} / \mathrm{min}$ for cations, following the manufacturer's instructions.

\section{Postharvest product management}

Postharvest was performed in the watercress and lettuce assays.

\section{Postharvest process}

Harvested plants were placed in plastic bags and transported immediately in a portable box with ice from the ESEA to the Institute of Plant Biotechnology UPCT, where they were stored at $5{ }^{\circ} \mathrm{C}$ for 4 hours. Then, in a disinfected cold room at $10{ }^{\circ} \mathrm{C}$, all shoots/leaves free from defects were disinfected by washing for 2 min with a solution containing 100 ppm NaOCl (Panreac, Barcelona, Spain) and $0.2 \mathrm{~g} \mathrm{~L}^{-1}$ of citric acid $(\mathrm{pH} 6.5)$ at $5^{\circ} \mathrm{C}$. The shoots/leaves were then rinsed for 2 min under tap water to eliminate chlorine residues. Excess surface water was removed using a handheld salad spinner for $30 \mathrm{sec}$. Subsequently, $20 \mathrm{~g}$ of shoots/leaves were placed in polypropylene (PP) baskets of $1 \mathrm{~L}$ capacity, the top 
of which were thermosealed with a 34-mm thick film composed of polyethylene terephthalate (PET) +oriented polypropylene (OPP) and stored at $5^{\circ} \mathrm{C}$ for $7 \mathrm{~d}$ (Kader and Saltveit, 2003).

\section{Respiration rate}

Changes in $\mathrm{O}_{2}$ and $\mathrm{CO}_{2}$ partial pressures within the PP baskets were monitored daily throughout the shelf life. A $0.5 \mathrm{~mL}$ sample of the headspace was withdrawn from the PP baskets with a gas-tight syringe and $\mathrm{O}_{2}$ and $\mathrm{CO}_{2}$ levels were determined by gas chromatography with a Perkin-Elmer apparatus (Norwalk, CT) equipped with a thermal conductivity detector (Tomás-Callejas et al., 2011).

\section{Microbiological quality}

Microbial growth was assessed after processing and after storage time. Samples of $10 \mathrm{~g}$ fresh weight $(\mathrm{FW})$ from each treatment were blended with 90 $\mathrm{mL}$ of sterile tryptone phosphate water (Scharlab, Barcelona, Spain) at $\mathrm{pH} 7.0$ for $1 \mathrm{~min}$ in a sterile bag by using a stomacher. Serial dilutions were prepared in 9 $\mathrm{mL}$ tryptone phosphate water. From each dilution, $1 \mathrm{~mL}$ aliquots were aseptically pipetted for microbial population counting. Plate count agar (Scharlab) (pH 7.0) for both mesophilic aerobic microorganisms, incubated at $26^{\circ} \mathrm{C}$ for 3 days, and psychrophilic microorganisms, incubated at $4{ }^{\circ} \mathrm{C}$ for 10 days, were used. Duplicates were made for each dilution, counts were reported as $\log _{10}$ colonyforming units (CFU) per gram of FW.

\section{Sensory quality}

The sensory quality was evaluated in a tasting room after $7 \mathrm{~d}$ of cold storage by a test panel consisting of 11 people. Visual quality factors (overall visual quality and global quality) were scored on a 9-point hedonic scale ( $1=$ extremely poor, $3=$ poor, $5=$ acceptable and limit of usability, $7=\operatorname{good}$, and $9=$ excellent). Disorders (browning, visual dehydration, off-odors, off-colour, and off-flavors) were scored according to the following scale of damage incidence and severity: 1 = none, 2 = slight, $3=$ moderate (limit of usability), $4=$ severe, 5 = extreme (Tomás-Callejas et al., 2011). 


\section{PGPR EXPERIMENTS}

\section{Lettuce experiment (Chapter 4)}

\section{Plant material and growing conditions}

The experiment reported in Chapter 4 was conducted at the "Tomás Ferro" Experimental Agro-Food Station, Technical University of Cartagena (UPCT; lat. 37_41' N; long. 0_57' W). Two cultivars of lettuce (Lactuca sativa L.), 'Ganeria' and 'Diveria'(Rijz Zwaan Seeds Company, De Lier, Netherland). Two crop cycles were carried out, with sowing on 2 December 2009 and 17 February 2010. Sowing was carried out manually under the same conditions as those shown in experiments aeration.

One week after sowing, the tap water in the beds was replaced with a nutrient solution Different nutrient solutions with a combination of two different concentrations of nitrogen (4 and $12 \mathrm{mM}$ of $\mathrm{N}$ ) (ratio NO3-/NH4+: 60:40). All nutrient solutions contained the following base composition in mol/L: $\mathrm{H}_{2} \mathrm{PO}_{4}{ }^{-} 2$ $\mathrm{mM} ; \mathrm{K}^{+} 6 \mathrm{mM} ; \mathrm{Ca}^{2+} 2.6 \mathrm{mM}$ and $\mathrm{Mg}^{2+} 1.5 \mathrm{mM}$. A commercial mixture of microelements at a concentration of $0.02 \mathrm{~g} \mathrm{~L}^{-1}$ (Nutromix, Biagro S.L., Valencia, Spain) and Fe chelate at a concentration of $0.02 \mathrm{~g} \mathrm{~L}^{-1}$ (Sequestrene, Syngenta AG, Basel, Switzerland) were added to the solution.

\section{Bacterial strain and inoculation}

Two nutrient solutions were combined with three bacterial inoculations (Bacillus subtilis, Bacillus velenzensis and a non-bacterial control). The PGPR were added by denominated commercial products: Larminar ${ }^{\circledR}\left(10^{12} \mathrm{CFU} / \mathrm{g}\right.$ of $B$. subtilis strain AP-01, Agrimor, Agricultura Moderna S.A., Madrid, Spain) with a concentration of $5 \mathrm{~g} / \mathrm{L}$ and Botribel ${ }^{\circledR}\left(10^{8} \mathrm{UFC} / \mathrm{mL}\right.$ of Bacillus velezensis strain AH2, Probelte S.A., Murcia, Spain) with a concentration of $0.25 \mathrm{~L} / \mathrm{L}$ of water. 


\section{Analysis at harvesting time}

\section{Biometrical measurements}

Plant height, number of leaves, shoot fresh weight (FW), leaf area, the relative chlorophyll content (RCC) and root growth were measured in 20 plants per tray. Measurements were determined as described in aeration experiments.

\section{Determinations of phytochemicals}

Nitrate was extracted in three samples of $0.2 \mathrm{~g}$ of shoot dry matter per treatment and repetition. The ion concentration was determined by ion chromatography using a Metrosep A SUPP 5 column with a flow rate of $0.7 \mathrm{~mL}$ $\min ^{-1}$. Methodology described in the aeration experiments.

\section{Watercress experiment (Chapter 5)}

\section{Plant material and growing conditions}

The experiment reported in Chapter 5 was conducted in the Experimental Centre Tetti Frati of the Department DISAFA (44'53'11,117'’N; 741'7,00'’E $231 \mathrm{~m}$ a.s.l. Carmagnola (TO), Italy) in a greenhouse. Maximum, minimum and mean temperatures during the growing season were 43,17 and $29.1^{\circ} \mathrm{C}$, respectively. The plant material used was a commercial cultivar of watercress (Nasturtium officinale R. Br.) type Large Leaf (Tozer Seeds Co., Cobham, Surrey, UK). The experiment consisted of growing plants in 60-cell styrofoam trays $(0.51 \mathrm{~m} \times 0.30 \mathrm{~m} ; 44 \mathrm{~mm}$ top and $25 \mathrm{~mm}$ lower diameter $)$ containing a substrate (Neuhaus Huminsubstrat N17, Klasmann-Deilmann, Geeste-Groß, Hesepe, Germany) floating in a nutrient solution (NS). The seeded trays were placed in a plastic greenhouse until seed germination. Four days after sowing, the trays were moved into the flotation beds previously arranged and filled with 200 $\mathrm{L}$ of a 40/60 N-NO ${ }_{3}{ }^{-} / \mathrm{N}-\mathrm{NH}_{4}{ }^{+} \mathrm{NS}$ solution composed of $12 \mathrm{mM} \mathrm{N}, 6 \mathrm{mM} \mathrm{K}, 2$ $\mathrm{mM} \mathrm{P}, 2 \mathrm{mM} \mathrm{Mg}$ and $2.5 \mathrm{mM} \mathrm{Ca}$. Then Lysodin ${ }^{\circledR}$ Multimix formulation of microelements (Intrachem, Grassobbio, Italy) was added to the NS at a dose of $0.48 \mathrm{~g} \mathrm{~L}^{-1}$. The $\mathrm{pH}$ and the electrical conductivity of the nutrient solution were 
monitored weekly and kept close to 5.5 and $2 \mathrm{dS} / \mathrm{m}$, respectively. The nutrient solution was aerated by a compressor connected to a perforated pipe trellis positioned in each flotation tank, to maintain levels of dissolved oxygen close to ca. 5 ppm throughout the growing cycle.

\section{Bacterial strain and inoculation}

Two factors were considered, disinfection of the substrate and inoculation with Bacillus subtilis. Substrate disinfection was carried out in a flow steam at $100^{\circ} \mathrm{C}$ for $45 \mathrm{~min} .50 \%$ of the substrate used in the assay was disinfected (Fig. 1). For bacterial inoculation $(\mathrm{BI})$ the commercial product Larminar ${ }^{\circledR}\left(10^{12} \mathrm{CFU} / \mathrm{g}\right.$ of B. subtilis strain AP-01, Agrimor, Agricultura Moderna S.A., Madrid, Spain) was used. Inoculation was performed twice: first inoculating part of the substrate and all the seeds before sowing, and second, inoculating the substrate contained in the trays after sowing. One day before sowing, $50 \%$ of the disinfected substrate (DS) and $50 \%$ of non-disinfected substrate (NDS) were inoculated with Larminar® at a dose of $0.5 \mathrm{~kg} / \mathrm{m}^{3}$. Half of the seeds used were disinfected in $20 \% \mathrm{NaClO}$ and rinsed with sterile distilled water three times. $50 \%$ of the disinfected seeds were inoculated by immersion for $1 \mathrm{~h}$ in a $B$. subtilis suspension at a concentration of $10^{8} \mathrm{CFU} \mathrm{mL}$ in $0.9 \%$ of $\mathrm{NaCl}$ obtained from Larminar® in Plate Count Agar (PCA) (Fluka Analytical, Sigma-Aldrich S.r.l., Milan, Italy). In the case of noninoculated (NBI) seeds and substrate, the seeds were kept for $1 \mathrm{~h}$ in $0.9 \%$ of $\mathrm{NaCl}$. Eleven days after sowing, a re-inoculation was performed placing the inoculated trays (substrate and seeds) on a solution containing $0.167 \%$ of Larminar®/water (w/v).

\begin{tabular}{|l|l|l|}
\hline \multirow{3}{*}{ SUSTRATE and SEEDS } & $\rightarrow$ Disinfected $\gg$ & Inoculated \\
\cline { 2 - 3 } & $\rightarrow$ No disinfected $\gg$ & Inon inoculated \\
\cline { 2 - 3 } & & Non inoculated \\
\hline
\end{tabular}

Figure 1: Explanation of treatments in PGPR assay.

\section{Analysis at harvesting time}

\section{Biometrical measurements}

Whole plants were harvested and divided into aerial and root parts. The biometrical measurements were: 
- Fresh and dry weight of the aerial part of 30 plants per treatment and per block. This measurements let us to calculated yield and dry matter from shoot.

- Aerial part height.

- Leaf number per plant.

- Leaf area using a pictures analyzer with Image J $1,47 \mathrm{v}$ developed at the National Institutes of Health (Bethesda, Maryland, USA). This measure let us to calculate specific leaf area.

- Leaf colour using a colorimeter CR10 (Konica-Minolta Sensing Inc., Osaka, Japan), relative chlorophyll content with a chlorophyllmeter (Minolta SPAD-502; Konica-Minolta Sensing Inc., Osaka, Japan). These measurements let us to calculate parameters such as Hue and Chroma.

- Fresh and dry weight of roots of 12 plants per treatment and per block. These measurements let us to calculate dry matter from roots.

\section{Determinations of phytochemicals}

\section{Antioxidant capacity}

Antioxidant capacity (AC) was performed following the procedures of Benzie and Strain (1996) with some modifications (Pellegrini et al., 2003; Llorach et al., 2008) using the Ferric Reducing Ability of Plasma (FRAP) assay as a measure of antioxidant power. For each sample $2 \mathrm{~g}$ of frozen tissue were used. The absorbance was spectrophotometrically determined at a wavelength of $593 \mathrm{~nm}$. The results were expressed as $\mu \mathrm{mol} \mathrm{Fe}{ }^{2+} / \mathrm{g} \mathrm{FW}$ with the calibration curve prepared daily with a methanolic solution of ammonium ferrous sulfatehexahydrate.

\section{Total phenolics}

Total phenolics (TP) were determined using the Folin-Ciocalteu procedure based on the method of Singleton and Rossi (1965) with some modifications (Du et al., 2009). For each sample $2 \mathrm{~g}$ of frozen tissue were used. The absorbance was spectrophotometrically determined at a wavelength of $760 \mathrm{~nm}$. The results were 
expressed as mg gallic acid/g FW with the calibration curve prepared daily with a methanolic solution gallic acid.

\section{Vitamin C}

Ascorbic acid and dehydroascorbic acid (AA and DHAA, respectively) were determined as described in aeration experiments.

\section{Pigments}

Chlorophyll $a$, chlorophyll $b$ and carotenoids (Chl. $a$, Chl. $b$ and Car., respectively) were determined according to the Lichtenthaler and Wellburn (1983) method with some modifications (Wellburn, 1994; Dere et al., 1998; Zhan et al., 2009). For each sample $1 \mathrm{~g}$ of frozen tissue was used. The entire process of extraction of pigments was conducted on ice. Chl. $a$, Chl. $b$ and Car. were spectrophotometrically determined at a wavelength of 662, 645 and $470 \mathrm{~nm}$, respectively. The results were expressed as $\mathrm{mg} / \mathrm{g} \mathrm{FW}$ according to the Lichtenthaler and Wellburn formulas: Chl. $a=11,115 \times \mathrm{A}_{662 \mathrm{~nm}}-2,35-+. \times$ $\mathrm{A}_{645 \mathrm{~nm}}$; Chl. $b=18,181 \times \mathrm{A}_{645 \mathrm{~nm}}-3,96 \times \mathrm{A}_{662 \mathrm{~nm}} ;$ Car. $=\left(1000 \times \mathrm{A}_{470 \mathrm{~nm}}-2,27 \times\right.$ Chl. $a-81.811 \times$ Chl. $b) / 227$.

\section{POD, PPO and PAL}

Peroxidase, polyphenol oxidase and phenylalanine ammonia lyase (POD, PPO and PAL, respectively) activities were determined from $0.5 \mathrm{~g}$ of frozen tissue for each sample. POD activity was determined as described by Nickel and Cunningham (1969) with some modifications (Zhan et al., 2009; Mousavizadeh and Sedaghathoor, 2011) and the absorbance was spectrophotometrically determined at a wavelength of $470 \mathrm{~nm}$ at time $0\left(\mathrm{t}_{0}\right)$ and after $1 \mathrm{~min}\left(\mathrm{t}_{1}\right)$. The results were expressed as $\Delta \mathrm{A} / \mathrm{min} \mathrm{g} \mathrm{FW}$ with the calibration curve prepared daily with a pH 7.0 phosphate buffered saline solution (PBS) and peroxidase. PPO activity was determined as described by Degl'innocenti et al. (2005) with some modifications (Doğan and Salman, 2007). The absorbance was spectrophotometrically determined at a wavelength of $480 \mathrm{~nm}$ and the results were expressed as PPO Unit/g FW with the calibration curve prepared daily with a pH 7.0 PBS solution and tyrosinase. PAL activity was determined as described by Campos et al. (2004) and Degl'innocenti et al. (2005) with some modifications (Zhan et al., 2009). The absorbance was spectrophotometrically 
determined at a wavelength of $290 \mathrm{~nm}$ and the results were expressed as $\mu$ molcinnamic acid/h g FW with the calibration curve prepared daily with a $\mathrm{pH}$ 8.0 PBS solution and trans-cinnamic acid. All the spectrophotometric analyses were conducted using a Beckman DU ${ }^{\circledR}-65$ spectrophotometer (Beckman Coulter Inc., Fullerton, CA, USA).

\section{BP and So-Q}

Browning potential and soluble o-quinone (BP and So-Q, respectively) were determined based on the method of Couture et al. (1993) and LoaizaVelarde and Saltveit (2001) with some modifications (Tardelli et al., 2013). For each sample $5 \mathrm{~g}$ of frozen tissue were used. BP and So-Q content were spectrophotometrically determined at a wavelength of 340 and $437 \mathrm{~nm}$, respectively. The results were expressed as raw absorbance units $\left(\mathrm{Abs}_{340} \mathrm{FW}\right.$ and $\mathrm{Abs}_{437} \mathrm{FW}$ for BP and So-Q, respectively) with the calibration curve prepared daily with pure methanol. Nitrate, phosphate and calcium carbonate $\left(\mathrm{NO}_{3}{ }^{-}, \mathrm{PO}_{4}{ }^{3-}\right.$ and $\mathrm{CaCO}_{3}$, respectively) were determined on the aerial part using a refractometric kit (Merck Reflectoquant RQflex $2^{\odot}$, Merck KGaA, Darmstadt, Germany), following manufacturer's instructions. For each sample $10 \mathrm{~g}$ of frozen tissue were used, which were stomached for $2 \mathrm{~min}$ at normal speed with $10 \mathrm{~mL}$ of distilled water and subsequently filtered. The results were expressed as $\mathrm{mg} / \mathrm{g}$ FW.

\section{Microbiological quality}

Total bacterial count (TBC) was determined using the PCA (Fluka Analytical, Sigma-Aldrich S.r.l., Milan, Italy) while the yeast and mould count (YC and MC, respectively) were determined using the Yeast Extract Glucose Chloramphenicol Agar (YEGCA) (Fluka Analytical, Sigma-Aldrich S.r.l., Milan, Italy). For each sample $25 \mathrm{~g}$ of fresh tissue of the aerial part were used. The enumeration of TBC was performed after incubation at $30{ }^{\circ} \mathrm{C}$ for $48 \mathrm{~h}$. The enumeration of $\mathrm{YC}$ and $\mathrm{MC}$ were performed after incubation at $30{ }^{\circ} \mathrm{C}$ for $5 \mathrm{~d}$. The results were expressed as the log colony-forming unit per g (Log CFU/g FW). 
CHAPTER 1 


\section{EFFECT OF AERATION OF NUTRIENT SOLUTION ON THE GROWTH AND QUALITY OF PURSLANE (Portulaca oleracea)}

\section{Introduction}

Purslane (Portulaca oleracea L.) is a neglected plant which is enjoying increased commercial interest as a potential food crop because it provides a rich source of bioprotective compounds such as anti-oxidants and vitamins, omega-3 fatty acids, and essential amino acids (Gonnella et al., 2010). Moreover, purslane is a good source of several minerals, especially potassium (Mohamed and Hussein, 1994). Among the cultivation techniques used to grow this species, a floating system is one of the most suitable since purslane plants can be grown at high densities, thereby producing high yields in a short time, while the resulting product is clean and ready to be packed as a "ready-to-eat" vegetable (Cros et al., 2007).

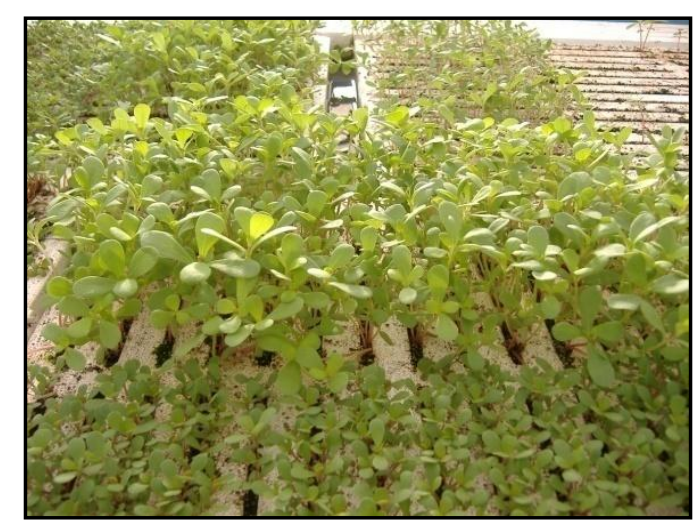

Picture 2: Purslane cultivars grown in floating system.

As in other hydroponic systems, plants grown in a floating system may suffer hypoxia because the roots gradually consume the oxygen dissolved in the nutrient solution. The phenomenon of hypoxia is particularly acute in the Summer, since, as temperatures rise, the quantity of dissolved oxygen decreases and the rate of root respiration increases (Morard and Silvestre, 1996). 
An adequate concentration of oxygen in the root environment is necessary to ensure the functionality of the roots, since a lack of oxygen reduces water and mineral uptake by the plant, which may limit growth and, consequently, crop yield (Tesi et al., 2003a).To avoid any negative repercussions on yield, growers aerate the nutrient solution to enrich it with oxygen, especially in the case of purslane plants grown in a closed hydroponic system (Palaniswamy et al., 2004). There are, however, significant differences in sensitivity to oxygen deficiency in the rooting medium among plant species, even among cultivars (Veen, 1988). Many studies have revealed that anatomical and morphological adaptations that facilitate the transport of oxygen from the shoot to the roots are the most important features for plant tolerance to hypoxia (e.g., see Armstrong et al., 2009). In response to hypoxia stress, some plants create aerenchyma, a specialized tissue in the roots which consists of longitudinal gas-filled channels that facilitate the internal diffusion of gases (Evans, 2003). Reports on the development of aerenchyma due to oxygen deficiency in purslane are scarce. However, Harwood and Bantilan (1974) indicated that purslane was a species that was only moderately sensitive to "puddling" or waterlogging, which suggests that purslane plants can create aerenchyma in response to root hypoxia. It is known that purslane is an oxalate- and nitrate accumulating plant, the exact contents of which vary with cultivar (Kașkar et al., 2009). A reduced concentration of oxygen in the nutrient solution of a floating system has been shown to reduce the nitrate content of rocket (Ferrante et al., 2003), possibly due to an increase in the activity of nitrate reductase (Garcia-Novo and Crawford, 1973). It has also been suggested that nitrate can alleviate the effects of anoxia by acting as an alternative electron acceptor (Morard et al., 2004). As regards oxalate accumulation, no report has been found on the effect of oxygen deprivation in the nutrient solution.

The production of functional phytochemicals in plants is influenced by both genetic and environmental factors that induce stress. Recently, Rajapakse et al. (2009) suggested that low-oxygen stress induced the production of protective phytochemicals in lettuce, which may, in turn, enhance its marketable value. The high nutritional and anti-oxidant properties of purslane are well-known and, according to the above hypothesis, both could be increased under hypoxic conditions. 


\section{Specific material and methods}

\section{Growing conditions}

The experiment was conducted at the "Tomás Ferro" Experimental AgroFood Station, Technical University of Cartagena (UPCT; 37 $41^{\prime} \mathrm{N} ; 0^{\circ} 57^{\prime} \mathrm{W}$ ). Two cultivars of purslane ( $P$. oleracea L.), namely 'Golden Purslane' with succulent, glossy golden-green oblate leaves produced in rosettes (Tozer Seeds Co., Cobham, UK) and the local Spanish accession, C-215, provided by the germplasm bank of UPCT, were cultivated in a floating system in an unheated greenhouse covered with polycarbonate. The Spanish accession C-215 was selected for these experiments for its good agronomic behaviour in a floating system (Franco et al., 2011). Four crop cycles were carried out, with sowings on 23 October 2008 (Experiment 1), 24 March 2009 (Experiment 2), 18 June 2009 (Experiment 3), and 8 July 2009 (Experiment 4). Sowing was carried out manually into 'stryrofloat' trays containing peat, which were then transferred to flotation beds floating on fresh tap water with an electrical conductivity (EC) of $1.1 \mathrm{dS} \mathrm{m}^{-1}$ and a $\mathrm{pH}$ of 7.8 .

After transferring the trays to flotation beds, aeration was provided at three levels using a blow pump connected to a pipe trellis positioned at the bottom of each flotation bed. The pipes were perforated with holes at 0,6 , or 36 holes $\mathrm{m}_{-2}$ to provide the different levels of aeration to be tested (no aeration, low, or high aeration, respectively). Each level of treatment was carried out in $135 \mathrm{~cm} \times 125$ $\mathrm{cm} \times 20 \mathrm{~cm}$ beds located at three places inside a greenhouse for all the experiments. Each bed had four floating trays of $60 \mathrm{~cm} \times 41 \mathrm{~cm}$ (two for each cultivar).

One week after sowing, the purslane plants were thinned, leaving 20 plants per hole $\left(2,050\right.$ plants $\left.\mathrm{m}^{-2}\right)$. At the same time, the tap water in the beds was replaced with a nutrient solution (Egea-Gilabert et al., 2009). The crop cycle lasted 32 days in Experiment 1, 29 days in Experiment 2, 22 days in Experiment 3, and 15 days in Experiment 4. Harvesting was carried out when four-or five pairs of leaves had been formed on each plant. The EC and temperature of the nutrient solution were monitored during the growing cycles using Campbell CS547 sensors (Campbell Scientific Inc., Logan, UT, USA) and the oxygen concentrations were also monitored using Campbell CS512 sensors located in 
each flotation bed. The temperature and light conditions during the experiments were as follows: Experiment 1, minimum, average, and maximum air temperatures of $5.4{ }^{\circ} \mathrm{C}, 18.4{ }^{\circ} \mathrm{C}$, and $38.7^{\circ} \mathrm{C}$, respectively, and an average daily light integral (DLI) of $8.5 \mathrm{~mol} \mathrm{~m}^{-2} \mathrm{~s}^{-1}$; Experiment 2, minimum, average, and maximum air temperatures of $8.1^{\circ} \mathrm{C}, 17.6^{\circ} \mathrm{C}$, and $39.1{ }^{\circ} \mathrm{C}$, and an average DLI of $15.0 \mathrm{~mol} \mathrm{~m} \mathrm{~m}^{-2} \mathrm{~s}^{-1}$; Experiment 3, minimum, average, and maximum air temperatures of $19.5^{\circ} \mathrm{C}, 27.8^{\circ} \mathrm{C}$, and $39.5^{\circ} \mathrm{C}$, and an average DLI of $17.5 \mathrm{~mol} \mathrm{~m}$ ${ }^{2} \mathrm{~s}^{-1}$; and Experiment 4, minimum, average, and maximum air temperatures of $20.1^{\circ} \mathrm{C}, 29.3^{\circ} \mathrm{C}$, and $42.5^{\circ} \mathrm{C}$, and an average DLI of $19.7 \mathrm{~mol} \mathrm{~m}^{-2} \mathrm{~s}^{-1}$.

\section{Plant growth measurements}

Shoot fresh weights (FW), leaf areas, relative chlorophyll contents (RCC), and root growth were measured on 20 plants in each tray. Leaf areas were measured using a leaf area meter (LICOR-3100 C; LICOR Biosciences Inc., Lincoln, NE, USA) and RCC with a chlorophyll meter (Minolta SPAD-502; Konica- Minolta Sensing Inc., Osaka, Japan). Root lengths, areas, and volumes, and the number of branches were determined using a Winrhizo LA 1600 root counter (Regent Inc., Quebec, Canada) from pictures taken of each root system by a double-pass scanner incorporated in the counter. The dry weights (DW) of shoots and roots were determined by drying in an oven at $60{ }^{\circ} \mathrm{C}$ until constant weight. At harvest, root sections were obtained from taproots $1.0 \mathrm{~cm}$ from the root collar. Fresh sections were fixed in a formalin-acetic acid-alcohol (FAA) solution containing 17:1:1 (v/v/v) 50\% ethanol : 37\% formaldehyde : glacial acetic acid at $4^{\circ} \mathrm{C}$ for $24 \mathrm{~h}$. The fixed samples were then dehydrated in a graduated series containing ethanol and tert-butyl alcohol. The stepwise substitution was performed by decreasing the ratio of $100 \%(\mathrm{v} / \mathrm{v})$ ethanol to tertbutyl alcohol from $2: 1$, to $1: 1$, to $1: 2$ (24 $\mathrm{h}$ in each). The samples were then infiltrated and embedded using a JB4 Plus Embedding Kit (Electron Microscopy Sciences, Hatfield, PA, USA). Transverse sections, $8 \mu \mathrm{m}$-thick, were cut using an RM 2265 rotary microtome (Leica, Wetzlar, Germany) and were stained with hematoxylin and eosin for light microscope observation (Kiernan, 2008). The percentage of aerenchyma tissue (i.e., the ratio between the area occupied by aerenchyma and the total cross-sectional area of the root) was determined in four samples per treatment and experiment. To measure the percentage of 
aerenchyma, the photomicrographs were digitalised using the AutoCAD programme (Autodesk Inc., San Rafael, CA, USA).

\section{Determinations of phytochemical contents}

For phytochemical extraction, three $20 \mathrm{~g}$ shoot FW samples per treatment and per experiment were frozen in liquid $\mathrm{N}_{2}$ and stored at $-80{ }^{\circ} \mathrm{C}$. Total phenolics contents and anti-oxidant capacities were analysed according to Tarazona-Díaz et al. (2011). Briefly, $0.5 \mathrm{~g}$ of each sample was homogenised in $3.0 \mathrm{~mL} 100 \%(\mathrm{v} / \mathrm{v})$ methanol and centrifuged at $1,200 \times \mathrm{g}$ for $15 \mathrm{~min}$ at $4{ }^{\circ} \mathrm{C}$ (Heraeus Fresco 21; Thermo Scientific, Osterode, Germany). The total phenolics contents were determined by the Folin- Ciocalteu colorimetric method, based on the procedure of Singleton and Rossi (1965). A $0.1 \mathrm{~mL}$ aliquot of the extract supernatant was mixed with $0.15 \mathrm{~mL}$ of Folin- Ciocalteu reagent and $1.0 \mathrm{~mL} 4 \mathrm{~g} \mathrm{~L}^{-1} \mathrm{NaOH} / 20 \mathrm{~g}$ $\mathrm{L}^{-1} \mathrm{Na} 2 \mathrm{CO}$. The absorption of the solution was measured at $750 \mathrm{~nm}$ in a spectrophotometer (SmartSpecTM Plus; Bio- Rad Laboratories, Inc., Hercules, CA, USA). Each measurement was compared with a standard curve of chlorogenic acid and expressed as mg chlorogenic acid equivalent (CAE) $\mathrm{kg}^{-1}$ FW. Anti-oxidant activity was evaluated in terms of free radical-scavenging capacity, according to Brand- Williams et al. (1995). A fresh solution of $0.7 \mathrm{mM}$ 1,1- diphenyl-2-picryl-hydrazyl (DPPH) radical in $100 \%$ (v/v) methanol was prepared each day. A $0.1 \mathrm{~mL}$ aliquot of the extract supernatant was added to 0.9 $\mathrm{mL}$ of DPPH stock solution. The absorption of each sample was measured at 515 $\mathrm{nm}$ in a spectrophotometer against a blank of $100 \%(\mathrm{v} / \mathrm{v})$ methanol. Measurements were compared with a standard curve of ascorbic acid concentrations and expressed as $\mathrm{mg}$ ascorbic acid equivalent anti-oxidant capacity (AAE) $\mathrm{kg}^{-1} \mathrm{FW}$. Glutathione contents were determined using a glutathione assay kit (CS0260) from Sigma-Aldrich (St. Louis, MO, USA), following the manufacturer's instructions. Measurements were carried out in a spectrophotometer (Thermo-Scientific Multiskan EX, Shanghai, P.R. China) at $412 \mathrm{~nm}$. A standard curve of reduced glutathione was used to determine the amount of glutathione in each sample.

\section{Experimental design and statistical analysis}

The experiment was arranged in a split-plot design with level of aeration as the main plot factor, and cultivar as the sub-plot factor. INFOSTAT 1.1 
(Universidad Nacional de Córdoba, Córdoba, Argentina) was used for statistical analyses by ANOVA. The interaction between aeration and cultivar was not included in the ANOVA because it was not significant. Treatment means were separated with the LSD Test $(\mathrm{P} \leq 0.05)$.

\section{Results}

A decrease in aeration led to lower levels of dissolved oxygen (DO) in the nutrient solution, especially during later stages of the crop growth cycle, but had no effect on temperature (Figure 2). Electrical conductivity was not affected by aeration, and increased slowly towards the end of each cultivation cycle, probably due to water consumption by the plants (data not shown). In general, the level of DO decreased faster in the Summer cycles due to the higher temperatures of the nutrient solutions and increased plant growth. The level of DO fell from $8.6 \mathrm{mg}$ $\mathrm{L}^{-1}$ to $6.1 \mathrm{mg} \mathrm{L}^{-1}$ at the highest level of aeration, whereas at the other two aeration levels (low and no aeration) it decreased more sharply, particularly in the non-aerated treatment (Figure 2).

\section{Plant growth}

In all crop cycles, 'Golden Purslane' shoots had a larger leaf area, FW, and DW than C-215 shoots. In general, harvested purslane shoots had a larger leaf area in the Summer (Experiment 3 and Experiment 4) than in the Autumn and Spring (Table 4). Furthermore, shoot DW growth increased with increasing aeration level in all crop cycles. The two cultivars differed in their DW percentage during the Summer cycles, but aeration had no effect on this parameter. 'Golden Purslane' plants had lower SPAD values (due to the light green colour of their leaves) than C-215 plants in all cycles. In the Spring and Summer cycles, increasing aeration decreased the SPAD values. Aeration increased root DW, surface area, and the length of fine roots (i.e., those between $0.5-1.5 \mathrm{~mm}$ in diameter; Table 5). Other root parameters (total length, volume, and number of branches) were not affected. There was hardly any difference in root growth between the two cultivars. Aerenchymatous spaces were produced within the cortical parenchyma of roots in both cultivars (Picture 3). Aerenchyma occupied approx. $10 \%$ of root sections in the non-aerated treatments in both cultivars (data not shown). Aerenchyma tissue diminished significantly as 
aeration increased, reaching an average of $7.4 \%$ and $4.4 \%$ of the cross-sectional areas of roots at low and high aeration levels, respectively, in both cultivars.

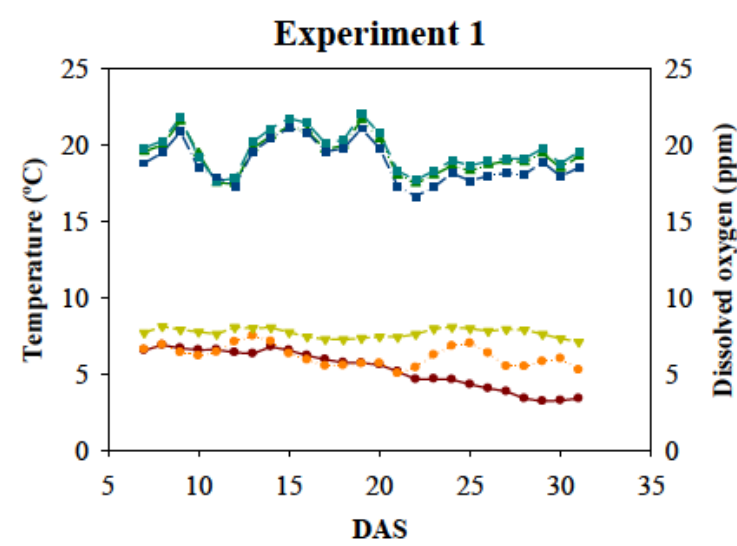

Experiment 3

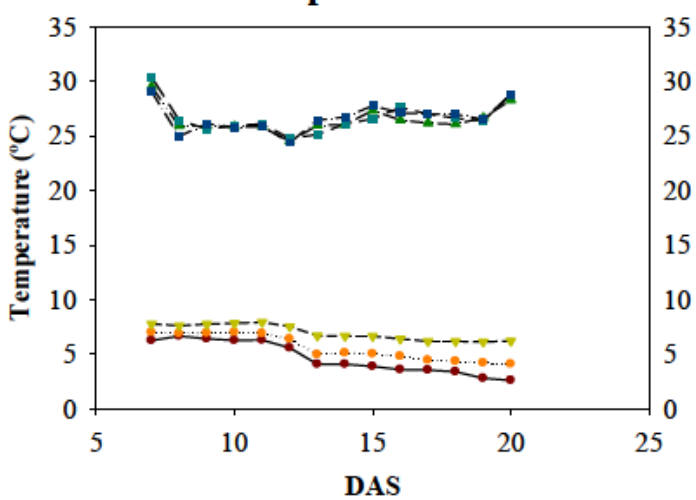

Experiment 2

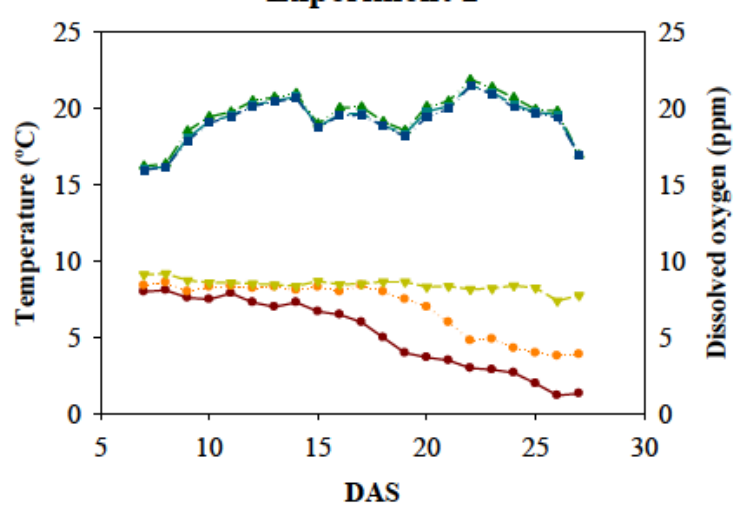

Experiment 4

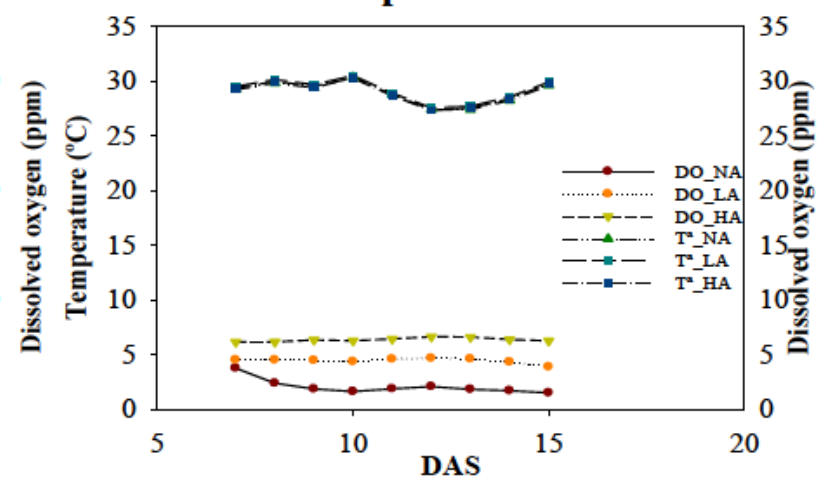

Figure 2: Evolution of dissolved oxygen (DO; Panels A, B, E, F) and temperature (Panels C,D,G, H) of the nutrient solutions under different levels of aeration (no aeration, low, or high aeration) in four different crops cycles. Panels A, C = Experiment 1 (Autumn). Panels B, D = Experiment 2 (Spring). Panels E, G = Experiment 3 (Summer). Panels $\mathrm{F}, \mathrm{H}=$ Experiment 4 (Summer). Each datum point for each day after sowing (DAS) is the average of 24 hourly measurements..

\section{Mineral ion concentrations}

Aeration of the nutrient solution increased shoot nitrate concentrations, but had no effect on oxalate concentrations (Table 6). The accumulation of nitrates and oxalates in purslane shoots depended on cultivar. For example, nitrate concentrations were significantly higher in 'Golden Purslane' than in C-215 in all crop cycles, while oxalate levels were always higher in C-215 plants. Shoot $\mathrm{Na}^{+}$ ion concentrations decreased as the level of aeration increased, while shoot $\mathrm{K}^{+}$ ion concentrations increased under the same conditions (Table 6). C-215 was characterised by having higher $\mathrm{K}^{+}$and $\mathrm{Na}^{+}$ion concentrations than those observed in 'Golden Purslane'. 


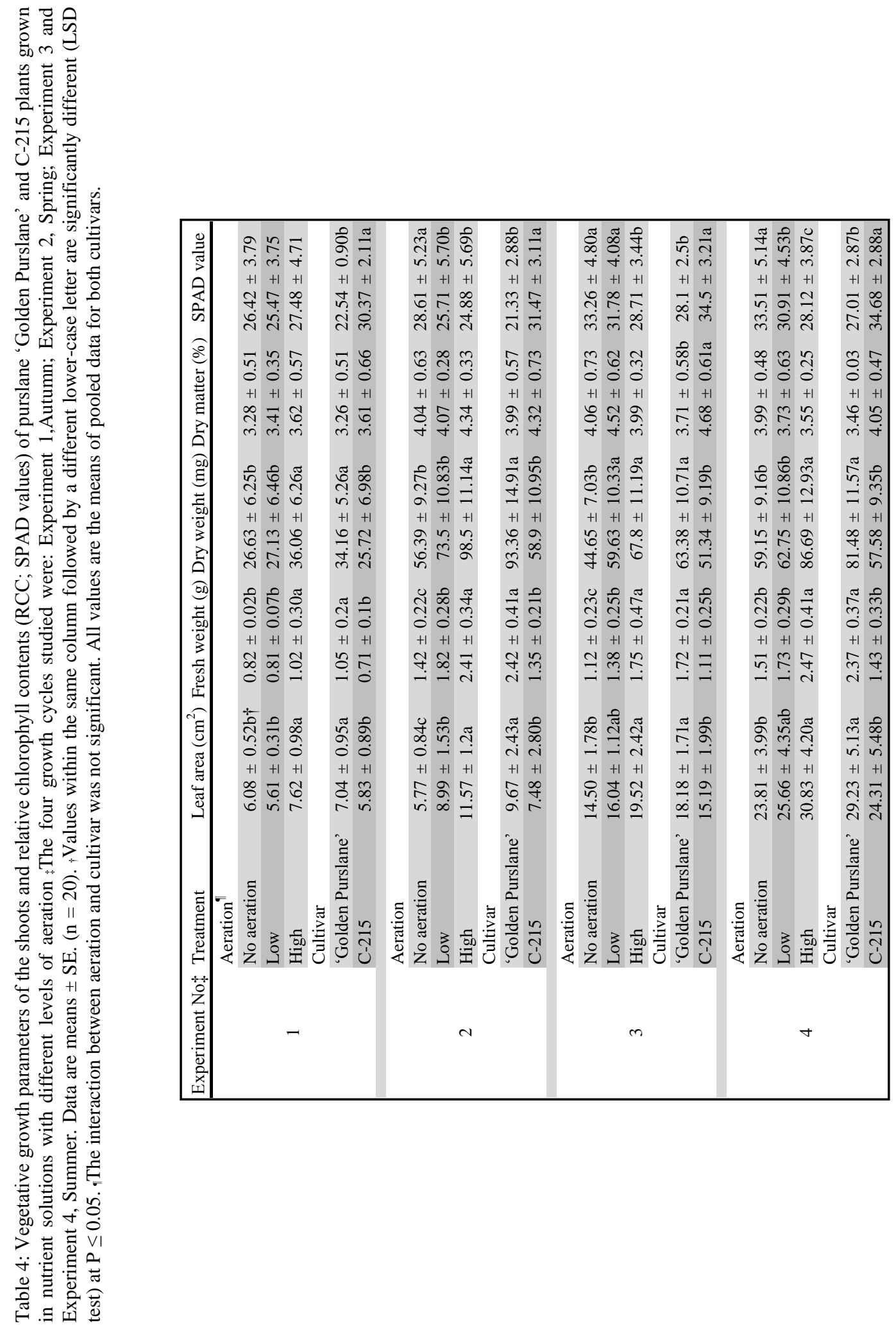




\section{Phytochemical compounds}

The total phenolics contents of shoots were higher during the Summer cycles than the Autumn and Spring cycles (Table 6). In both Summer cycles, total phenolics contents decreased with increasing aeration. The total phenolics contents in C-215 plants were significantly higher than in 'Golden Purslane', but only in Experiment 4. Aeration significantly decreased the anti-oxidant capacity of purslane in the Spring and Summer cycles. 'Golden Purslane' showed the highest anti-oxidant values in all cycles, except Spring. Aeration decreased glutathione concentrations in all crop cycles while C-215 contained significantly more glutathione than 'Golden Purslane' plants.

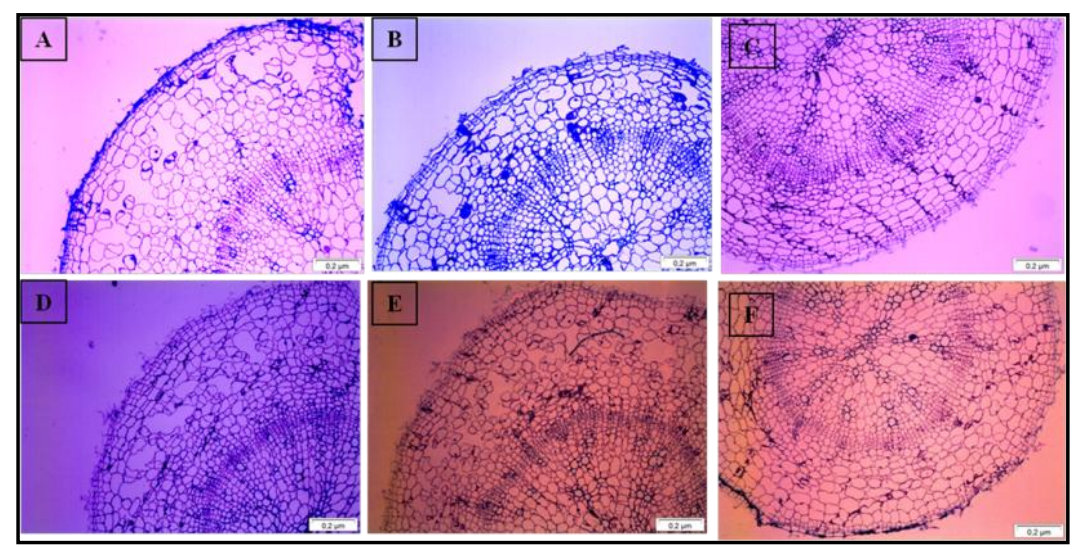

Picture 3 Root aerenchyma tissue in transverse sections of the roots of 'Golden Purslane' grown under different levels of aeration: no aeration (Panel A), low aeration (Panel B), or high aeration (Panel C); and of C-215 purslane grown under different levels of aeration: no aeration (Panel D), low aeration (Panel E), or high aeration (Panel F). Samples represent roots at harvest time in the Summer cycle (Experiment 4). Arrows indicate aerenchyma air spaces. All scale bars $=0.2 \mu \mathrm{m}$.

\section{Discussion}

Our results show that purslane is marginally sensitive to a lack of aeration in the rooting medium, perhaps because the plants were able to adapt to the gradual reduction in oxygen levels in the root medium from the time the seedling emerged. Furthermore, the floating system of production had a large volume of nutrient solution available per plant and resulted in a short growth cycle. Furthermore, the period of stress in our experiment was short and the conditions were not anoxic. Low oxygen concentrations lead to morphological adaptations such as the development of aerenchyma in the roots.

In our experiments, aerenchyma tissue represented approx. $10 \%$ of root cross-sectional areas in the non-aerated treatment at harvest, which is far from the $60 \%$ found in some wetland plant roots (Armstrong, 1979), but enough to 
maintain growth in non-aerated purslane plants. Purslane shoot growth increased with increasing levels of aeration (Table 4). Tesi et al. (2003a) also found a positive effect of aeration on spinach grown in a floating system. In contrast, Pimpini et al. (2000) demonstrated reduced growth in Eruca sativa, probably due to an interaction between oxygen and the solubilisation of some micronutrients. As regards RCC, in most of the growth cycles studied, aeration let to a decrease in SPAD values, resulting in the greenest leaves being observed in the absence of aeration, perhaps as a result of slower plant growth (Zheng et al., 2007). This result agrees with Tesi et al. (2003b) who found that lettuce heads grown without aeration showed a higher RCC and a darker green colour than aerated lettuce. In contrast, some authors found no differences in the RCC of the leaves of nonaerated and aerated spinach and maize (Tesi et al., 2003a;Vodnik et al., 2009).

Aeration increased root growth, particularly root DW, root area, and the length of roots $0.5-1.5 \mathrm{~mm}$ in diameter (Table 5). The decrease in root DW as a result of oxygen depletion was probably due to an increase in root porosity in the aerenchymatous tissues. The aeration treatments increased the lengths of fine roots, thereby improving plant growth since these are the primary pathway for water and nutrient uptake by plants (Jackson et al., 1997). In addition, the greater lengths of fine roots were responsible for increasing the root areas in the aeration treatments. Shoot nitrate concentrations were higher in 'Golden Purslane' than in C-215 (Table 6), which agrees with the results of Kașkar et al. (2009).

A lack of aeration of the nutrient solution decreased the nitrate concentrations in purslane, which agreed with the results obtained in other species grown in floating systems (Ferrante et al., 2003; Tesi et al., 2003b). Igamberdiev and Hill (2004) suggested that nitrate can be viewed as an intermediate electron acceptor under conditions of oxygen deficiency. It appears that plants can activate an alternative respiratory pathway in which nitrate is used to release oxygen. This could reduce the availability of nitrate and $\mathrm{NO}_{3}{ }^{-}$ion concentrations in shoots compared with plants grown under aerated conditions.

The level of oxygen did not influence oxalate contents in any crop cycle. Ala et al. (1995) showed that the hypoxic conditions of waterlogging did not affect oxalate concentrations in Atriplex amnicola after 4 weeks of growth, although Karimi and Ungar (1986) found that a lack of aeration decreased the total oxalate 


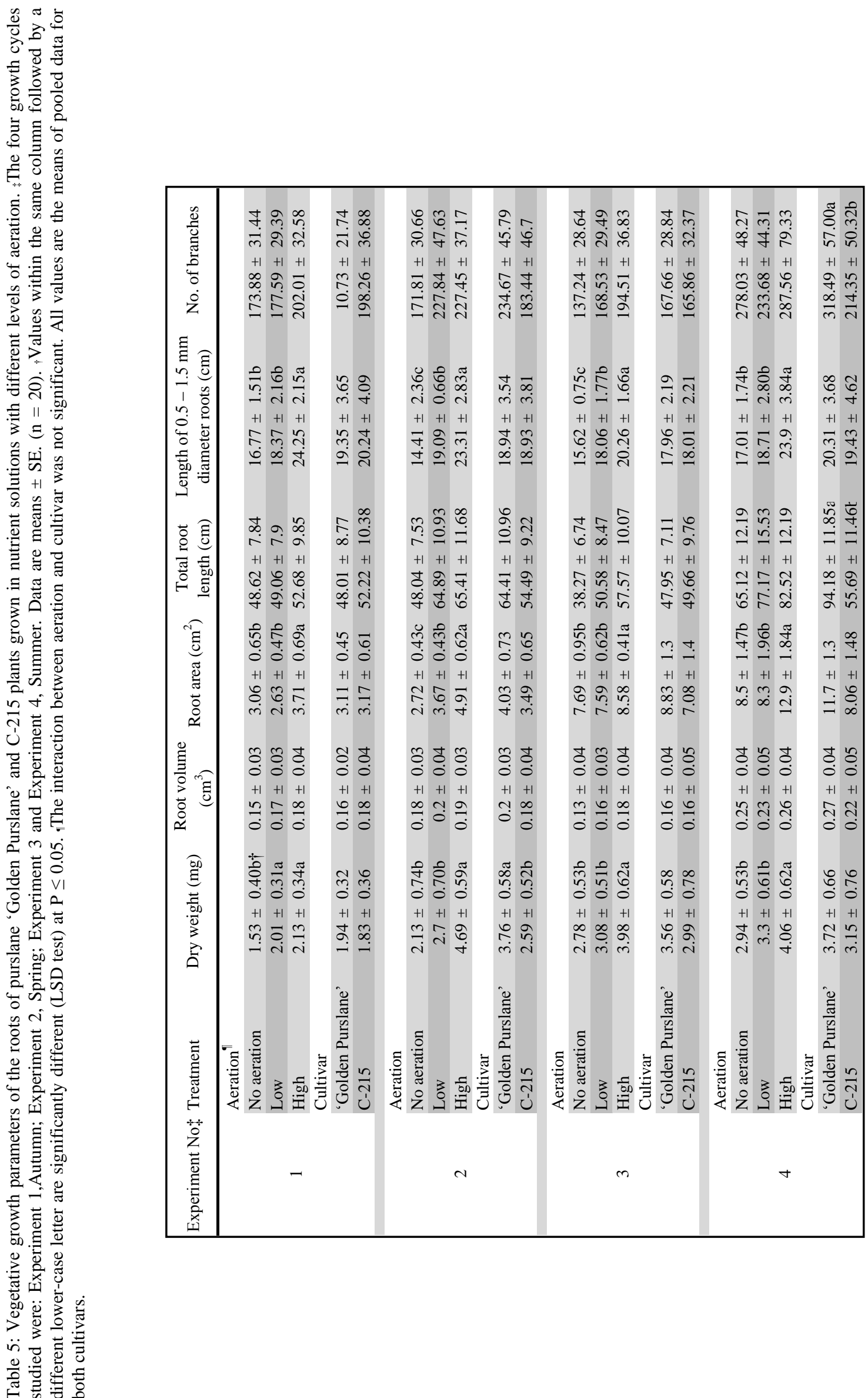


content of $A$. triangularis. These conflicting results may be explained by the fact that oxalic acid is synthesised via several major pathways in plants, for which, glyoxylate, glycolate, and ascorbic acid appear to be the major precursors (Noonan and Savage, 1999).

Usually, low-oxygen solutions have a negative effect on nutrient acquisition by roots because ion uptake by cells is affected by oxygen level. The ability of a plant to regulate its shoot ion composition relies, in part, on selective uptake and transport processes in the root. Hypoxia causes a decrease in the fluidity of root membranes, which is important for controlling the selective uptake of ions by plants (Barrett-Lennard, 2003). In our case, the concentrations of $\mathrm{Na}^{+}$ions increased and those of $\mathrm{K}^{+}$ions decreased in plants grown in nonaerated or low-aerated solutions. Our results agree with those of Buwalda et al. (1988), who demonstrated that the concentrations of $\mathrm{K}^{+}$ions decreased, while $\mathrm{Na}^{+}$ions increased in wheat shoots as hypoxia became more intense. Another consequence of oxygen stress is the generation of reactive oxygen species (ROS), although the adverse effects of these free radicals was abolished by the presence of low-molecular-weight endogenous anti-oxidants (Blokina et al., 2003). In our experiments, glutathione levels decreased when the oxygen concentrations increased in all crop cycles (Table 6).

These results agree with studies on the anti-oxidant defence system in wheat seedlings grown under oxygen stress (Biemelt et al., 1998), when significant increases in ascorbate and glutathione were observed. In our study, total phenolics contents were higher in the Summer cycles, when oxygen concentrations were the lowest (Table 6), in agreement with the results obtained by Rajapakse et al. (2009) in lettuce. In general, the non-aerated treatment resulted in a higher anti-oxidant capacity than those observed with high aeration (Table 6). The anti-oxidant capacities attained in the different treatments were similar to the levels of phenolic compounds. Available evidence points to phenolic compounds possessing anti-oxidant activity (Rice-Evans et al., 1999), while Oliveira et al. (2009) described a correlation between phenolic compounds and antioxidant capacity in different samples of purslane under non-stressed conditions. 


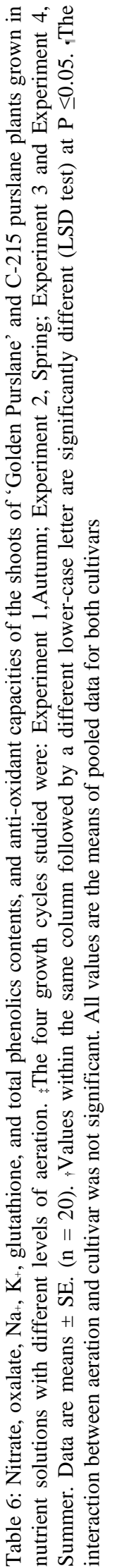

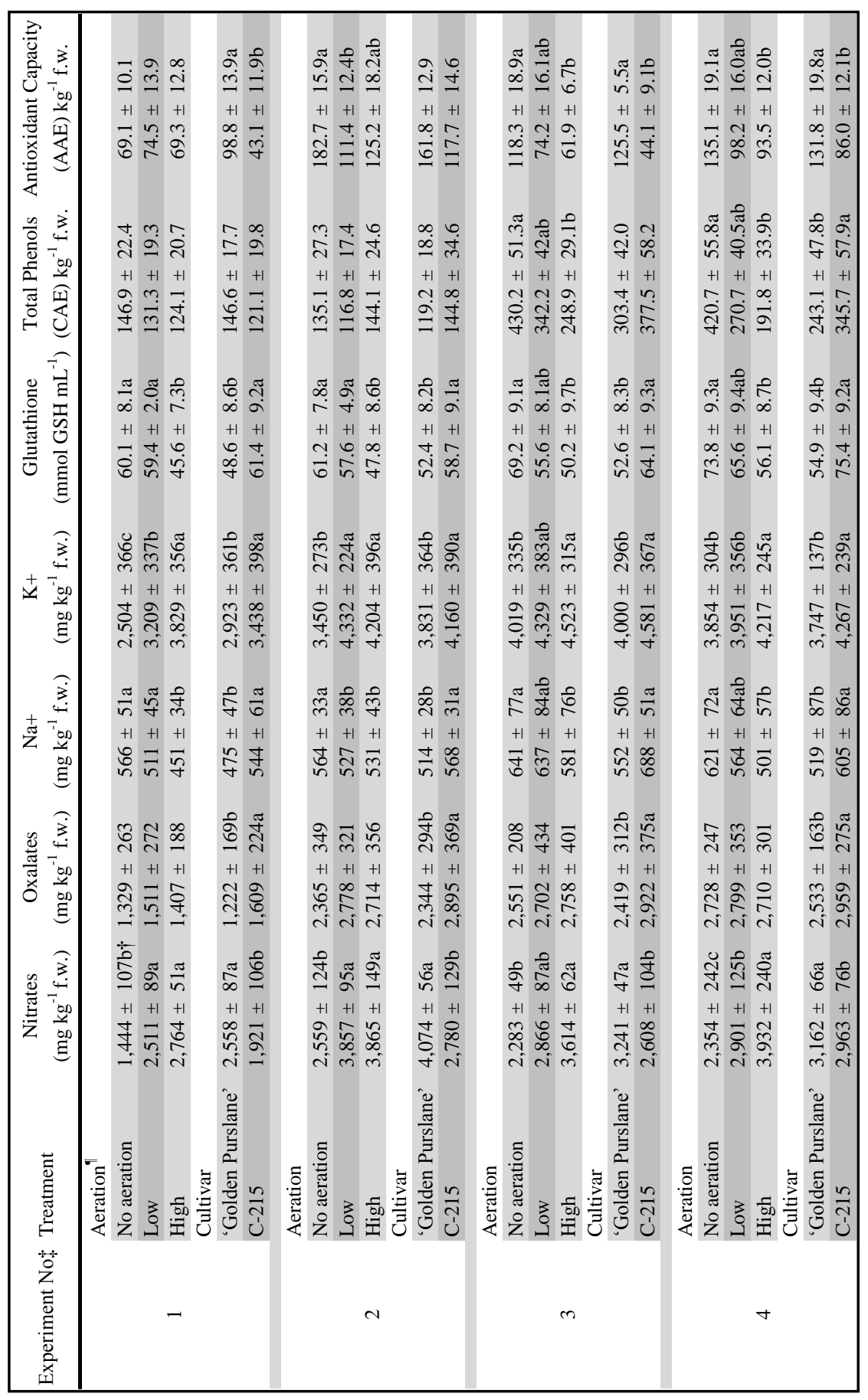


In conclusion, purslane plants showed little sensitivity to oxygen depletion in the root medium, and were able to adapt to a gradual reduction in oxygen level. However, aeration is advisable to increase yields, although the final quality of the product, in terms of nitrate levels, the concentrations of functional phytochemicals, and SPAD values, may be slightly lower. 


\section{COMBINED EFFECTS OF GROWTH CYCLE AND DIFFERENT LEVELS OF AERATION IN NUTRIENT SOLUTION ON PRODUCTIVITY, QUALITY, AND SHELF LIFE OF WATERCRESS (Nasturtium officinale R. BR.) PLANTS}

\section{Introduction}

Nowadays, there is a high demand for fresh-cut vegetables as a result of the consumer's desire for healthy, convenient, fresh, and ready-to-eat commodities. Consequently, there is a much larger variety of salad leaves on the market than was the case quite recently. They include watercress [Rorippa nasturtium-aquaticum (L.) Hayek = Nasturtium officinale R. Br.], alone or mixed with another leafy vegetable. Watercress is native from Europe to central Asia and is one of the oldest of the leafy vegetables known to be consumed by humans. Currently in the fresh salads industry, watercress is regarded as a valuable food product (Picture 4), being recognized for its high content of healthpromoting compounds such as antioxidants and phenolic compounds (MartínezSánchez et al., 2008). It is known to contain one of the highest concentrations of the beneficial antioxidant, phenethyl isothiocyanate, which has been shown to increase the body's potential to resist certain carcinogenic agents (Palaniswamy et al., 1997; Alwi et al., 2010).

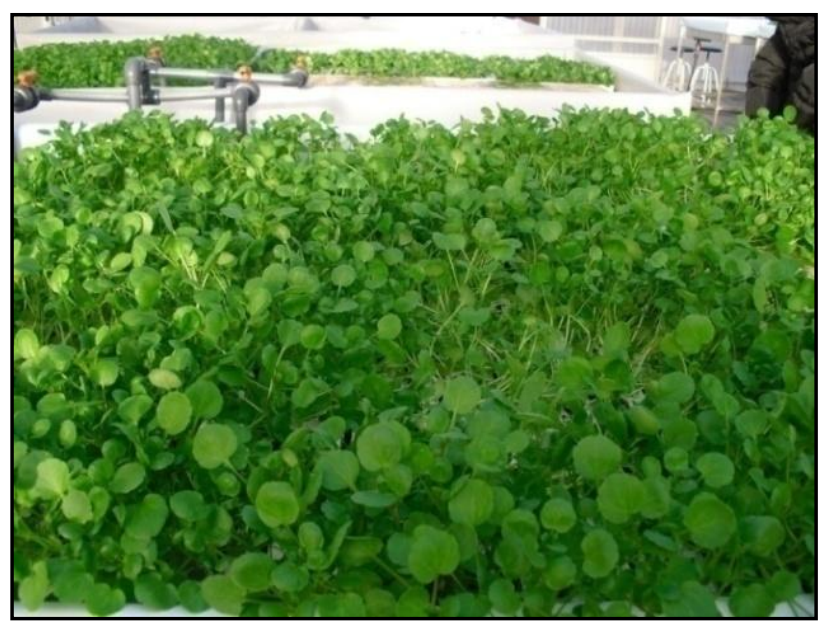

Picture 4: Watercress plant grown in floating system. 
Watercress grows wild in streams, ponds, and reservoirs. Taking advantage of the fact that it is a semi aquatic plant, watercress can be grown in hydroponic cultivation. Among such hydroponic methods, the floating system is one of the most suitable for growing leafy vegetables, because plants can be grown at high densities, thereby producing high yields in a short time, whereas the resulting product is clean and very suitable to be processed as a ready-to-eat vegetable. Like in other hydroponic systems, plants growing in a floating system may suffer hypoxia because the roots gradually consume the oxygen dissolved in the nutrient solution. Therefore, a suitable concentration of oxygen in the root environment is necessary to ensure the functionality of the root, because a lack of oxygen reduces water and mineral uptake by the plant, which may limit growth and, consequently, crop yield (Tesi et al., 2003a). To avoid negative repercussions on yield, growers aerate the nutrient solution to enrich it with oxygen. There are, however, significant differences in sensitivity to oxygen deficiency in the rooting medium among plant species, even among cultivars (Visser et al., 2000). This is because in some plants, the low oxygen concentrations can lead to anatomical and morphological adaptations that facilitate the transport of oxygen from the shoot to the roots. For example, some plants create aerenchyma, a specialized tissue in the roots that consists of longitudinal gas-filled channels that facilitate the internal diffusion of gases (Evans, 2003). Another developmental adaptation to depleted oxygen is the presence of adventitious roots, which often contain extensive aerenchymatous tissue and are thus less affected by hypoxia conditions (Visser et al.,1997). In watercress, adventitious roots are produced in the leaf axils and are exogenous in origin (Kaskey and Tindall, 1979). Watercress plants growing in no aeration conditions may promote the formation and growth of new adventitious roots to adapt to the mentioned conditions.

The quality of the final product can be affected by metabolic adaptations to oxygen deficiency, reducing the potential accumulation of antinutritional end compounds and improving, in many cases, the concentrations of functional phytochemicals. In general, a lack of aeration in the nutrient solution has been seen to decrease shoot nitrate concentrations (Ferrante et al., 2003; Tesi et al., 2003b) and increase the concentrations of functional phytochemicals in several leafy species (Lara et al., 2011). The quality of the raw material is essential to 
ensure the quality of fresh-cut products during storage (Bonasia et al., 2013). Although the horticultural literature contains numerous reports describing effects of preharvest factors on postharvest quality of fruits and vegetables (Mattheis and Fellman, 1999), too little attention has been paid to the effects of preharvest factors on the shelf life of baby leaf vegetables. It is well known that cultivation conditions such as the culture system, irrigation, climate, and fertilization influence the quality of the raw material and therefore can modify its physiological behaviour and suitability for fresh-cut processing (Nicola et al., 2009). In particular, the quality of processed baby leaf spinach was slightly affected by growing cycle conditions (Conte et al., 2008). It is highly likely that leaves with improved quality will be more able withstand the rigorous processing that includes harvest, transportation, washing, sanitization, dewatering, and packaging (Clarkson et al., 2003). Besides, any preharvest condition that stresses a plant such as the non-aeration of the nutrient solution could affect the quality and shelf life of the final product. For example, in purslane grown in a floating system, it was demonstrated that aeration treatments did not significantly affect the gas changes pattern within packages, although shoots cultivated without aeration showed slightly lower total antioxidant capacity during their shelf life (Rodríguez-Hidalgo et al., 2010a).

The objective of this research was to study the effects of growing cycle and nutrient solution aeration and the combination of both factors on yield, quality, and on shelf life as a fresh-cut product of watercress grown in a floating system.

\section{Specific material and methods}

\section{Plant material and growing conditions}

The experiments were conducted at the "Tomás Ferro", Experimental Agro-Food Station, Technical University of Cartagena (UPCT; lat. $37^{\circ} 41^{\prime} \mathrm{N}$; long. $0^{\circ} 57^{\prime} \mathrm{W}$ ). The commercial cultivar of watercress (Nasturtium officinale R. Br.) 'Large leaf' (Tozer Seeds Co., Cobham, U.K.) was cultivated in a floating system in an unheated greenhouse covered with thermal polyethylene. Two crop cycles were carried out with sowings on 18 April 2011 (spring cycle) and 2 December 2011 (winter cycle). "Styrofloat" trays of $60 \mathrm{~cm} \times \cdot 41 \mathrm{~cm}$ were used 
in the trials. These trays have pyramidal-trunk $172 \mathrm{~mm}$ long fissures $20 \mathrm{~mm}$ apart and grouped in three for a total of 42 fissures per tray; fissures measure $10 \mathrm{~mm}$ on the top and $2.5 \mathrm{~mm}$ on the bottom, leading to a volume of $32.4 \mathrm{~cm}^{3}$ per fissure.

Sowing was carried out manually into "styrofloat" trays containing peat, which were then transferred to flotation beds, floating on fresh tap water with an electrical conductivity (EC) of $1.1 \mathrm{dS} \cdot \mathrm{m}^{-1}$ and a $\mathrm{pH}$ of 7.8 . After transferring the trays to flotation beds, aeration was provided at three levels using a blow pump connected to a pipe trellis positioned at the bottom of each flotation bed. The pipes were perforated with holes at 0,6 , or 36 holes $/ \mathrm{m}^{2}$ to provide the different levels of aeration: NA, LA, or HA (Lara et al., 2011). Each level of treatment was carried out in $135 \mathrm{~cm} \times 125 \mathrm{~cm} \times 20 \mathrm{~cm}$ beds located at three places inside a greenhouse for all the experiments. Each bed had four floating trays of $60 \mathrm{~cm} \times$ $41 \mathrm{~cm}$.

A week after sowing, the tap water in the beds was replaced with a nutrient solution (Egea-Gilabert et al., 2009). A week after transferring to the floating beds, the plants were thinned, leaving 12 plants per fissure (2050 plants $/ \mathrm{m} 2)$. The EC and temperature of the nutrient solution were monitored during the growing cycles using Campbell CS547sensors (Campbell Scientific Inc., Logan, UT) and the oxygen concentrations were monitored using Campbell CS512 sensors located in each flotation bed. The temperature and light conditions during the experiments were as follows: spring cycle, minimum, average, and maximum air temperatures of $14.6,27.9$ and $36.5^{\circ} \mathrm{C}$, respectively, and an average daily light integral (DLI) of $20.51 \mathrm{~mol} \cdot \mathrm{m}^{-2} \cdot \mathrm{s}^{-1}$; winter cycle, minimum, average, and maximum air temperatures of $11.7,15.2$ and $18.7^{\circ} \mathrm{C}$, and an average DLI of $6.58 \mathrm{~mol} \cdot \mathrm{m}^{-2} \cdot \mathrm{s}^{-1}$.

Harvesting was carried out at the same phenological stage for both cycles, that is, when seven to eight leaves had been formed on each plant. This occurred $25 \mathrm{~d}$ after sowing in spring and $39 \mathrm{~d}$ in winter. Forty eight plants from four fissures randomly chosen from each tray were harvested for each treatment. The plants were divided randomly into two sets, one for harvest analysis and one for postharvest analysis. 


\section{Analysis at harvesting time}

Dry matter content (\%) of shoots, specific leaf area (SLA), leaf colour, root growth, and number of adventitious roots developing exogenously from the stem at the nodes were measured. Leaf area was measured with a leaf area meter (LICOR-3100 C; LICOR BiosciencesInc., Lincoln, NE). The colour parameters in leaves were determined using a tristimulus colorimeter $\left(\mathrm{L}^{*} \mathrm{a}^{*} \mathrm{~b}^{*}\right.$ colour space) (MinoltaCR-10; Konica- Minolta Sensing Inc., Osaka, Japan) and calculating the hue angle $=\tan ^{-1}\left(\mathrm{~b}^{*} / \mathrm{a}^{*}\right)$ and chromaticity $\left(\mathrm{C}^{*}\right)=\left[\left(\mathrm{a}^{*}\right)^{2}+\left(\mathrm{b}^{*}\right)^{2}\right]^{1 / 2}$. Total root length and diameter were determined with a Winrhizo LA 1600 root counter (Regent Inc., Quebec, Canada). The dry matter contents were determined by drying in an oven at $50{ }^{\circ} \mathrm{C}$ until constant weight was reached. In addition, the total production (yield) was calculated.

After harvesting of the spring cycle plants, root sections were obtained from tap roots $1.0 \mathrm{~cm}$ from the root collar. Fresh sections were fixed, dehydrated, stained, embedded using a JB4 Plus Embedding Kit (Electron Microscopy Sciences, Hatfield, PA), and observed by optical microscopy to calculate the percentage of aerenchyma tissue (Lara et al., 2011).

At both harvesting times, the following biochemical parameters were analyzed: nitrate, oxalate, potassium, and calcium contents were extracted in triplicate by using $0.2 \mathrm{~g}$ of shoot dry samples per each treatment and quantified by ion chromatography (Lara et al., 2011). The total phenolic content was determined by the Folin-Ciocalteu colorimetric method (Tarazona-Díaz et al., 2011). The antioxidant capacity was evaluated in terms of their free radicalscavenging capacity (Brand-Williams et al., 1995). The content of vitamin C, measured as ascorbic acid (AA) and dehydroascorbic acid, was measured in shoots using high-performance liquid chromatography (Shimadzu Corporation, Canby, OR) equipped with a degasser, DGU-20A, autosampler SIL-30AC, column oven CTO- 10AS, communications module CMB-20A, and diode array detector SPDM-20 (Rodríguez- Hidalgo et al., 2010b).

\section{Postharvest product management and analysis}

Harvested plants were placed in plastic bags and immediately transported $6 \mathrm{~km}$ in a portable box with ice to the Instituto de Biotecnología Vegetal of the UPCT where they were stored for $4 \mathrm{~h}$ at $5{ }^{\circ} \mathrm{C}$. Then, in a disinfected cold room at 
$10{ }^{\circ} \mathrm{C}$, all shoots free from defects were disinfected by washing for 2 min with a solution containing $100 \mathrm{ppm} \mathrm{NaOCl}$ (Panreac, Barcelona, Spain) and $0.2 \mathrm{~g} \cdot \mathrm{L}^{-1}$ citric acid ( $\mathrm{pH} 6.5)$ at $5^{\circ} \mathrm{C}$. The shoots were then rinsed for 2 min under tap water to eliminate chlorine residues. Excess surface water was removed by using a handheld salad spinner for $30 \mathrm{~s}$. Then, $20 \mathrm{~g}$ of shoots were placed in polypropylene (PP) baskets of $1 \mathrm{~L}$ capacity, the top of which were thermo sealed with a $34 \mathrm{~mm}$ thick film composed of polyethylene terephthalate (PET) + oriented polypropylene (OPP) and stored at $5{ }^{\circ} \mathrm{C}$ for 7 days. $\mathrm{O}_{2}$ transmission was 1.0 to $1.2\left[\mathrm{~mL}\left(\mathrm{~m}^{2} 24 \mathrm{~h} \mathrm{~atm}\right)^{-1}\right]$ measured at $23{ }^{\circ} \mathrm{C}$ and $0 \%$ relative humidity $(\mathrm{RH})$, and water vapor transmission was $1.3\left[\mathrm{~mL}\left(\mathrm{~m}^{2} 24 \mathrm{~h} \mathrm{~atm}\right)^{-1}\right]$ at $38{ }^{\circ} \mathrm{C}$ and 100\% RH. Permeation values were supplied by Plásticos del Segura (Murcia, Spain). The storage temperature was selected as the maximum limit recommended and most commonly used for fresh-cut vegetables during their commercial distribution and retail sale (Tomás-Callejas et al., 2011).

Microbial growth was assessed after processing. Samples of $10 \mathrm{~g}$ fresh weight $(\mathrm{FW})$ from each treatment were blended with $90 \mathrm{~mL}$ of sterile tryptone phosphate water (Scharlab, Barcelona, Spain) at $\mathrm{pH} 7.0$ for $1 \mathrm{~min}$ in a sterile bag by using a stomacher. Serial dilutions were prepared in $9 \mathrm{~mL}$ tryptone phosphate water. From each dilution, 1-mL aliquots were aseptically pipetted for microbial population counting. Plate count agar (Scharlab) ( $\mathrm{pH}$ 7.0) for both mesophilic aerobic microorganisms, incubated at $26{ }^{\circ} \mathrm{C}$ for 3 days, and psychrophilic microorganisms, incubated at $4{ }^{\circ} \mathrm{C}$ for 10 days, were used. Duplicates were made for each dilution. Microbial counts were reported as $\log _{10}$ colony-forming units (CFU) per gram of FW.

Changes in $\mathrm{O}_{2}$ and $\mathrm{CO}_{2}$ partial pressures within the PP baskets were monitored daily throughout the shelf life. A $0.5 \mathrm{~mL}$ sample of the headspace was withdrawn from the PP baskets with a gas-tight syringe and $\mathrm{O}_{2}$ and $\mathrm{CO}_{2}$ levels were determined by gas chromatography with a Perkin-Elmer apparatus (Norwalk, CT) equipped with a thermal conductivity detector (Tomás-Callejas et al., 2011). After 7 days at $5{ }^{\circ} \mathrm{C}$, microbial growth and leaf colour were determined as described previously. 


\section{Sensory quality test}

The sensory quality was evaluated in a tasting room after 7 days of cold storage by a test panel consisting of 11 people. Visual quality factors (overall visual quality and global quality) were scored on a 9 point hedonic scale $(1=$ extremely poor, $3=$ poor, $5=$ acceptable and limit of usability, $7=$ good, and $9=$ excellent). Disorders (browning, visual dehydration, off-odors, off-colour, and off-flavors) were scored according to the following scale of damage incidence and severity: $1=$ none, 2 = slight, $3=$ moderate (limit of usability), $4=$ severe, 5 = extreme (Tomás-Callejas et al., 2011).

\section{Statistical analysis}

A randomized complete block design with three replicates per level of aeration was used in the greenhouse in both growing seasons. Data were analyzed using Statgraphics Plus. Analysis of variance (three-way ANOVA) was performed in which levels of aeration (NA, LA, HA), growing seasons (spring and winter), and storage time (0 and 7 days) were included. When the variables were measured at harvesting time, only two factors (aeration and growing season) were included. When interactions were significant they were included in the ANOVA, a least significant difference test was performed to compare level of aeration, growing seasons, and storage time.

\section{Results}

\section{Temperature and dissolved oxygen in the nutrient solution}

The aeration treatments did not affect the temperature of the nutrient solution in either cycle (Figure 3). However, the different levels of aeration affected the quantity of dissolved oxygen (DO) in the nutrient solution. DO mean levels were $3.3,5.8$ and $6.9 \mathrm{mg} \cdot \mathrm{L}^{-1}$ in NA, LA, and HA conditions, respectively, during the spring cycle and $8.4,9.0$ and $9.2 \mathrm{mg} \cdot \mathrm{L}^{-1}$ in $\mathrm{NA}, \mathrm{LA}$, and HA conditions, respectively, during the winter cycle. In the spring cycle, the decrease of aeration rapidly led to lower levels of DO than in the winter cycle as a result of the higher temperatures of the nutrient solution. The level of DO in the NA conditions fell from $6.5 \mathrm{mg} \cdot \mathrm{L}^{-1}$ to $3.1 \mathrm{mg} \cdot \mathrm{L}^{-1}$ in the spring cycle and hardly decreased in the winter cycle (from $8.4 \mathrm{mg} \cdot \mathrm{L}^{-1}$ to $8.1 \mathrm{mg} \cdot \mathrm{L}^{-1}$ ). 


\section{Growth, yield, and quality characteristics of watercress at}

\section{harvesting time}

There were significant differences for SLA, yield, total root length, root diameter, and length of 0 to $0.5 \mathrm{~mm}$ diameter root for the cycle, but not for the aeration factor (Table 7). In addition, the dry matter content was not affected by the cycle or by the aeration conditions. There was no statistically significant interaction between cycle and aeration for any growth parameter. The yield was $20 \%$ higher in the spring cycle but SLA was $26 \%$ lower than in the winter cycle (Table 7). In the winter cycle, the root was thinner and longer as a result of the greater length of fine roots ( 0 to $0.5 \mathrm{~mm}$ in diameter).
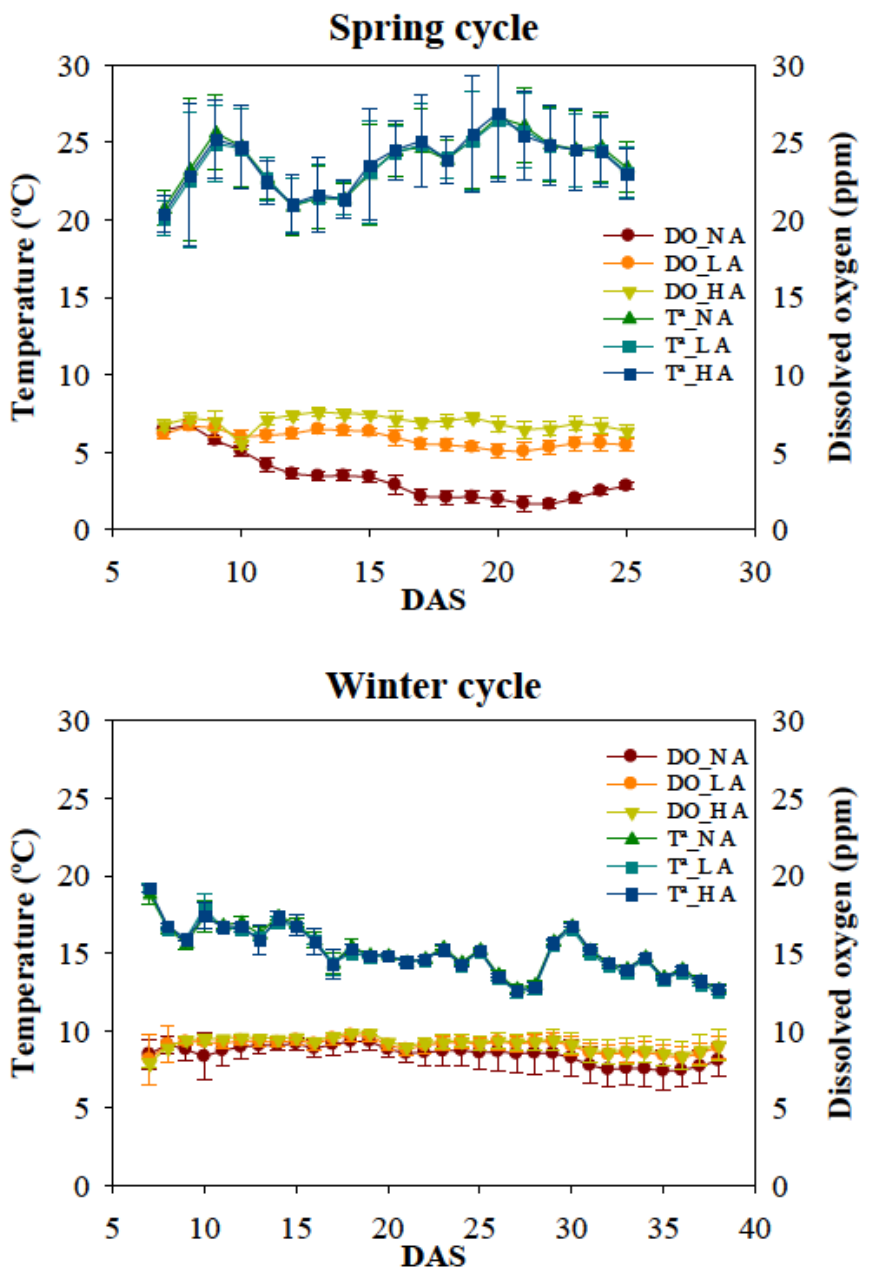

Figure 3: Evolution of dissolved oxygen (DO) and temperature $\left(\mathrm{T}^{\mathrm{a}}\right)$ of the nutrient solution under different levels of aeration-no aeration (NA), low aeration (LA), high aeration (HA) - in two different crop cycles. Each datum point for each day after sowing (DAS) is the average of 24 hourly measurements $(n=3)$. 
Table 7: Influence of aeration of the nutrient solution - no aeration (NA), low aeration (LA), high aeration (HA) - at harvest on the growth parameters [specific leaf area (SLA), dry matter content, yield, total root length, root diameter, length of 0 to 0.5 diameter root] of watercress cultivated in spring and winter cycles in a floating system. zValues within the same column followed by a different lower-case letter are significantly different (least significant difference test) at $\mathrm{P} \# 0.05$. yAsterisks indicate significances at $* \mathrm{P} \leq 0.05$; ** $\mathrm{P} \leq$ $0.01 ; * * * \mathrm{P} \leq 0.001 ; \mathrm{ns}=$ non significant.

\begin{tabular}{|c|c|c|c|c|c|c|c|}
\hline Cycle (A) & $\begin{array}{c}\text { Aeration } \\
\text { (B) }\end{array}$ & $\begin{array}{c}\text { SLA } \\
\left(\mathrm{m}^{2} \mathrm{~kg}^{-1}\right) \\
\end{array}$ & $\begin{array}{l}\text { Dry matter } \\
\text { content }(\%)\end{array}$ & $\begin{array}{r}\text { Yield } \\
\left(\mathrm{Kg} / \mathrm{m}^{2}\right) \\
\end{array}$ & $\begin{array}{l}\text { Total root } \\
\text { lenght }(\mathrm{cm}) \\
\end{array}$ & $\begin{array}{c}\text { Root diameter } \\
(\mathrm{mm})\end{array}$ & $\begin{array}{c}\text { Length of } 0-0.5 \\
\text { diameter root }(\mathrm{mm})\end{array}$ \\
\hline Spring & & $0.73 b^{z}$ & 4.72 & $3.48 \mathrm{a}$ & $70.77 \mathrm{~b}$ & $0.20 \mathrm{~b}$ & $44.03 \mathrm{~b}$ \\
\hline \multirow[t]{4}{*}{ Winter } & & $0.99 \mathrm{a}$ & 4.45 & $2.99 \mathrm{~b}$ & $195.40 \mathrm{a}$ & $1.11 \mathrm{a}$ & $188.70 \mathrm{a}$ \\
\hline & NA & 0.85 & 4.77 & 3.06 & 137.29 & 0.66 & 119.74 \\
\hline & LA & 0.85 & 4.58 & 3.36 & 135.70 & 0.67 & 118.31 \\
\hline & HA & 0.89 & 4.41 & 3.28 & 126.25 & 0.65 & 111.03 \\
\hline \multicolumn{2}{|c|}{ A } & $* * * y$ & $* * *$ & $* * *$ & $* * *$ & $* * *$ & $* * *$ \\
\hline \multicolumn{2}{|c|}{ B } & $\mathrm{ns}$ & ns & ns & ns & ns & $\mathrm{ns}$ \\
\hline \multicolumn{2}{|c|}{$\mathrm{AxB}$} & ns & ns & ns & ns & ns & ns \\
\hline
\end{tabular}

The anatomical root study in the spring cycle demonstrated that the low oxygen concentrations led to some morphological adaptations such as the development of aerenchyma tissue in the roots and the presence of adventitious roots. The aerenchyma occupied a low percentage of root section $(2 \%$ or less in NA, $0.8 \%$ or less in LA, and $0.3 \%$ or less in HA conditions). On the other hand, watercress had several adventitious roots developing exogenously from the stem at the nodes, significantly higher in NA than in LA and HA conditions (mean values per plant: 4.5, 2.6 and 2.8 in NA, LA, and HA conditions, respectively), and some of those roots were able to grow into the media. In addition, the number of nodes with adventitious roots longer than $2 \mathrm{~mm}$ was significantly higher in NA conditions than in the aerated conditions (mean values per plant: 1.7, 0.8 and 0.8 in NA, LA, and HA conditions, respectively).

ANOVA showed that aeration conditions had a statistically significant effect on antioxidant capacity, vitamin $\mathrm{C}$, nitrate, and $\mathrm{Ca}^{2+}$ contents (Table 8). Statistical analysis showed a significant interaction between both factors for nitrate, oxalate, $\mathrm{Ca}^{2+}$, and $\mathrm{K}^{+}$contents, whereas no significant interaction was observed for total phenolics, antioxidant capacity, or vitamin C. In addition, the total phenolic contents were not affected by the cycle or by the aeration conditions.

Aeration reduced the antioxidant capacity in both cycles, the highest values being obtained in the spring cycle (Table 8). The vitamin $\mathrm{C}$ content was significantly higher in NA conditions in the spring cycle and also higher than in the winter cycle. The nitrate content was lowest in the NA condition in the winter 
cycle, whereas there were no differences in the nitrate contents among the different levels of aeration in the spring cycle. The oxalate content was lower in the spring cycle, particularly in the aerated treatments. The $\mathrm{Ca}^{2+}$ content was higher in the spring cycle and its content increased in the winter cycle with aeration treatments. Finally, the $\mathrm{K}^{+}$content was also increased by aeration in the winter cycle, whereas there were no differences between levels of aeration in the spring cycle.

\section{Visual and microbiological quality of fresh-cut product}

Both microbial populations (mesophilic and psychrophilic microorganisms) were affected by the cycle and storage time (Table 9). The mesophilic microorganisms were also affected by the aeration treatments. The interaction between aeration treatment and cycle was significant for both microbial populations. The microbial load for mesophilic microorganisms was significantly lower in the winter cycle NA conditions than in the spring cycle NA and LA conditions (Figure 4A). In addition, the microbial charge of psychrophilic microorganisms in NA and LA conditions in winter was lower than in any aeration treatment in the spring cycle (Figure 4B). The interaction between aeration treatment and storage time was significant only for psychrophilic microorganisms (Table 9), being significantly lower in NA conditions at Day 0 than in any aeration treatment at Day 7 (Figure 4C).

The ANOVA of the colour parameters showed that hue angle and $\mathrm{C}^{*}$ were affected by both cycle and storage time and $\mathrm{L}^{*}$ only by storage time (Table 9 ). The aeration treatment had no effect on any of the measured parameters. The interaction of the three factors was significant for $\mathrm{C}^{*}$ and $\mathrm{L}^{*}$. The percentage of variance explanation was very low as a result of the high residual value obtained (43\% and 64\%, respectively). C* was significantly lower in spring than in winter and increased significantly with storage time (Table 10). In winter, $C^{*}$ increased significantly only in the HA treatments at Day 7 with respect to Day 0.

At harvesting time, there were significant differences between spring and winter cycles only in NA conditions (Table 10). In general, L* was higher at Day 7 than at Day 0 in both cycles in all the aeration treatments. The steady-state atmosphere within PP baskets was reached at the second day of storage in both crop cycles. No differences in $\mathrm{O}_{2}$ and $\mathrm{CO}_{2}$ levels were observed among aeration 
treatments during storage. Therefore, respiration rates were only affected by the crop cycle (Figure 5). Hence, the $\mathrm{O}_{2}$ at equilibrium was lower in the shoots of watercress grown in winter $(15 \mathrm{kPa})$ than in watercress grown in spring, where the level of the same metabolic gas ranged from 17 to $19 \mathrm{kPa}$. In contrast, $\mathrm{CO}_{2}$ was quite similar in the two cycles, 3 to $4 \mathrm{kPa}$ at equilibrium. Cycle was the main factor that influenced the differences observed in visual quality and dehydration of watercress at the end of the storage, whereas the aeration did not affect any of the measured parameters. In general, dehydration was very low in both crop cycles although slightly higher in winter (1.23 and 1.76 over 5 points hedonic scale in the spring and winter cycles, respectively). The visual quality was significantly higher in the spring cycle ( 7.5 over 9 points hedonic scale) than in winter (6.7 over 9 ). The global quality was significantly higher ( 7.8 over 9 ) in the spring cycle than in winter (7.0 over 9$)$, the score reflecting their marketable value.

\section{Discussion}

Plant species tolerant to oxygen depletion in the root medium can develop morphological traits or can alter their metabolism in response to oxygen shortage to survive or to maintain (Fukao and Bailey-Serres, 2004). Watercress is a semi aquatic crop plant with special adaptations that facilitate the transport of oxygen from the shoot to the roots, particularly the adventitious roots developing exogenously from the stem at the nodes. Some of those roots are able to grow into the medium, particularly in non-aerated conditions, partially replacing the function of the original root system and maintaining normal plant growth. In this study, oxygen depletion promoted the number of nodes with adventitious roots longer than $2 \mathrm{~mm}$. Although this may be an advantage for growing in these conditions, the appearance of these root lowers the product's market value (Smith, 2007).

The aeration treatment had no effect on the yield and growth traits measured (Table 7) showing that watercress is not sensitive to the oxygen depletion. This was especially evident in the spring cycle, where the levels of DO reached in NA conditions were lower as a result of the higher temperatures of the nutrient solution (Figure 3). 

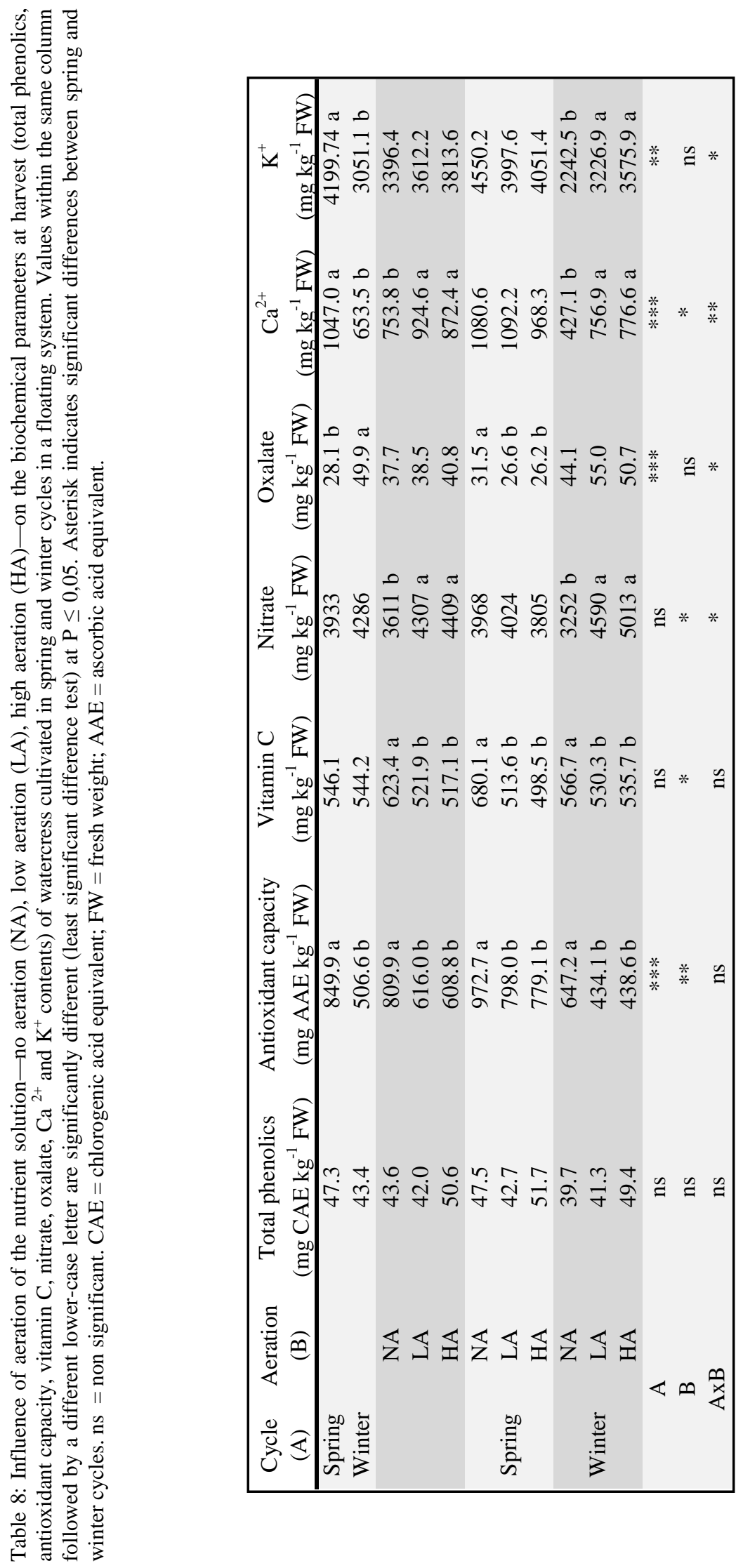

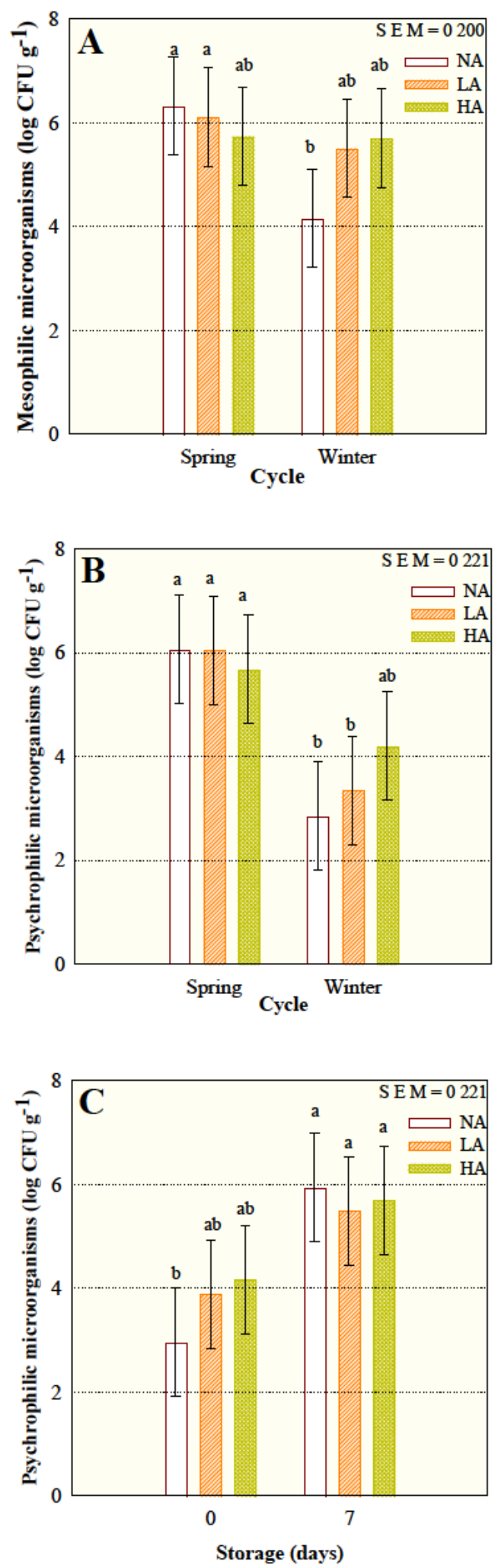

Figure 4: Effect of the aeration level of the nutrient solution-no aeration (NA), low aeration (LA), high aeration (HA) - on mesophilic (A) and psychrophilic (B) microorganisms in watercress, cultivated in a floating system, either in spring or winter cycles; and the effect on psychrophilic microorganisms $(\mathrm{C})$ at harvest or 7 days at $5^{\circ} \mathrm{C}$. Values are the mean of three replicates and vertical lines are the least significant difference (LSD) intervals at $\mathrm{P} \leq$ 0.05. Different letters indicate significant differences $(\mathrm{P}<0.05)$. 
Table 9: Analysis of variance (in percentage of the total sum of squares and probability) of microbial growth (mesophilic and psychrophilic microorganisms) and leaf colour parameters [hue angle, chromaticity $\left(\mathrm{C}^{*}\right)$ and lightness $\left(\mathrm{L}^{*}\right)$ ] of watercress either at harvest or $7 \mathrm{~d}$ at $5{ }^{\circ} \mathrm{C}$. Asterisks indicate significances at $* \mathrm{P} \leq 0.05 ; * * \mathrm{P} \leq 0.01 ; * * * \mathrm{P} \leq 0.001 ; \mathrm{NS}=$ non significant.

\begin{tabular}{|lccccccc|}
\hline Source of variation & df & $\begin{array}{c}\text { Mesophilic } \\
\text { microorganisms }\end{array}$ & $\begin{array}{c}\text { Psychrophilic } \\
\text { microorganism }\end{array}$ & df & Hue angle & C* & L* \\
\hline $\begin{array}{l}\text { Main effects } \\
\text { Cycle (A) }\end{array}$ & 1 & $14.11 * * *$ & $44.90 * * *$ & 1 & $4.85 * * *$ & $27.87 * * *$ & $0.73 \mathrm{~ns}$ \\
Storage time (B) & 1 & $11.10 * * *$ & $30.57 * * *$ & 1 & $30.72 * * *$ & $20.94 * * *$ & $2.20 * * *$ \\
Aeration (C) & 2 & $4.50 *$ & $1.09 \mathrm{~ns}$ & 2 & $1.16 \mathrm{~ns}$ & $0.93 \mathrm{~ns}$ & $1.11 \mathrm{~ns}$ \\
Interactions & & & & & & & \\
AxB & 1 & $24.69 * * *$ & $0.12 \mathrm{~ns}$ & 1 & $1.22 *$ & $5.09 * * *$ & $6.05 * * *$ \\
AxC & 2 & $13.26 * * *$ & $3.49 *$ & 2 & $0.22 \mathrm{~ns}$ & $1.01 \mathrm{~ns}$ & $2.07 *$ \\
BxC & 2 & $2.12 \mathrm{~ns}$ & $3.59 *$ & 2 & $0.21 \mathrm{~ns}$ & $0.03 \mathrm{~ns}$ & $0.92 \mathrm{~ns}$ \\
AxBxC & 2 & $2.24 \mathrm{~ns}$ & $0.53 \mathrm{~ns}$ & 2 & $0.18 \mathrm{~ns}$ & $1.24 *$ & $3.04 *$ \\
Residual & 56 & 27.98 & 15.71 & 255 & 61.45 & 42.88 & 63.89 \\
\hline
\end{tabular}

In our study, growing season influenced yield and SLA. Among others growth factors, it has been demonstrated that an increase in light levels enhances watercress growth and production (Going et al., 2008; Seelig, 1974). Furthermore, Going et al. (2008) demonstrated that the SLA of watercress decreased linearly along a gradient of increasing light levels, developing thinner leaves in low light conditions. The mentioned results agree with our study, where the spring cycle, with the average DLI 3-fold higher than in winter, produced the highest yield and the lowest SLA.

Among the metabolic adaptations to oxygen deficiency, the results showed that the aeration treatment affected the nitrate, $\mathrm{Ca}{ }^{2+}$, and vitamin $\mathrm{C}$ contents as well as the antioxidant capacity (Table 8). Watercress roots have a high ability to remove nitrate from water, which makes this plant ideal for stripping nitrate from stream water (Vicent and Downes, 1980). In our study, nitrate was accumulated in high concentrations in both cycle experiments (Table 8), which confirms that watercress is a nitrate-accumulating plant (Santamaria, 2006). A lack of aeration in the nutrient solution decreased the nitrate concentration in the winter cycle, which agrees with the results obtained in other species grown in floating systems (Ferrante et al., 2003; Lara et al., 2011; Tesi et al., 2003b). On the other hand, light is one of the main factors influencing nitrate concentration, which increases in the plant tissue under poor light conditions, e.g., in the greenhouse in winter and in green leafy vegetables (Gruda, 2005). In addition, Michalsky et al. (1997) demonstrated that artificial light decreased the nitrate content in watercress grown in an ebb-flow system. In our study, the 
nitrate concentration (Table 8) in HA conditions was higher in the winter cycle under lower light conditions, confirming the importance of light on its concentration. The oxalate content in the shoots was quite low compared with other leafy species and aeration had no statistically significant effect on the oxalate content.

Usually, low-oxygen solutions have a negative effect on nutrient acquisition by roots because ion uptake by cells is affected by oxygen level. In our study, $\mathrm{K}^{+}$and $\mathrm{Ca}^{2+}$ concentrations decreased under NA conditions in the winter cycle, in agreement with the results of Trought and Drew (1980) who demonstrated that under hypoxic conditions, $\mathrm{K}^{+}$and $\mathrm{Ca}^{2+}$ concentrations fell in the shoots of wheat.

Another physiological response of plants to oxygen depletion stress is the involvement of antioxidant defense mechanism to cope with post-hypoxia stress oxidative (Colmer and Voesenek, 2009). In our experiment, the total antioxidant capacity was higher in NA conditions in both growing seasons and significantly higher in spring when the lack of oxygen was more noticeable (Table 8; Figure 3). According to Gökmen et al. (2000), phenolic compounds, along with vitamin $\mathrm{C}$, are the major antioxidants of Brassica vegetables as a result of their high content and high antioxidant activity. In our study, the phenolic compounds were unaffected by oxygen stress as antioxidant capacity and vitamin $\mathrm{C}$ were. We assume that the variations in antioxidant capacity were the result of vitamin $\mathrm{C}$ and probably other sources such as glutathione and other phytonutrients, etc., which were not quantified in this study. We found a high level of correlation between the antioxidant capacity and the vitamin $\mathrm{C}$ content (Table 8), as other authors have demonstrated in other baby leaf Brassicacea species (MartínezSánchez et al., 2008), confirming a fundamental role of AA in the plant defense system to protect metabolic processes against $\mathrm{H}_{2} \mathrm{O}_{2}$ and other toxic derivatives of oxygen (Shao et al., 2008).

The high concentrations of vitamin $\mathrm{C}$ in watercress (Table 8), especially in the spring NA conditions, compared with other salad vegetables (Souci et al., 2008), should be noted, underlining its value as a healthy food for human consumption. The different levels of vitamin $\mathrm{C}$ detected in watercress according to the growing season could be the result of light intensity, because in general, the 
lower the light intensity, the lower the content of AA in plant tissues (Lee and Kader, 2000).

Preharvest treatments of fruits and vegetables are primarily aimed at increasing yields, whereas postharvest storage performance is normally neglected (Workneh and Osthoff, 2010). Weston and Barth (1997) hypothesized that the diversified postharvest responses of fruits and vegetables during storage are in part the result of preharvest cultural practice. Reflecting this, our results indicated that the aeration treatment influenced the microbial population during storage, especially regarding psychrophilic microorganisms (Table 9; Figure 4C).
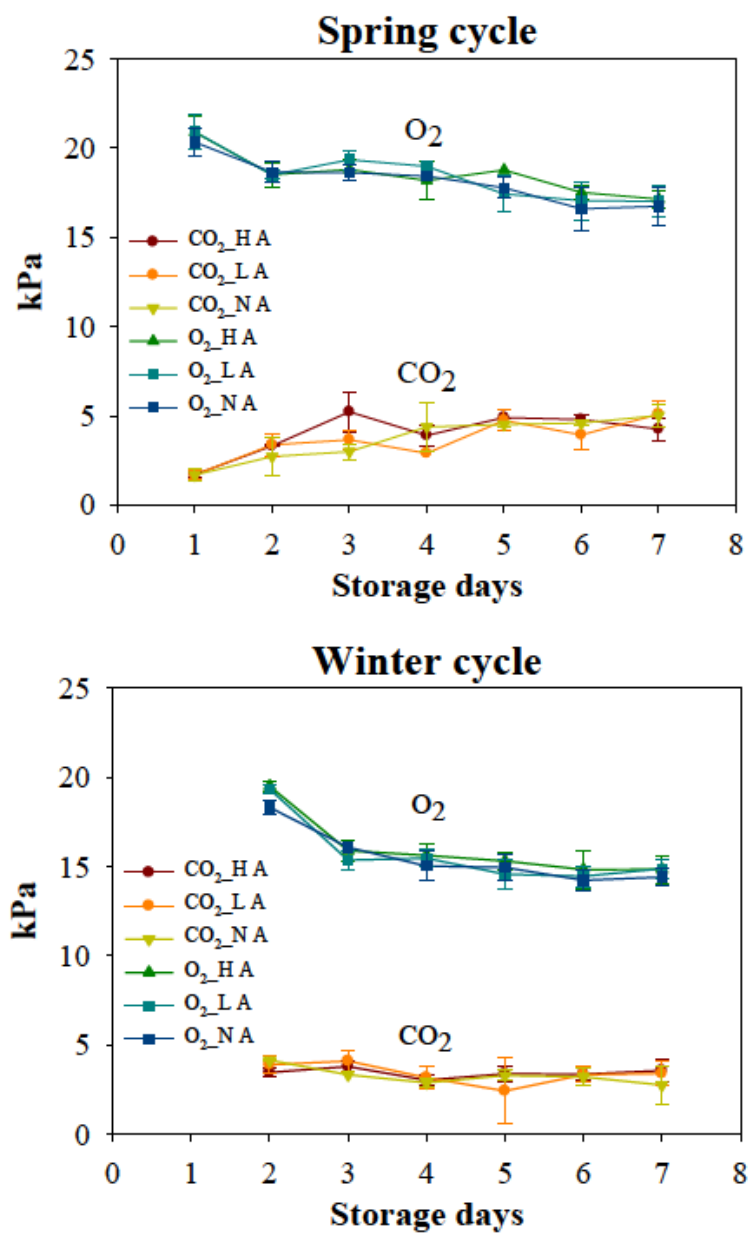

Figure 5: Influence of the aeration level of the nutrient solution-no aeration (NA), low aeration (LA), high aeration (HA) - on the headspace partial pressure of $\mathrm{O} 2$ and $\mathrm{CO} 2$ within the polypropylene basket of freshcut watercress cultivated in two cycles (spring and winter) and stored for 7 days at $5{ }^{\circ} \mathrm{C}$. Values are the mean of three replicates $\pm \mathrm{SD}$. 
In NA conditions psychrophiles had increased by Day 7, which indicates that there was more organic matter available in watercress under non-aerated conditions probably as a result of the physical stress caused by oxygen depletion (probably more microfractures, more dead cells, etc.). However, the number of mesophiles at Day 0 was similar to those at the end of storage because of the temperature $\left(5^{\circ} \mathrm{C}\right)$, which was not ideal for their growth. In winter, the NA conditions led to significantly lower microbial counts (4 log CFU/g) than in spring (Figure 4A-B), probably as a result of the climatic conditions. The microbial counts in LA and HA conditions in both cycles were similar to those obtained in lamb's lettuces growing in aerated nutrient solutions in a floating system (Manzocco et al., 2011). However, in our study, there were no significant differences between initial and final counts, probably as a result of the small cut surface of the watercress shoots.

Steady-state atmosphere revealed high $\mathrm{O}_{2}$ and low $\mathrm{CO}_{2}$ values (Figure 5) in the headspace of PP baskets thermo sealed with a film of PET + OPP of low permeability. However, the respiration rate of watercress is very high (Hardenburg et al., 1986), 44 to $49 \mathrm{mg} \mathrm{CO}\left(\mathrm{kg} \cdot \mathrm{h}^{-1}\right)$, which, together with the low gas metabolic permeability of PET + OPP, means that the total $\mathrm{CO}_{2}$ production resulting from respiration was low because the total mass of product within the PP baskets was low as well.

The modified atmosphere packaging (MAP) conditions recommended for watercress are the following: $5 \%$ to $15 \% \mathrm{CO}_{2}$ and $1 \%$ to $5 \% \mathrm{O}_{2}$. However, metabolic gas values obtained in our experiments were quite different from the optimum MAP conditions for this product and global quality ranged from good to excellent. Therefore, the resulted atmosphere was suitable for 7 days storage at 5 ${ }^{\circ} \mathrm{C}$.

Variations in the colour of green leafy vegetables after harvest are a result of high biological variance and heterogeneity of the product at harvest (Løkke et al., 2013). During postharvest senescence, the green chlorophyll pigments are oxidized into colourless substances revealing the yellow carotenoids (Toivonen and Brummell, 2008). Our data showed higher $C^{*}$ (Table 10) at harvest in the winter cycle, which means vivid colour than in the spring cycle as a result of the lower light intensity. At Day 7, $\mathrm{C}^{*}$ and $\mathrm{L}^{*}$ increased in the spring cycle indicating Less chlorophyll and probably as a result of the formation of pheophytin, an 
olive-coloured pigment that is synthesized when chlorophyll loses its bound magnesium atom, which is substituted by hydrogen. More than $50 \%$ conversion of the chlorophyll to pheophytin may occur before a change in colour from bright green to olive brown is observed (Lau and Swanson, 2000). Also in winter, L* was higher at Day 7 in LA and HA than in NA conditions, which means bleaching of leaves with storage. This bleaching was not observed by Hinojosa et al. (2013) who denoted a slight decrease in $\mathrm{L}^{*}$ value during storage from 51 to 49 after 7 days at $5{ }^{\circ} \mathrm{C}$, depending on disinfectant treatment.

Table 10: Interaction (cycle $\cdot$ aeration - storage time) in the parameters of colour [chromaticity $\left(\mathrm{C}^{*}\right)$ and lightness $\left.\left(\mathrm{L}^{*}\right)\right]$ of watercress, cultivated in a floating system, with different levels of aeration of the nutrient solution, no aeration (NA), low aeration (LA), high aeration (HA), in two crop cycles (spring and winter) stored at $5{ }^{\circ} \mathrm{C}$ for up to 7 days. $\mathrm{zSEM}=0.77$; LSD $=1.79$. ySEM $=0.81 ; \mathrm{LSD}=1.88$. $\mathrm{LSD}=$ least significant difference.

\begin{tabular}{|lcccccc|}
\hline \multirow{2}{*}{ Cycle } & & \multicolumn{2}{c}{ Chromaticity $^{\mathrm{z}}$} & & \multicolumn{2}{c|}{ Lightness $^{\mathrm{y}}$} \\
\cline { 3 - 4 } \cline { 6 - 7 } Spring & Aeration & Day 0 & Day7 & & Day 0 & Day 7 \\
& NA & 21.42 & 29.64 & & 38.24 & 47.19 \\
& LA & 22.42 & 28.19 & & 41.29 & 45.6 \\
\multirow{3}{*}{ Winter } & HA & 24.46 & 29.98 & & 42.79 & 47.09 \\
& NA & 31.09 & 32.06 & & 44.5 & 45.43 \\
& LA & 32.5 & 31.89 & & 42.74 & 44.99 \\
& HA & 29.41 & 32.05 & & 43.19 & 45.53 \\
\hline
\end{tabular}

The overall quality of the watercress at 7 days of storage was generally good and the aeration treatments had no effect on the same. The mild dehydration problems observed in the winter cycle that led to a lower overall product quality could have been the result of the development of thinner leaves (higher SLA) under low light conditions and also the differences in the respiration rates (Figure 5) compared with the spring cycle. In conclusion, the floating system is a very important preventive tool to obtain cleaner raw material such as watercress as a result of, among other things, the low microbiological contamination. Spring season seemed to be more suitable than the winter season to reach high yield and quality, possibly as a result of high light and temperature conditions available. Thus, plants from the spring cycle in general had higher yield, antioxidant capacity, and $\mathrm{Ca}^{2+}$ and $\mathrm{K}^{+}$contents and lower oxalate content. A lack of aeration slightly improved the quality of the final product, which was richer in vitamin $\mathrm{C}$ and antioxidants and had lower nitrate content. 
CHAPTER 3 


\section{NUTRIENT SOLUTION AERATION AND GROWING CYCLES AFFECT QUALITY AND YIELD OF FRESH-CUT BABY LEAF RED LETTUCE}

\section{Introduction}

Lettuce is an important dietary leaf vegetable that is primarily consumed fresh or in salad mixes. Among different production modalities, the "baby leaf" form, presented as whole leaves, $8-12 \mathrm{~cm}$ in length, with only one very small section, the petiole, exposed to oxidation, has grown in popularity as minimally processed vegetable products (Rodríguez-Hidalgo et al., 2010b). Besides, in comparison with whole-head lettuce, the baby leaf form shows greater efficiency, with a higher percentage of usable product and easier and faster processing; packed, it has a more attractive presentation and suffers minimal oxidation (MartínezSánchez et al., 2012). Among the varieties of lettuce, red lettuce has several attractive traits for the consumer, particularly colour and the high contents of phytochemicals with healthy effects (García-Macías et al., 2007). Besides, the red lettuce cultivars generally contain more phenolic compounds and have stronger antioxidant activities than the other lettuce cultivars in the same growing conditions (Liu et al., 2007).

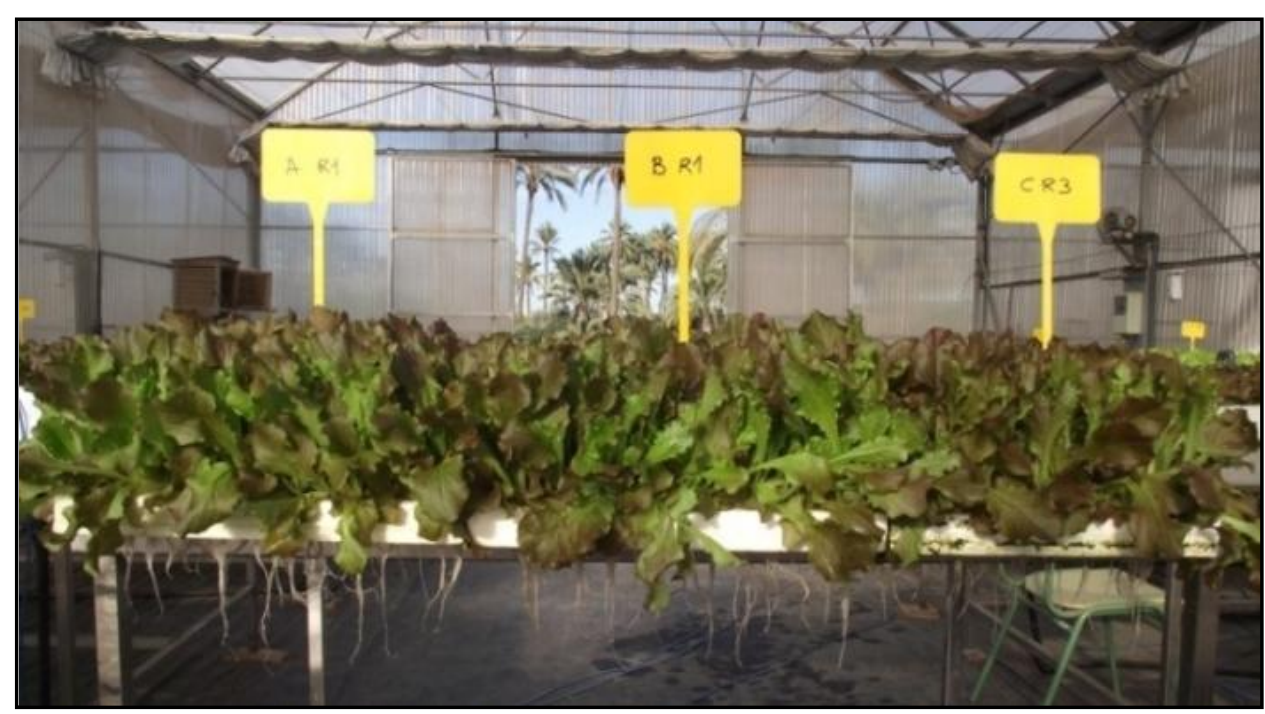

Picture 5: Red lettuce at the end of the experience. 
The floating system is an easy and profitable growing technique for the cultivation of baby-leaf vegetable crops. Furthermore, the initial microbial load in leaves in this system at harvesting is lower than in conventionally grown crops (Rodríguez-Hidalgo et al., 2010b). Although the floating system is easy to use, it is limited by the concentration of oxygen in the nutrient solution (Carrasco et al., 2011), and plants may suffer hypoxia because the roots gradually consume the oxygen dissolved therein. Furthermore, this effect is more pronounced in the summer when temperatures rise (Morard and Silvestre, 1996). A lack of oxygen reduces water and mineral uptake by the plant, which may limit growth and, consequently, crop yield (Tesi et al., 2003a). However, there are significant differences in sensitivity to oxygen deficiency in the rooting medium among plant species, and even among cultivars (Veen, 1988). Furthermore, the quality of the final product can be affected by metabolic adaptations to oxygen deficiency. It is known that a reduced concentration of oxygen in the nutrient solution of a floating system reduces the nitrate content of rocket (Ferrante et al., 2003), purslane (Lara et al., 2011), lettuce (Tesi et al., 2003a) and watercress (Niñirola et al., 2014). A decrease in the nitrate content is important because the maintenance of nitrate concentrations within the foliage at levels below EU maxima is an indicator of the nutritional quality (Konstantopoulou et al., 2010).On the other hand, non-aeration in the nutrient solution increases the antioxidant capacity and total phenolics in purslane, especially in summer, when high temperatures strongly reduce the amount of dissolved oxygen (Lara et al., 2011). Product colour, another very important parameter that influences consumer choice, is affected by the lack of aeration (Tesi et al., 2003b; Lara et al., 2011).

The final quality of the product is also affected by the different environmental factors that occur in different growing seasons. Conte et al. (2008) demonstrated that the lower nitrate content in spinach harvested in March can be explained by the higher temperature regime and sunlight availability during the growing period compared with plants harvested in February. Likewise, Fernández et al. (2012) demonstrated the nitrate content of lettuce leaves was lower in spring cycles than in autumn because of the greater radiation during the cycle as a consequence of the greater nitrate reductase activity associated with greater light intensity (Gaudreau et al., 1995). Also, the production of functional phytochemicals in 
plants is influenced by environmental factors that may induce stress in plants, since they respond to these stresses by inducing antioxidants as a defence mechanism (Oh et al., 2009). Finally, the colour is also affected by environmental conditions. Conte et al. (2008) suggested that the colour of spinach leaves was influenced by the environmental conditions of the growing period, while Lara et al. (2011) found that purslane leaves had a more intense green colour in summer than in autumn and winter.

In recent years, the fresh-cut industry has tried to prolong shelf-life through postharvest treatments; however maximum postharvest quality can be achieved only by understanding and managing the various roles that preharvest factors play in postharvest quality (Mattheis and Fellman, 1999). However, far too little attention has been paid to the effect that cultivation techniques can have on the final stored product. In the present study we evaluate the influence of different levels of nutrient solution aeration during three growing cycles in a floating system on the quality, microbiological load and characteristics of fresh-cut red lettuce "Diveria" at harvesting and after storage.

\section{Material and methods}

\section{Plant material and growing conditions}

The experiment was conducted at the "Tomás Ferro" Experimental AgroFood Station, Universidad Politécnica de Cartagena (UPCT) ( $37^{\circ} 41^{\prime}$ N; $0^{\circ} 57^{\prime}$ W). A cultivar of red baby leaf lettuce (Lactuca sativa L.), var. 'Diveria' from Rijz Zwaan Seeds Company was cultivated in a floating system in an unheated greenhouse covered with thermal polyethylene. Three growing cycles were carried out, with manual sowings on 15 October 2010 (autumn), 4 February 2011 (winter) and 24 June 2011(summer) in 'stryrofloat' trays containing peat. These trays have pyramidal-trunk 172-mm long fissures $20 \mathrm{~mm}$ apart and grouped in three for a total of 42 fissures per tray. After seedling emergence, the trays were transferred to flotation beds and maintained floating on fresh tap water with an electrical conductivity (EC) of $1.1 \mathrm{dS} \mathrm{m}^{-1}$ and $\mathrm{pH}$ 7.8. Aeration at three levels was provided by a blow pump connected to a pipe trellis positioned at the bottom of each flotation bed. The pipes were perforated with holes at 0,6 or 36 holes $\mathrm{m}^{-2}$ to provide the different levels of aeration to be tested: no aeration (NA), low 
aeration (LA) and high aeration (HA), respectively. Each level of treatment was carried out in $135 \times 125 \times 20 \mathrm{~cm}$ beds located at three places inside a greenhouse for all the experiments. Each bed had four floating trays of $60 \times 41 \mathrm{~cm}$.

A week after sowing, the lettuce plants were thinned, leaving 10 plants per hole $\left(1,700\right.$ plants $\left.\mathrm{m}^{-2}\right)$. At the same time, the tap water in the beds was replaced with a nutrient solution (Egea-Gilabert et al., 2009). The plants were harvested by hand 27, 26 and 18 days after sowing in autumn, winter and summer, respectively, when the plants had 3 - 4 leaves. The samples of each treatment were divided in two sets, one for harvest analysis and the other one for postharvest analysis.

The meteorological conditions during the experiment were $7.9^{\circ} \mathrm{C}, 37.6{ }^{\circ} \mathrm{C}$, $18.8{ }^{\circ} \mathrm{C}$ minimum, maximum and average air temperature, respectively, for autumn; $8.5^{\circ} \mathrm{C}, 37.5^{\circ} \mathrm{C}$ and $19.7^{\circ} \mathrm{C}$ for winter, and $19.5^{\circ} \mathrm{C}, 41.8^{\circ} \mathrm{C}$ and $27.9{ }^{\circ} \mathrm{C}$ for summer. The average daily light integral (DLI) was $11.20 \mathrm{~mol} \mathrm{~m}^{-2} \mathrm{~s}^{-1}$ for autumn, $13.53 \mathrm{~mol} \mathrm{~m}^{-2} \mathrm{~s}^{-1}$ for winter and $18.21 \mathrm{~mol} \mathrm{~m}^{-2} \mathrm{~s}^{-1}$ for summer. The oxygen concentration was monitored using Campbell CS512 sensors located in each flotation bed. The EC and temperature of the nutrient solution were monitored during the growing cycles using Campbell CS547 sensors (Campbell Scientific Inc., Logan, UT, USA).

\section{Analysis at harvesting time}

The specific leaf area (SLA), determined by the relationship between total leaf area and total leaf dry weight, percentage of dry matter, yield and root growth were measured in 20 plants from two fissures randomly chosen from each tray at harvesting time. The total leaf area was measured with a leaf area meter (LICOR 3100 C, Biosciences Inc., Lincoln, USA). The leaf dry matter content was determined by drying in an oven at $60{ }^{\circ} \mathrm{C}$ until constant weight. The colour parameters in leaves were determined using a tristimulus colorimeter $\left(\mathrm{L}^{*} \mathrm{a}^{*} \mathrm{~b}^{*}\right.$ colour space) (Minolta CR-10; Konica- Minolta Sensing Inc., Osaka, Japan), calculating the Hue angle $=\tan ^{-1}\left(\mathrm{~b}^{*} / \mathrm{a}^{*}\right)$ and chromaticity $\left(\mathrm{C}^{*}\right)=\left[\left(\mathrm{a}^{*}\right)^{2}+\right.$ $\left.\left(b^{*}\right)^{2}\right]^{1 / 2}$. Root lengths and diameters were determined using a Winrhizo LA 1600 root counter (Regent Inc., Quebec, Canada).

Also, the biochemical parameters detailed below were analyzed. The nitrate content was extracted in triplicate by using $0.2 \mathrm{~g}$ of shoot dry samples per 
treatment and quantified by ion chromatography (Lara et al., 2011). The total phenolic content was determined by the Folin-Ciocalteu colorimetric method (Tarazona-Díaz et al., 2011). The antioxidant capacity was evaluated in terms of their free radical-scavenging capacity (Brand-Williams et al., 1995). The total vitamin $\mathrm{C}$ was determined from three samples of $50 \mathrm{mg}$ of fresh leaves using $5 \%$ aqueous metaphosphoric acid (Conesa et al., 2009).

Microbial growth, for both mesophilic and psychrophilic aerobic microorganisms, was assessed in $10 \mathrm{~g}$ FW from each treatment following Niñirola et al. (2014).

\section{Postharvest product management and analysis}

Harvested plants were placed in plastic bags and immediately transported 6 $\mathrm{km}$ in a portable ice box to the Instituto de Biotecnología Vegetal of the UPCT where they were stored for $4 \mathrm{~h}$ at $5{ }^{\circ} \mathrm{C}$. Then, in a disinfected cold room at $10{ }^{\circ} \mathrm{C}$, all leaves free from defects were disinfected by washing for 2 min with a solution containing $100 \mathrm{ppm} \mathrm{NaOCl}$ and $0.2 \mathrm{~g} \mathrm{~L}^{-1}$ citric acid $(\mathrm{pH} 6.5)$ at $5^{\circ} \mathrm{C}$. The leaves were rinsed for 2 min under tap water in order to remove residues of $\mathrm{NaOCl}$. Excess surface water was removed in a handheld salad spinner for $30 \mathrm{~s}$. Then, 20 $\mathrm{g}$ of leaves were placed in polypropylene (PP) baskets of $1 \mathrm{~L}$ capacity and thermosealed with a $34 \mu \mathrm{m}$ thick film of polyethylene terephthalate (PET) + oriented polypropylene (OPP) and stored at $5{ }^{\circ} \mathrm{C}$ for 7 days.

Changes in $\mathrm{O}_{2}$ and $\mathrm{CO}_{2}$ partial pressures within the baskets were monitored daily throughout storage, by withdrawing a $0.5 \mathrm{~mL}$ sample of the headspace from the baskets with a gas-tight syringe and determining $\mathrm{O}_{2}$ and $\mathrm{CO}_{2}$ levels by gas chromatography (Tomas Callejas et al., 2011).

After 7 days of storage at $5{ }^{\circ} \mathrm{C}$, the colour $\left(\mathrm{L}^{*}, \mathrm{H}^{*}\right.$ and $\left.\mathrm{C}^{*}\right)$, nitrate and total phenol contents, antioxidant capacity and microbial growth were determined as described above.

\section{Experimental design and statistical analysis}

A randomized complete block design with three replicates per level of aeration was used in the greenhouse in all the growing seasons. Data were analysed using Statgraphics Plus. Analysis of variance (three-way ANOVA) was performed in which levels of aeration (NA, LA and HA), growing season (autumn, winter and summer) and storage time ( 0 and 7 days) were included. 
When the variables were measured at harvesting time, only two factors (aeration and growing season) were included. When interactions were significant, they were included in the ANOVA, and a least significant difference test was performed to compare level of aeration, growing season and storage time.

\section{Results}

\section{Monitoring of dissolved oxygen and temperature of the nutrient solution}

The aeration level did not affect the temperature of the nutrient solution in any of the three growing seasons (Figure 6). The growing cycle and the different levels of aeration were two decisive factors for the amount of dissolved oxygen (DO) in the nutrient solution. During the autumn cycle, the mean values of DO were 8.1, 6.2 and $5.2 \mathrm{mg} \mathrm{L}^{-1}$ for HA, LA and NA, respectively. In winter cycle, due to rare high temperatures in the middle of the cycle, the mean values of DO were slightly lower than in the autumn cycle with values of 7.7, 6.7 and $3.9 \mathrm{mg} \mathrm{L}^{-}$ 1 for HA, LA and NA, respectively. In the summer cycle, the increased temperature caused a decrease in DO in all the aeration treatments in the nutrient solution. The mean values of DO were $6.9,5.4$ and $3.3 \mathrm{mg} \mathrm{L}^{-1}$ for HA, LA and NA, respectively (Figure 6).

\section{Growth parameters and yield at harvesting time}

All the growth parameters measured were significantly affected by growing season and some of them by aeration too (Table 11). Statistical analysis pointed to a significant interaction between both factors in the percentage of dry matter, whereas no significant interaction was observed for the rest of the measured parameters (Table 11). Analysis of the interaction between the growing cycle and aeration revealed that neither the cycle nor the aeration level significantly affected the percentage of dry matter (Figure 7A).

The SLA was significantly lower in the winter cycle compared to autumn and summer. The yield was only significantly affected by the growing cycle, the highest value being obtained in autumn. Total root system was thinner and shorter in summer cycle because of the lower length of 0 to $1.5 \mathrm{~mm}$ diameter roots. The lack of aeration produced shorter total root length but did not affect root diameter (Table 11). 

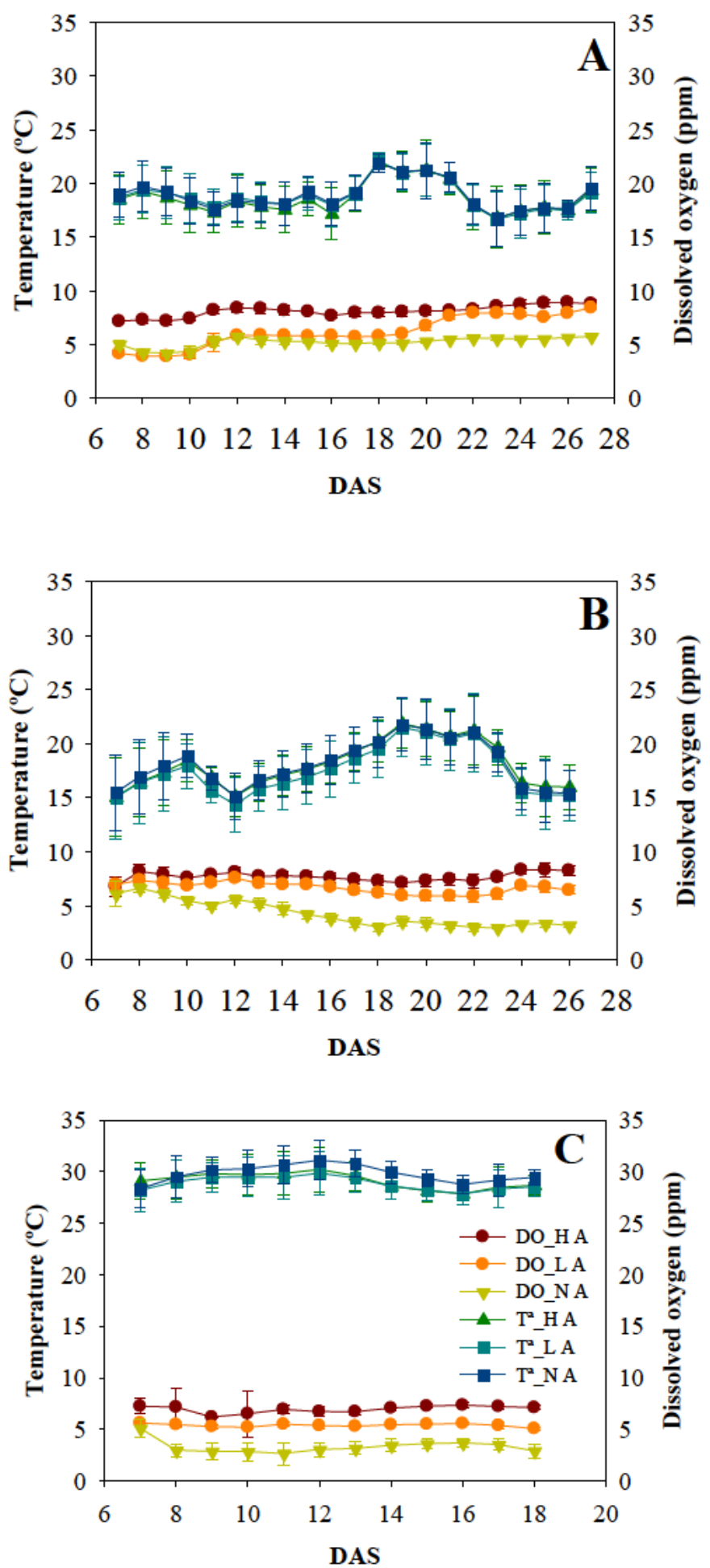

Figure 6: Evolution of dissolved oxygen (DO) and temperature $\left(\mathrm{T}^{\mathrm{a}}\right)$ of the nutrient solution under different levels of aeration (no aeration -NA-, low -LA-, high aeration -HA-) in three different crops cycles. Each datum point for each day after sowing (D.A.S.) is the average of 24 hourly measurements. Autumn cycle (A), Winter (B) and summer cycle (C). 
Table 11: Influence of aeration of the nutrient solution (no aeration -NA-, low aeration -LA-, high aeration HA-) at harvest on the vegetative plant growth parameters (\% dry matter, specific leaf area (SLA), yield, total root length, root diameter and length of 0 to $1.5 \mathrm{~mm}$ diameter roots) of baby leaf red lettuce cultivated in floating system in autumn, winter and summer cycles * Significant at $\mathrm{P} \leq 0.05$. ** Significant at $\mathrm{P} \leq$ 0.01 .*** Significant at $\mathrm{P} \leq 0.001$. Values in each row which do not have any letter in common are significantly different as described by LSD test $(\mathrm{P} \leq 0.05)$.

\begin{tabular}{|c|c|c|c|c|c|c|c|}
\hline & \multicolumn{3}{|c|}{ Season (A) } & \multicolumn{3}{|c|}{ Aeration (B) } & Interaction \\
\hline & Autumn & Winter & Summer & $\overline{\mathrm{NA}}$ & LA & HA & $\mathrm{AxB}$ \\
\hline Dry matter (\%) & $4.32 \mathrm{a}$ & $3.53 b$ & $3.75 b$ & $3.58 \mathrm{~b}$ & $3.95 \mathrm{ab}$ & $4.08 \mathrm{a}$ & * \\
\hline $\operatorname{SLA}\left(\mathrm{m}^{2} \mathrm{Kg}^{-1}\right)$ & $81.73 \mathrm{a}$ & $42.86 \mathrm{~b}$ & $79.96 \mathrm{a}$ & 68.56 & 71.71 & 64.29 & ns \\
\hline Yield $\left(\mathrm{Kg} \mathrm{m}^{-2}\right)$ & $2.29 a$ & $1.96 \mathrm{~b}$ & $1.09 \mathrm{c}$ & 1.67 & 1.80 & 1.87 & n.s. \\
\hline Total root length $(\mathrm{m})$ & $0.59 a$ & $0.58 \mathrm{a}$ & $0.41 b$ & $0.47 b$ & $0.51 \mathrm{ab}$ & $0.60 \mathrm{a}$ & n.s. \\
\hline Root diameter (mm) & $0.61 b$ & $0.92 \mathrm{a}$ & $0.14 \mathrm{c}$ & 0.62 & 0.55 & 0.50 & n.s. \\
\hline $\begin{array}{l}\text { Length of } 0-1,5 \\
\text { diameter roots }(\mathrm{m})\end{array}$ & $0.56 \mathrm{a}$ & $0.53 \mathrm{a}$ & $0.39 b$ & $0.44 b$ & $0.47 \mathrm{ab}$ & $0.56 \mathrm{a}$ & n.s. \\
\hline
\end{tabular}

\section{Quality characteristics of fresh cut lettuce}

The ANOVA showed a significant interaction between the growing cycle and aeration for the nitrate content, between aeration and storage time for total phenolics and mesophilic microorganisms, between growing cycle and storage time for Hue angle and $\mathrm{C}^{*}$, and among all three factors for antioxidant capacity, vitamin $\mathrm{C}, \mathrm{L}^{*}$ and psychrophilic microorganisms (Table 12).

The nitrate content was significantly reduced in the autumn cycle compared to the winter cycle in both LA and HA conditions. The lack of oxygen did not affect the nitrate content in any cycle (Fig. 7B).

The total phenolics content was significantly higher in NA at harvest than in LA at postharvest (Figure 7C). The antioxidant capacity was significantly higher in summer than in autumn and winter cycles for all the aeration treatments at harvest, the highest value being obtained in NA conditions (Table 13). There were no significant differences in the antioxidant capacity among the treatments at 7 days of storage. At harvest, the vitamin $\mathrm{C}$ content was significantly higher in winter compared to autumn and summer cycles for all the aeration treatments, reaching the highest value in NA conditions (Table 13). After 7 days of storage, the vitamin $\mathrm{C}$ content decreased in all treatments.

At harvest, $\mathrm{L}^{*}$ was significantly higher in summer in all aeration conditions than in autumn, which means lighter coloured leaves (Table 13). Aeration affected $\mathrm{L}^{*}$ only in the winter cycle, when the value of this parameter was significantly lower in NA than HA conditions. 

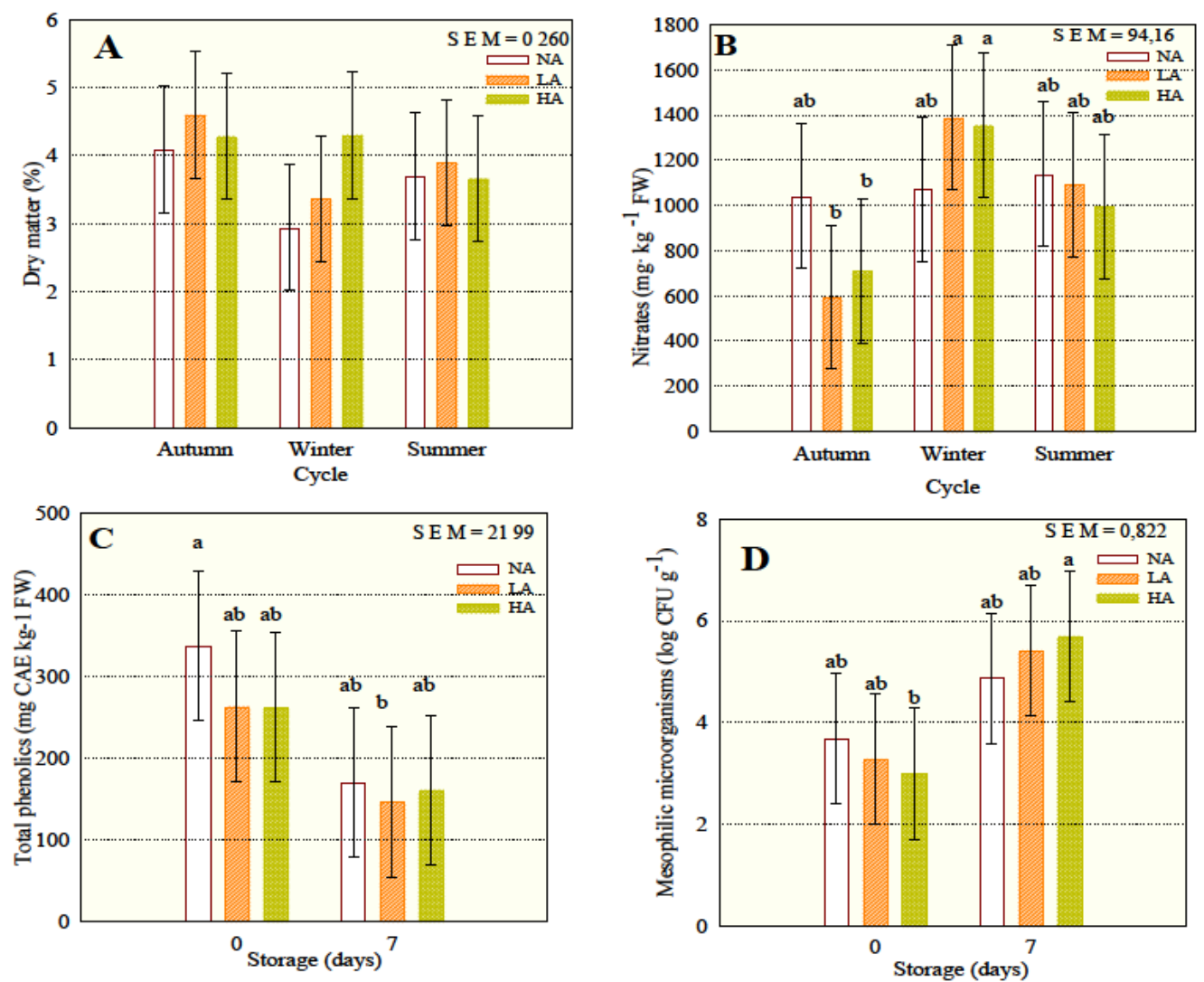

Figure 7: Effect on \% of dry matter (A) and nitrate content (B) of the aeration level of the nutrient solution (no aeration -NA-, low aeration -LA-, high aeration -HA-) in red lettuce cultivated in floating system, either in autumn, winter or summer and, the effect on total phenolics (C) and mesophilic microorganism (D) at harvest or 7 days at $5{ }^{\circ} \mathrm{C}$. Values are the mean of three replicates and vertical lines are the least significant difference $(L S D)$ intervals at $P \leq 0.05$. Different letters indicate significant differences $(P<0.05)$.

After 7 days of storage, the $\mathrm{L}^{*}$ values did not show significant differences between the cycles or the aeration treatments.

At harvest, the values of Hue angle were lower in autumn and winter than in summer, which means redder leaves, while $C^{*}$ was significantly higher in summer than in winter, which was reflected in a more vivider colour (data of interaction not shown).

The mesophilic microorganism load increased significantly with storage only in the HA treatment (Figure 7D). The psychrophilic microbial load showed maximum values in winter, both at harvest and after 7 days of storage (Table 13). After storage, the psychrophilic microbial load increased in all the cycles over harvest time levels.

A steady-state atmosphere within the PP baskets was reached on the third day of storage in all three growing cycles (Figure 8). No differences in $\mathrm{O}_{2}$ and $\mathrm{CO}_{2}$ levels were observed between aeration conditions during storage. Therefore, respiration rates were only affected by the growing cycle. 


\section{Discussion}

Agricultural production systems are critical for the yield and quality of freshcut products. Our results revealed that red lettuce cultivated in floating system is tolerant to a lack of aeration of the nutrient solution since the yield was not affected (Table 11). This agrees with the results obtained by Goto et al. (1996), who concluded that only DO below $2.1 \mathrm{mg} \mathrm{L}^{-1}$ will reduce the productivity of lettuce. Only in the summer experiment did DO fell below the limit proposed by Goto et al. (1996) due to the high temperatures reached in this cycle. However, in all growing cycles, the DO value was higher than $2.1 \mathrm{mg} \mathrm{L}^{-1}$ at the end of each cycle (Figure 6). The lowest SLA was obtained in the winter cycle (Table 11). This was not unexpected because SLA values normally decrease with lower radiation (Wolff and Coltman, 1990). This fact was true in the case of the autumn cycle with its lower DLI than in winter. In the case of the summer cycle, plants were grown under shading and high temperature conditions, which provoked a lower dry weight per plant and consequently a higher SLA. Total root length increased as aeration of the nutrient solution increased (Table 11). Aeration treatments increase the length of roots, particularly fine roots, improving plant growth (Lara et al., 2011). A similar result was reported by Tesi et al. (2003a) in spinach grown in a floating system. Neither the cycle nor aeration affected the percentage of dry matter (Figure 7A) in agreement with the results obtained by Lara et al. (2011) in purslane growing in a floating system.

The nitrate content was lower in the autumn cycle compared to the winter cycle in LA and HA conditions (Figure 7B), since light is one of the main factors influencing nitrate concentration, which increases in the plant tissue under poor light conditions (winter) (Burns et al., 2010). The lack of oxygen did not affect the nitrate content in any cycle (Figure 7B), which contrasts with the results obtained in other species grown in floating systems (Ferrante et al., 2003; Lara et al., 2011; Tesi et al., 2003a), where a lack of aeration in the nutrient solution decreased the nitrate concentration.

Among the metabolic adaptations to oxygen deficiency, the results showed that the aeration conditions did not affect the total phenolic content at harvest or postharvest (Figure 7C). 


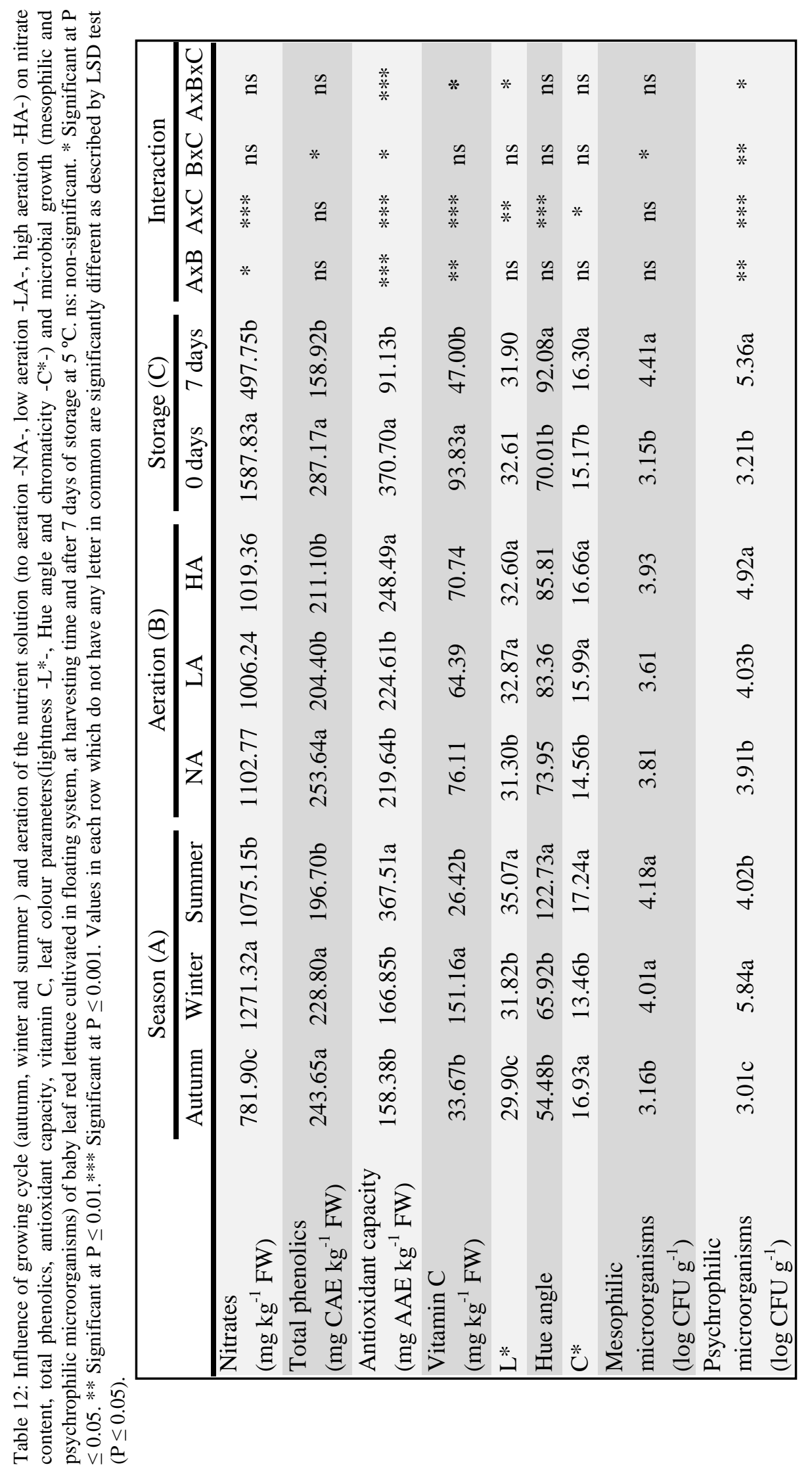


These results agree with those obtained by Niñirola et al. (2014) in watercress and also with those obtained by Lara el al. (2011) in purslane in autumn and spring cycles. The antioxidant capacity was higher in summer, particularly in NA conditions (Table 13), which agrees with the results of Rajapakse et al. (2009), who confirmed that low oxygen stress induced the production of protective phytochemicals in lettuce, which may enhance its marketable value. This response is similar to those observed in purslane and watercress (Lara et al., 2011; Niñirola et al., 2014). Also, the higher antioxidant capacity values reached in summer could be attributed to exposure to high temperature, which is associated with a higher antioxidant capacity (Liu et al., 2007). As regards storage time, the antioxidant capacity at 7 days was lower than at harvest, which agrees with the results of Rodriguez-Hidalgo et al. (2010b) in spinach. The vitamin C content was higher in winter in NA conditions (Table 13) as occurred in watercress in NA conditions grown in winter and spring (Niñirola et al., 2014). During storage, a significant decrease in vitamin $C$ was observed due to oxidation, which is exacerbated with increasing storage temperature and time (Konstantopoulou et al., 2010). In addition, the vitamin C content of fruits and vegetables can be influenced by various factors such as genotypic differences, preharvest climatic conditions and cultural practices, maturity and harvesting methods, and postharvest handling procedures (Lee and Kader, 2000).

Colour is important quality parameter in lettuce (Simonne et al., 2002) and is based, in part, on anthocyanin and chlorophyll levels. However, the pigments causing that give rise to the red colour of lettuce leaves are mainly anthocyanins, whose contents are genotype-, temperature- and light-dependents (Kleinhenz et al, 2003). More particularly, lettuce leaf pigment concentrations and growing temperatures are negatively related. In our study lettuce grown in autumn and winter, with lower temperatures than in summer, had lower hue angle values (Table 12). Since, increases in hue angle are associated with decreases in anthocyanin levels (Gazula et al., 2007), lettuce produced in autumn and winter had a higher content of anthocyanins, and consequently, were redder. Since the percentage of red colour varied in the different growing cycles, the degradation pigment process, i.e. formation of pheophytin from chlorophyll, could have had an effect on the $\mathrm{L}^{*}$ values at 7 days of storage (Table 13). 


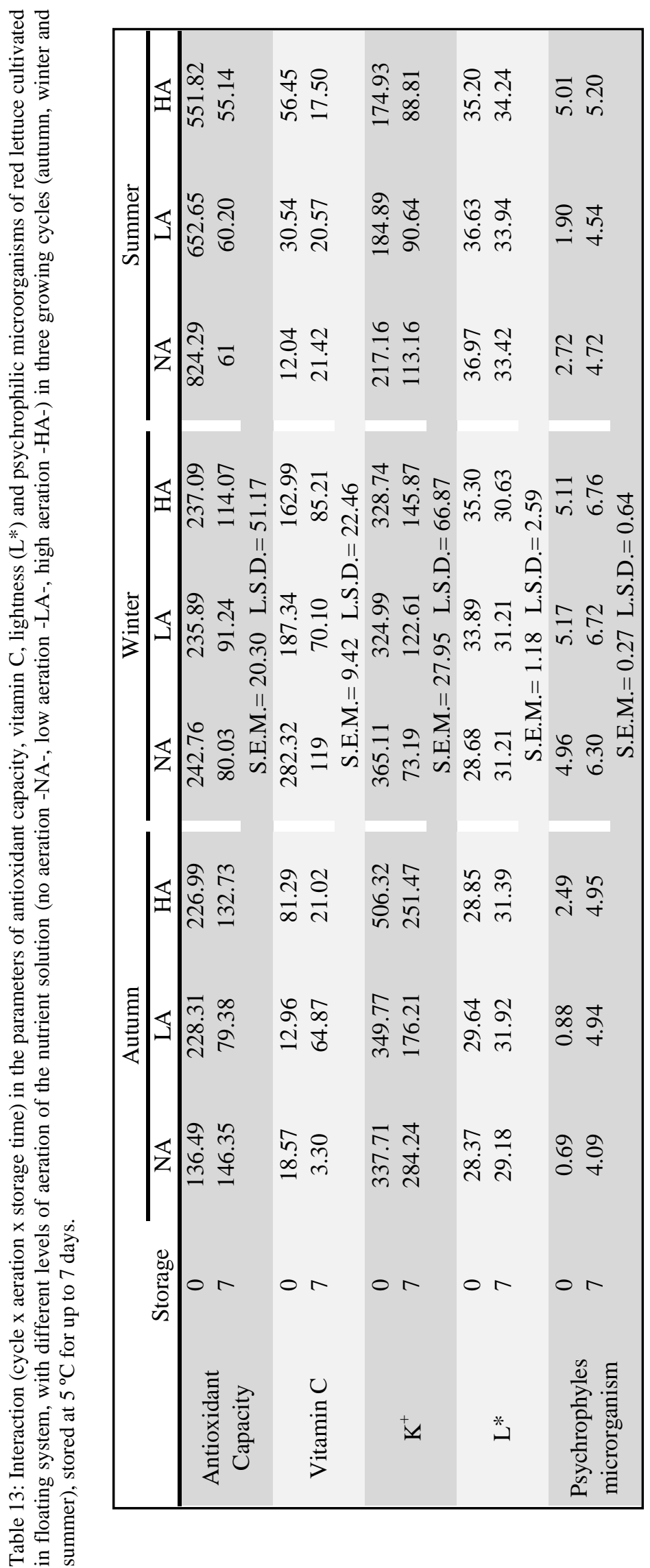



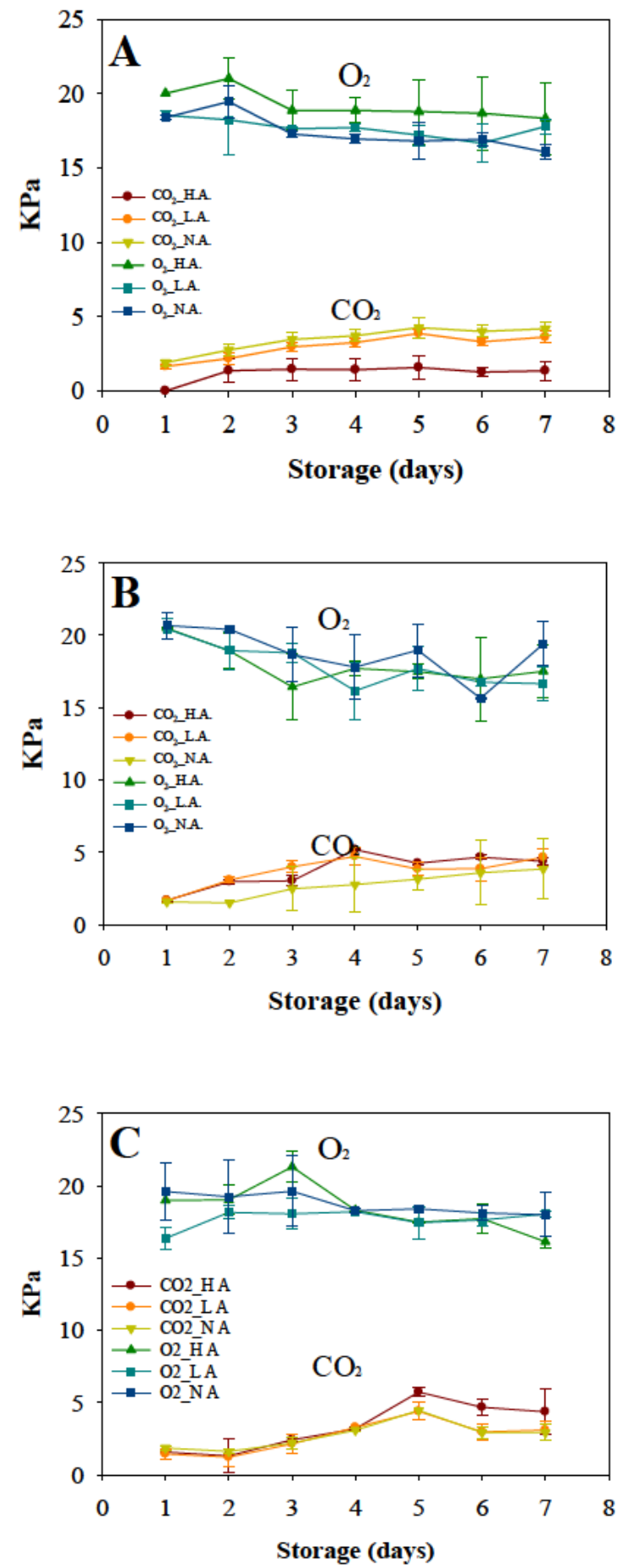

Figure 8: Influence of the aeration level of the nutrient solution (no aeration -NA-, low aeration-LA-, high aeration -HA-). on the headspace partial pressure of $\mathrm{O}_{2}$ and $\mathrm{CO}_{2}$ within the polypropylene basket of fresh-cut red lettuce cultivated in floating system in three different growing cycles (autumn -A-, winter -B- and summer $-\mathrm{C}$-) and stored for 7 days at $5^{\circ} \mathrm{C}$. Values are the mean of three replicates $\pm \mathrm{SD}$.

Among the intrinsic factors that should be examined to ensure the quality of horticultural products are the sanitary conditions. Our results indicate that the microbial load never exceeded $6 \log \mathrm{CFU} \mathrm{g}{ }^{-1}$ at the end of storage (Table 12) a value similar to that obtained in a commercial mixed salad (Abadías et al., 2008) 
and romaine lettuce (Oliveira et al., 2010). The lowest mesophilic and psychrophilic count was observed in autumn, probably due to the climatic conditions, because low temperatures were reached in this cycle (Conte et al., 2008). The HA conditions influenced the microbial population (Table 12), especially psychrophilic microorganisms in winter and summer (Table 13) and after storage in the case of mesophilic microorganisms (Figure 7D). This fact could have been caused by the splashing of nutrient solution onto lettuce leaves by vigorous aeration. Normally, microorganisms increase their populations during storage, as has been observed in spinach (Conte et al., 2008) and different varieties of lettuce (Oliveira et al, 2010; Selma et al., 2012). In our work, this was observed in the case of psychrophilic microorganisms due to the storage temperature used, while the mesophilic microorganisms load did not increase in NA or LA because of the storage temperature was not ideal for their growth.

The steady-state atmospheres reached within packages of leaves after diverse aeration treatments during growing were quite similar and ranged from $15-19 \mathrm{kPa}$ $\mathrm{O}_{2}$ and 1-4 $\mathrm{kPa} \mathrm{CO}_{2}$ (Figure 8). This result suggests that film permeability was relatively high and that the aeration supplied to the hydroponic system was not a critical factor to the respiration behaviour after harvest.

In conclusion, aeration did not affect yield, which was highest in autumn. The effect of aeration on the quality parameters was influenced by the growing cycle. 
CHAPTER 4 


\section{EFFECT OF PGPR APPLICATION AND NITROGEN DOSES ON BABY LEAF LETTUCE GROWN IN A FLOATING SYSTEM}

In recent years, changes in life-style and eating habits have led to the growing popularity of fresh-cut vegetables. The current high demand for freshcut vegetables is a result of the consumer desire for healthy, convenient, fresh and ready-to-eat commodities.

Among the different production modalities, the form the "baby leaf" has grown in popularity in minimally processed vegetable products. These are presented as whole leaves, $8-12 \mathrm{~cm}$ in length, with only one very small section exposed to oxidation, the petiole, thus increasing postharvest life (Gonzalez et al., 2004).

Soilless systems allow the production of clean leaves, facilitating and shortening postharvest handling and processing, and enabling growth factors to be controlled (Fontana and Nicola, 2004). Among the different systems available for the cultivation of baby leaf vegetable crops, the floating system is an easy and profitable growing technique.

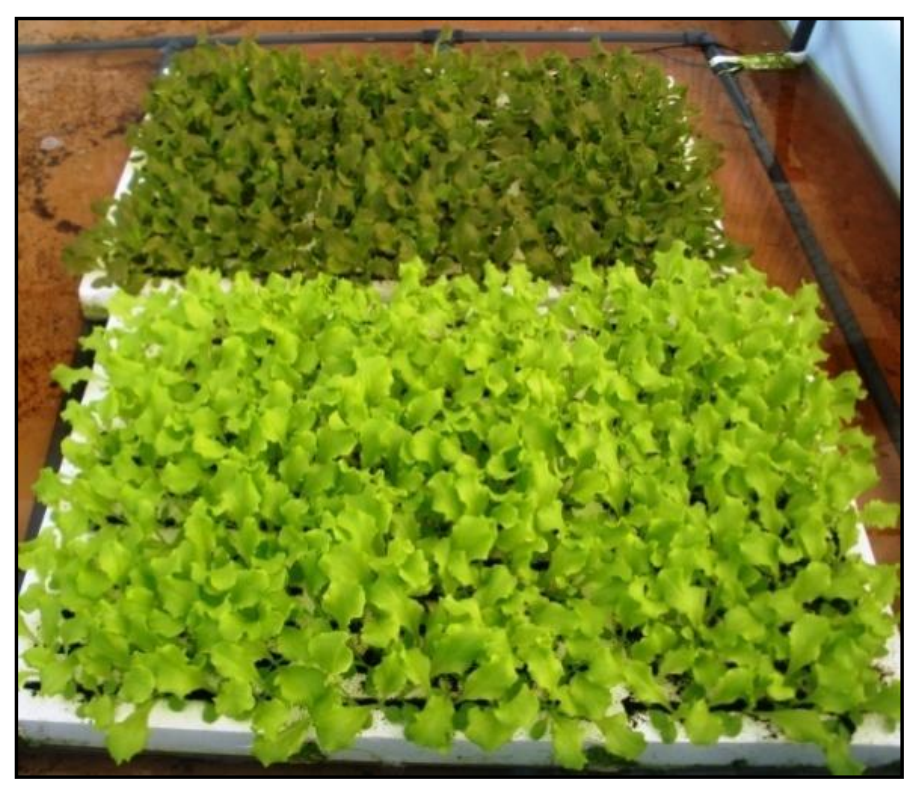

Picture 6: 'Ganeria' and 'Diveria' lettuce growing floating system. 
The floating system consists of trays floating continuously on a nutrient solution, resulting in a more efficient use of water and greenhouse space (Galloway et al., 2000). This system shortens the cultivation cycle compared with soil-based culture and is of interest to growers because it has low installation and manpower costs; weeds are avoided and harvesting is straightforward. Plants can be grown at high densities and the resulting products (leaf vegetables) are clean and ready to be packed (Gonnella et al., 2004). One of the main advantages of floating systems is the possibility of quickly influencing the nutritional status of plants. In this manner, by changing the composition of nutrient solution, modifying the oxygen concentration, adding chemical and biological compounds, etc., we can produce vegetable with better quality and sometimes with particular dietetic requirements (Santamaria and Valenzano, 2001). With the increasing problems associated with the use of synthetic chemicals in agriculture, there has been a rising interest in the use of native and non-native beneficial microorganisms to improve plant health and productivity (Avis et al., 2008). Some bacteria in the rhizosphere actively colonise plant roots in the presence of the existing native flora. These are known as rhizobacteria, and those which exert a beneficial effect on plant growth are called plant growth-promoting rhizobacteria (PGPR). Although direct effects on plant growth have been reported (Kloepper et al., 1988), growth promotion results mainly from the suppression of soil-borne pathogens and other deleterious microorganisms (Zehnder et al., 2000). This is particularly significant in baby leaf vegetables grown in floating systems, where damping off is one of the most important pathological problems (Pimpini et al., 2005). Reports on the use of PGPR in floating systems are extremely scarce. However, inoculated Pseudomonas spp. have been seen to satisfactorily colonize the spinach root in hydroponic culture, demonstrating the growth-promoting effect of PGPR on these plants (Yasufumi and Kaneaki, 2003).

Vegetables are the greatest dietary source of nitrate, and lettuce is one of the leafy vegetables that most accumulates nitrates (Santamaria, 2006). The amount of nitrate accumulated depends on genetic factors, environmental and the agronomic techniques used (Gonnella et al., 2002). It is known that the floating system can be used to produce vegetables with low nitrate levels using different cultivation techniques, but it would also be interesting to know whether PGPRs 
could be used to reduce the $\mathrm{N}$ doses in the nutrient solution without affecting plant growth. In this way a final product with similar yield and with lower nitrate content could be obtained. The aim of this work was to study the effect of applying two PGPRs (Bacillus subtilis and B. velezensis) and two doses of nitrogen (4 and $12 \mathrm{mM}$ ) on the yield quality and nitrate content of two baby leaf lettuce cultivars grown in a floating system.

\section{Material and methods}

\section{Growing Conditions}

The experiment was conducted at the "Tomás Ferro" Experimental AgroFood Station of the Technical University of Cartagena (UPCT). Two cultivars of lettuce, 'Ganeria' and 'Diveria', from Rijk Zwaan Ibérica were cultivated in a floating system in an unheated greenhouse covered with polycarbonate. Two crop cycles were carried out, with sowing on 2 December 2009 and 17 February 2010. Sowing was carried out manually into 'stryrofloat' trays containing peat, which were then transferred to a germination chamber at $21{ }^{\circ} \mathrm{C}$ and $90 \%$ relative humidity for 3 days. The trays were then transferred to a flotation bed of $135 \times 125 \times 20 \mathrm{~cm}$ and maintained floating permanently on fresh tap water with an electrical conductivity (EC) of $1.1 \mathrm{dS} \mathrm{m}^{-1}$ and $\mathrm{pH}$ 7.8. At the same time aeration was provided to tap water by a blow pump connected to a pipe trellis positioned at the bottom of each flotation bed. One week later, the lettuce plants were thinned leaving 1,700 plants $\mathrm{m}^{-2}$ and the tap water in the beds was replaced with nutrient solution. Different nutrient solutions with a combination of two different concentrations of nitrogen (4 and $12 \mathrm{mM}$ of $\mathrm{N}$ ) (ratio $\mathrm{NO}_{3}{ }^{-} / \mathrm{NH}_{4}{ }^{+}: 60 / 40$ ) and three bacterial inoculants (B. subtilis strain AP1 at $1.710^{9} \mathrm{CFU} \mathrm{L}^{-1}, B$. velenzensis strain $\mathrm{AH} 2$ at $8.310^{8} \mathrm{CFU} \mathrm{L}^{-1}$ and a non-bacterial control) were compared. All nutrient solutions contained the following base composition: $\mathrm{H}_{2} \mathrm{PO}_{4}^{-} 2 \mathrm{mM} ; \mathrm{K}^{+} 6 \mathrm{mM} ; \mathrm{Ca}^{2+} 2.6 \mathrm{mM}$ and $\mathrm{Mg}^{2+} 1.5 \mathrm{mM}$ plus a commercial solution of microelement Nutromix 10, Biagro (7.5\% p/p Fe, 3.3\% p/p Mn, 0.3\% $\mathrm{p} / \mathrm{p} \mathrm{Cu}, 0.6 \% \mathrm{p} / \mathrm{p} \mathrm{Zn}, 0.7 \% \mathrm{p} / \mathrm{p} \mathrm{B}, 0.2 \% \mathrm{p} / \mathrm{p} \mathrm{Mo}$ ) to $2 \mathrm{mg} / \mathrm{L}$ and Sequestrene (35.71\% p/p EDDHA-NaFe) to $1.5 \mathrm{mg} \mathrm{L}^{-1}$. The nutrient solution was maintained 


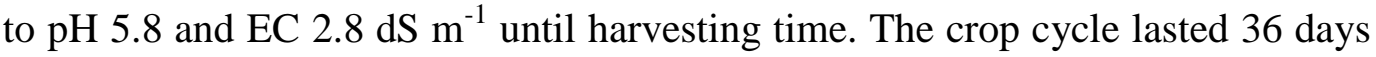
in experiment 1 and 30 days in experiment 2 .

\section{Plant Growth and Nitrate Measurements}

Plant height, number of leaves, shoot fresh weight (FW), leaf area, the relative chlorophyll content (RCC) and root growth were measured in 20 plants per tray. Leaf area was measured with a leaf area meter (LICOR-3100 C) and the RCC with a chlorophyllmeter (Minolta SPAD-502). Root length, area and volume and diameter were determined with a Winrhizo LA 1600 root counter, from pictures taken of the root system by double pass scanner incorporated in the counter. The dry matter contents of the shoots and roots were determined by drying in an oven at $60{ }^{\circ} \mathrm{C}$ until constant weight. Nitrate was extracted in three samples of $0.2 \mathrm{~g}$ of shoot dry matter per treatment and repetition.

The ion concentration was determined by ion chromatography using a Metrosep A SUPP 5 column with a flow rate of $0.7 \mathrm{~mL} \mathrm{~min}^{-1}$.

\section{Experimental Design and Statistical Analysis}

The experiment was a randomized complete block design with two factors: $\mathrm{N}$ concentration (two levels) and bacterial inoculant (three levels). Statgraphic 2.1 was used for statistical analyses by ANOVA. Treatment means were separated with the LSD Test.

The sample unit was a bed of $135 \times 125 \times 20 \mathrm{~cm}$, where a level of each treatment was applied. Six beds per block and three blocks were considered. Each bed had four floating trays of $60 \times 41 \mathrm{~cm}$ (two of each cultivar). 


\section{Results}

Tables 14 and 15 show the ANOVA of vegetative parameters, nitrate content and chlorophyll (SPAD values) content of shoots of two lettuce cultivars.

In 'Diveria' plants, plant height was affected by nutrient solution and bacterium in both experiments, number of leaves was affected by nutrient solution (exp 1) and bacterium (exp 1); leaf area by bacterium (exp 2); FW by bacterium (exp 1); DW by nutrient solution (exp 1) and bacterium (exp 1 and 2); RCC by nutrient solution (exp 1); and nitrate content by nutrient solution and bacterium in both experiments.

Some interactions between nutrient solution and bacterium were found in some parameters, but only that which was found in both experiments is shown (Figure 9). After studying this interaction, the result revealed that in the experiment 1 shoots were bigger (larger leaf area) when $4 \mathrm{mM} \mathrm{N}$ and non bacterial inoculation (control) or $12 \mathrm{mM} \mathrm{N}$ and $\mathrm{B}$. velezensis were applied, while in the experiment 2 the biggest shoots were obtained when $12 \mathrm{mM} \mathrm{N}$ and $B$. subtilis were applied.

In 'Ganeria' plants, plant height was affected by nutrient solution (exp 1) and bacterium (exp 1 and 2); number of leaves was affected by bacterium (exp 2); FW by bacterium (exp 2); RCC by nutrient solution (exp 1) and bacterium (exp 1); and nitrate content by nutrient solution in both experiments. Also, some interactions between nutrient solution and bacterium were found in some parameters, but only that which was found in both experiments is shown (Figure 10). After studying this interaction, the result revealed that in the experiment 1 shoots had a highest number of leaves when $4 \mathrm{mM} \mathrm{N}$ and B. subtilis were applied, while in the experiment 2 the highest number was obtained when $12 \mathrm{mM}$ $\mathrm{N}$ and $B$. velezensis were applied.

Root growth was not affected by neither nutritive solution nor bacterial inoculants (Tables 16 and 17). Furthermore, there were no interaction between nutritive solution and bacterium in none of the parameters of both cultivars in both experiments. 


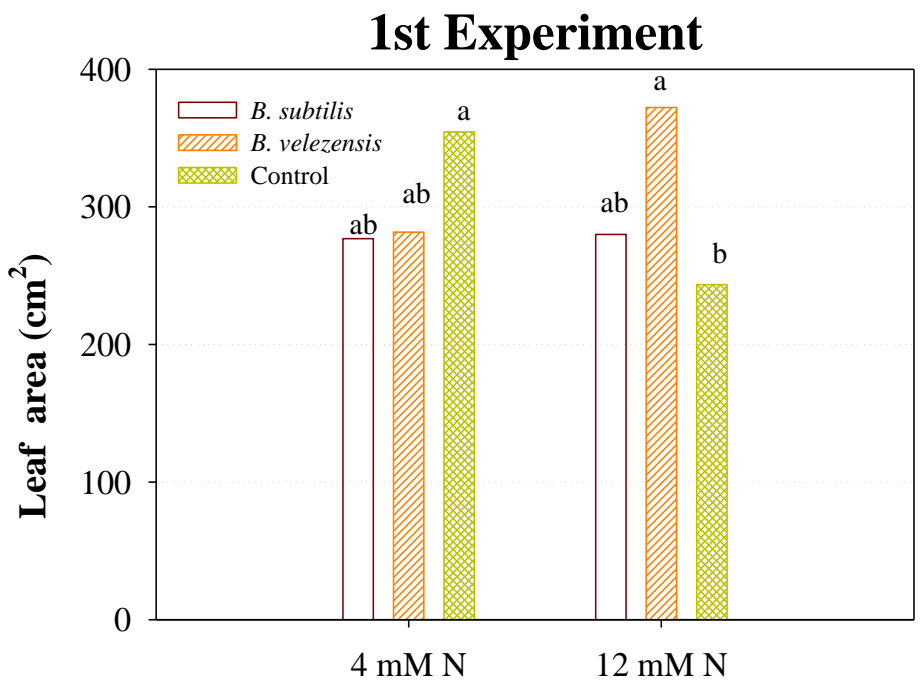

Nutrient Solution

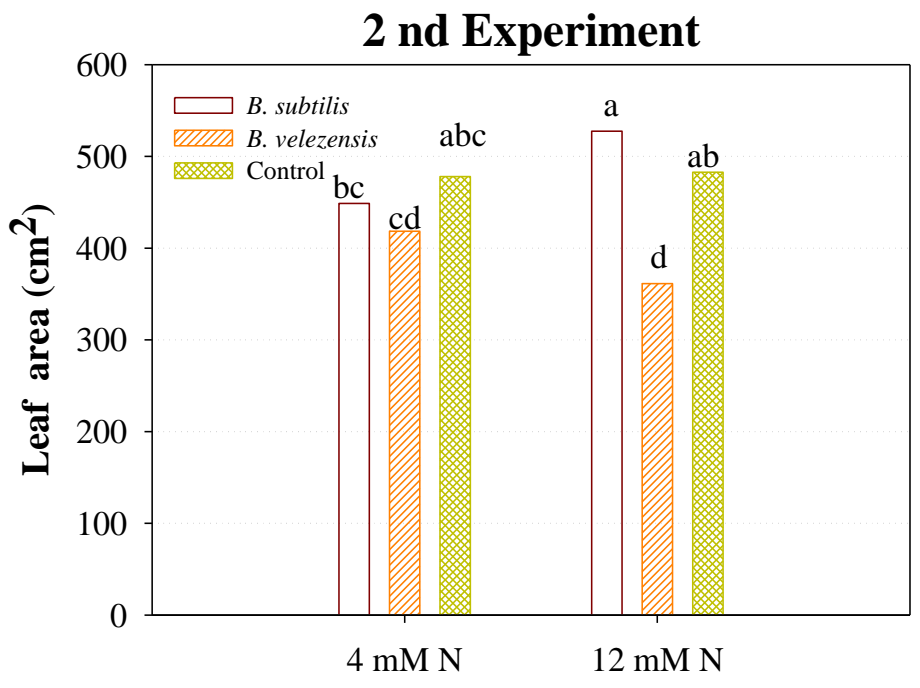

Nutrient Solution

Figure 9: Leaf area of lettuce 'Diveria' for the combination of nitrogen concentration in the nutrient solution and bacterial inoculation in two experiments. Different letters indicate significant differences $(\mathrm{P}<0.05)$. 


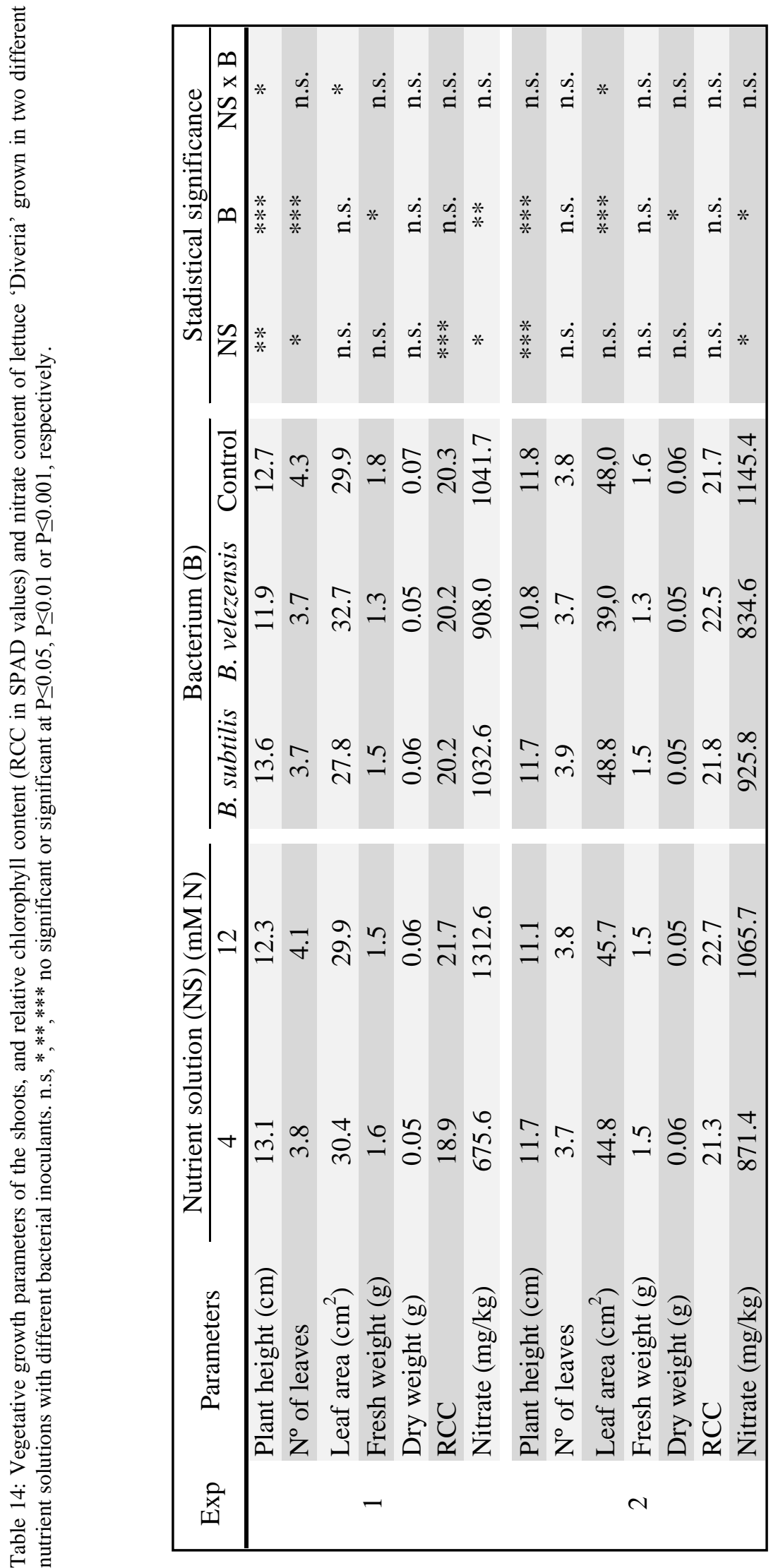




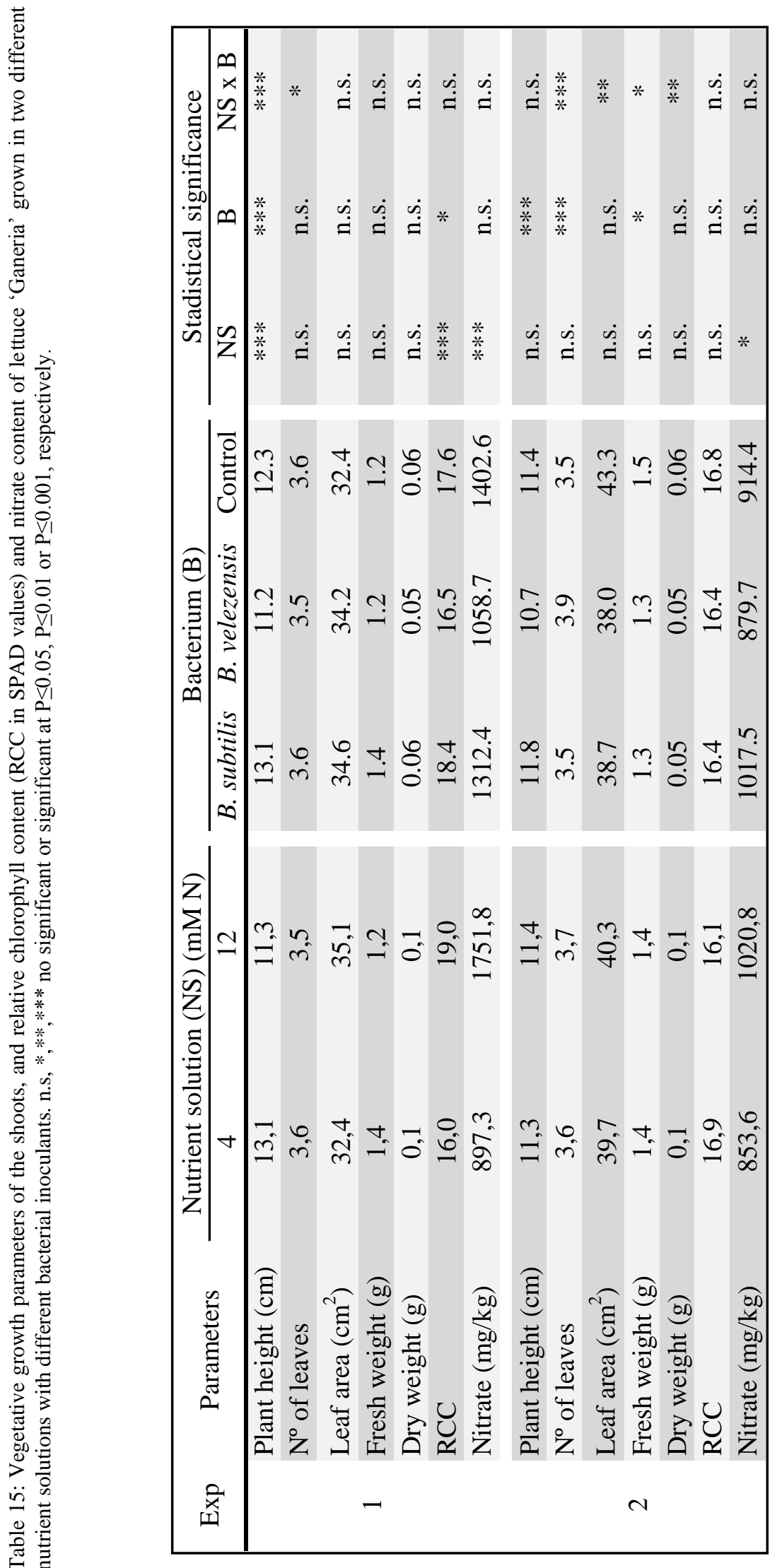




\section{Discussion}

Some vegetative parameters of shoots were affected by the level of $\mathrm{N}$ and the PGPR application. In general, the shoots growth when B. subtilis was applied to the nutrient solution was similar to the control, while there was a slight decrease in plant growth when B. velezensis was applied. Some studies have found a positive effect of PGPR application on shoot growth in a hydroponic culture (Yasufumi and Kaneaki, 2003), particularly when plants grown under salt stress (Woitke et al., 2004; Liu et al., 2010).

Several mechanisms have been postulated to explain how PGPR stimulate plant growth, among them the suppression of plant pathogens and deleterious rhizosphere microorganisms, production of plant hormones, phosphate solubilisation, etc. Therefore, PGPR application could have the function on abiotic stress relief. In our experiment, PGPR application had a positive influence when plants grown under low level of $\mathrm{N}$ in the nutrient solution (Figures 9 and 10) by which PGPRs could be used to reduce the $\mathrm{N}$ doses in the nutrient solution without affecting plant growth.

The use of the lower doses of $\mathrm{N}$ in the nutrient solution reduced the nitrate content in leaves as it was previously demonstrated by Conesa et al. (2009b). The application of $B$. velezensis in nutrient solution provoked a decrease of nitrate content in leaves respect to control, mainly in 'Diveria' plants, probably due to the use of nitrates by bacterium in an anaerobic respiration process.

Finally, the level of $\mathrm{N}$ and the PGPRs application did not influence the root growth in any crop cycle. However, some studies have demonstrated a positive effect of PGPR application on root growth (Fu et al., 2010), particularly when plants grown under salt stress (Liu et al., 2010). 

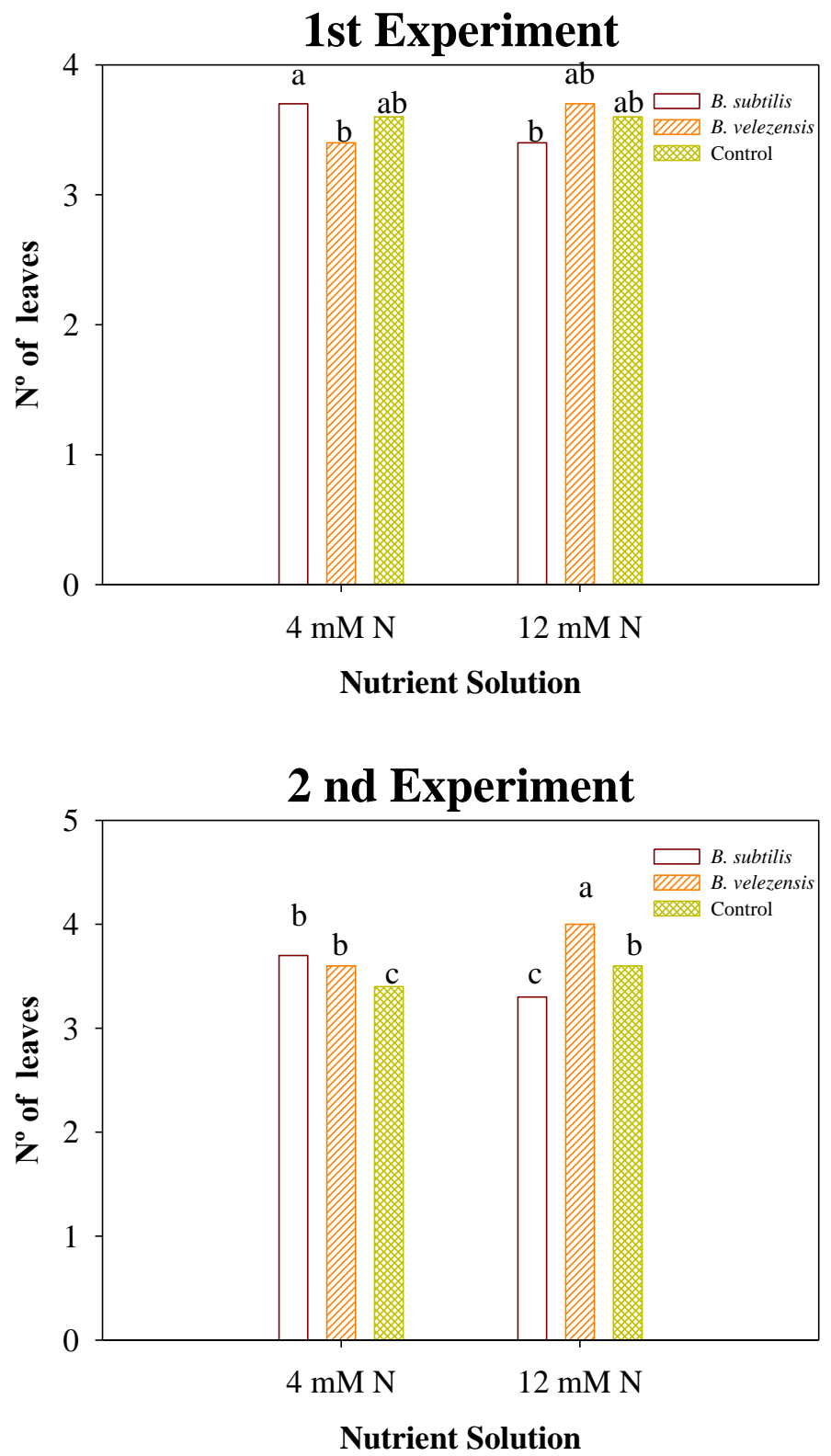

Figure 10: Number of leaves of lettuce 'Ganeria' for the combination of nitrogen concentration in the nutrient solution and bacterial inoculant in two experiments. Different letters indicate significant differences $(\mathrm{P}<0.05)$. 
CHAPTER 5 


\section{INHERENT QUALITY AND SAFETY OF WATERCRESS (Nasturtium officinale R. BR.) GROWN IN A FLOATING SYSTEM USING PLANT GROWTH-PROMOTING RHIZOBACTERIA (PGPR)}

Changes in life-style and eating habits have led to the growing popularity of fresh-cut vegetables. Among them, watercress is considered as a valuable food product in the fresh salads industry, for its supposed high content of healthpromoting compounds such as antioxidants and phenolics (Niñirola et al. 2014). Among the different systems available for the cultivation of watercress, the floating system (FS) is an easy and profitable growing technique, which enables plants to be grown at high densities, providing products that are clean and ready to be packed. One of the main advantages of FS is the possibility of directly influencing the nutritional status of plants by changing the composition of the nutrient solution (NS) and adding chemical and biological compounds, thus facilitating the production of vegetables of prime quality and sometimes fulfilling specific dietetic requirements.

In light of the problems associated to the use of synthetic chemicals in agriculture, there is growing interest in the use of native and non-native beneficial microorganisms to improve plant health and productivity (Avis et al. 2008).

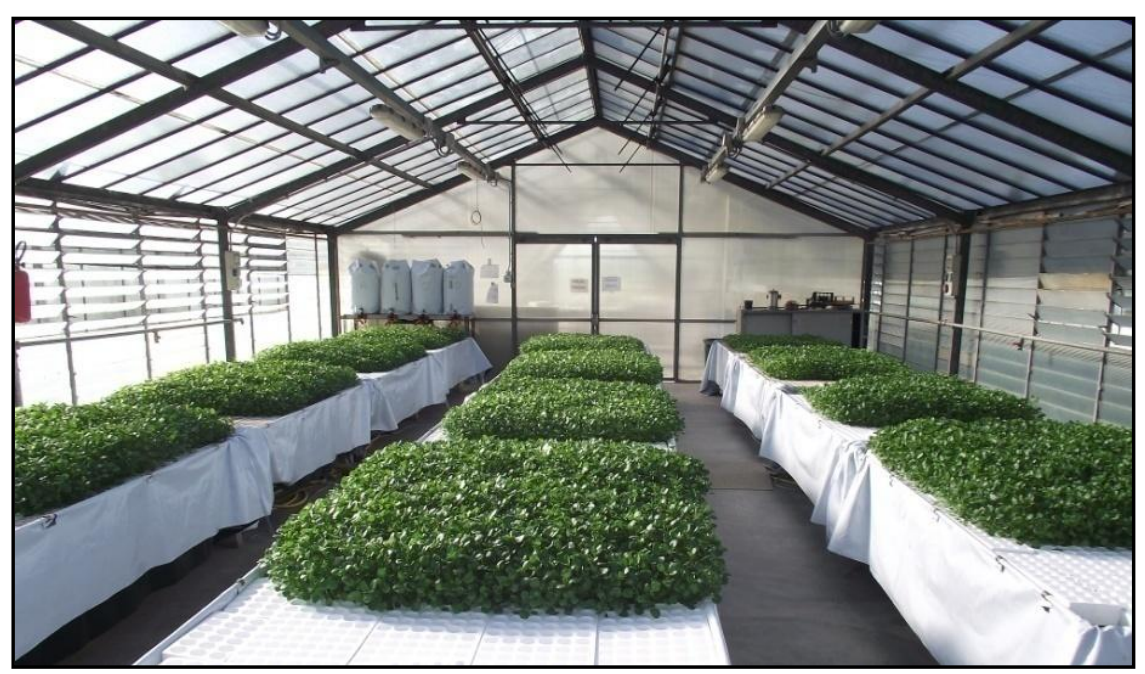

Picture 7: Watercress experience in the glasshouse in Torino. 
The use of plant growth-promoting rhizobacteria (PGPR) in agriculture is gaining in worldwide importance and acceptance, and appears to be the trend for the future (Niranjan Raj et al. 2005). Significant increases in growth and yield of important agronomic crops in response to inoculation with PGPR have been widely reported (e.g. Barreto-Figuereido et al. 2010, and citations therein). Among strains that show growth-promoting activity, species belonging to the genera Pseudomonas and Bacillus have been the most extensively studied. Recently, Kumar et al. (2011) reviewed the bibliography on the principal growth promotion mechanisms of Bacillus strains and found that they include the production of growth-stimulating phytohormones, phosphate solubilisation and mobilization, siderophore production, antibiosis (including the production of antibiotics, the inhibition of plant ethylene synthesis and the induction of plant systemic resistance to pathogens). It seems very likely that the above-mentioned plant growth promotion effects may be a result of the combined action of two or more of these mechanisms. Furthermore, the widely established knowledge of its controlling effect against pests and diseases would explain the commercial exploitation of different strains of Bacillus subtilis as biocontrol agents (Kumar et al. 2011).

PGPR and their formulations are commonly applied as a seed treatment, soil amendment or root dip in bacterial suspension before transplanting (Podile, and Kishore, 2006). In addition, PGPR can be successfully incorporated into soilless media in vegetable transplant production systems (Yan et al. 2003). The use of PGPR in soilless culture systems (SCS) is increasing as it is considered to induce resistance in plants against biotic and abiotic stress factors and to increase plant growth and yield (Gül et al. 2008). However, very little attention has been paid to the effects of PGPR application on the quality at harvest of baby leaf vegetables (BLV) produced in SCS. Improving quality at harvest is associated with beneficial changes in the postharvest maintenance of product quality, which is why microorganisms beneficial to the rhizosphere could be considered as a preharvest biotic factor that affects fruit and vegetable quality (Olalde-Portugal and Mena-Violante, 2008).

To our knowledge, little has been published on how PGPR may affect the inherent quality of fresh vegetables, particularly in the case of BLV. In addition, no research has been carried out into the effects of PGPR on the safety 
parameters usually considered at harvest, such as microbial spoilage. However, more needs to be learnt about the inherent quality of BLV, and the application of microorganisms during plant growth should be examined for their effect on the commercial products. The aim of this work was to study the effect of applying Bacillus subtilis on the yield, quality and safety of watercress grown in a FS.

\section{Material and methods}

\section{Plant material and growing conditions}

The experiment was conducted in the summer of 2012 in the Tetti Frati Experimental Centre of the DISAFA Department $\left(44^{\circ} 53^{\prime} 11.67^{\prime}\right.$ 'N; $7^{\circ} 41^{\prime} 7.00^{\prime}$ 'E; $231 \mathrm{~m}$ a.s.l. in Carmagnola (Turin), Italy) in a greenhouse. Maximum, minimum and mean temperatures during the growing season were 43,17 and $29.1^{\circ} \mathrm{C}$, respectively. The plant material used was a commercial cultivar of watercress (Nasturtium officinale R. Br.), "Large Leaf” (Tozer Seeds Co., Cobham, UK). The experiment consisted of growing plants in 60-cell styrofoam trays $(0.51 \mathrm{~m} \times$ $0.30 \mathrm{~m} ; 44 \mathrm{~mm}$ top and $25 \mathrm{~mm}$ lower diameter) containing a substrate (Neuhaus Huminsubstrat N17, Klasmann-Deilmann, Geeste-Groß, Hesepe, Germany) floating in a nutrient solution (NS). Sowing took place on 22 June 2012. The seeded trays were placed in a plastic greenhouse until seed germination. Four days after sowing, the trays were moved into the flotation beds previously arranged and filled with $200 \mathrm{~L}$ of a $40 / 60 \mathrm{~N}-\mathrm{NO}_{3}{ }^{-} / \mathrm{N}^{-\mathrm{NH}_{4}}{ }^{+} \mathrm{NS}$ composed of 12 $\mathrm{mM} \mathrm{N}, 6 \mathrm{mM} \mathrm{K}, 2 \mathrm{mM} \mathrm{P}, 2 \mathrm{mM} \mathrm{Mg}$ and $2.5 \mathrm{mM}$ Ca. Then Lysodin ${ }^{\circledR}$ Multimix formulation of microelements (Intrachem Production S.r.l., Grassobbio, Italy) was added to the NS at a dose of $0.30 \mathrm{~g} / \mathrm{L}$. The $\mathrm{pH}$ and the electrical conductivity of the NS were monitored weekly and kept close to ca 5.5 and $2 \mathrm{dS} / \mathrm{m}$, respectively. The NS was aerated by a compressor connected to a perforated pipe trellis positioned in each flotation tank, to maintain levels of dissolved oxygen close to ca. 5 ppm throughout the growing cycle. The watercress was thinned after cotyledon expansion to reach a final plant density of 300 plants per tray (ca 1,961 plants $/ \mathrm{m}^{2}$ ). Harvesting took place after 24 days of cultivation.

The experiment followed a randomized complete block design (RCBD) with three replicates per treatment. Each treatment was placed in a flotation tank (ca $2.50 \times 1.40 \times 0.15 \mathrm{~m})$ containing 12 trays. 


\section{Bacterial strain and inoculation}

Two factors were considered, disinfection of the substrate and inoculation with B. subtilis. Substrate disinfection was carried out in a flow steam at $100^{\circ} \mathrm{C}$ for $45 \mathrm{~min} .50 \%$ of the substrate used in the assay was disinfected. For bacterial inoculation $(\mathrm{BI})$ the commercial product Larminar ${ }^{\circledR}\left(10^{12} \mathrm{CFU} / \mathrm{g}\right.$ of $\mathrm{B}$. subtilis strain AP-01, Agrimor, Agricultura Moderna S.A., Madrid, Spain) was used.

Inoculation was performed twice: first inoculating part of the substrate and all the seeds before sowing, and second, inoculating the substrate contained in the trays after sowing. For the first inoculation, one day before sowing, $50 \%$ of the disinfected substrate (DS) and 50\% of non-disinfected substrate (NDS) were inoculated with Larminar ${ }^{\circledR}$ at a dose of $0.5 \mathrm{~kg} / \mathrm{m}^{3}$. All the seeds used were disinfected in $20 \% \mathrm{NaClO}(\mathrm{w} / \mathrm{v})$ and rinsed with sterile deionized water three times. $50 \%$ of the disinfected seeds were inoculated by immersion for $1 \mathrm{~h}$ in a $B$. subtilis suspension at a concentration of $10^{8} \mathrm{CFU} / \mathrm{mL}$ in $0.9 \%$ of $\mathrm{NaCl}$ solution (w/v) obtained from Larminar ${ }^{\circledR}$ in Plate Count Agar (PCA) (Fluka Analytical, Sigma-Aldrich S.r.l., Milan, Italy). In the case of non-inoculated (NBI) seeds were kept for $1 \mathrm{~h}$ in $0.9 \%$ of $\mathrm{NaCl}$. Eleven days after sowing, a re-inoculation was performed placing the inoculated trays (substrate and seeds) on a solution containing $0.167 \%$ of Larminar $^{\circledR} /$ water (w/v).

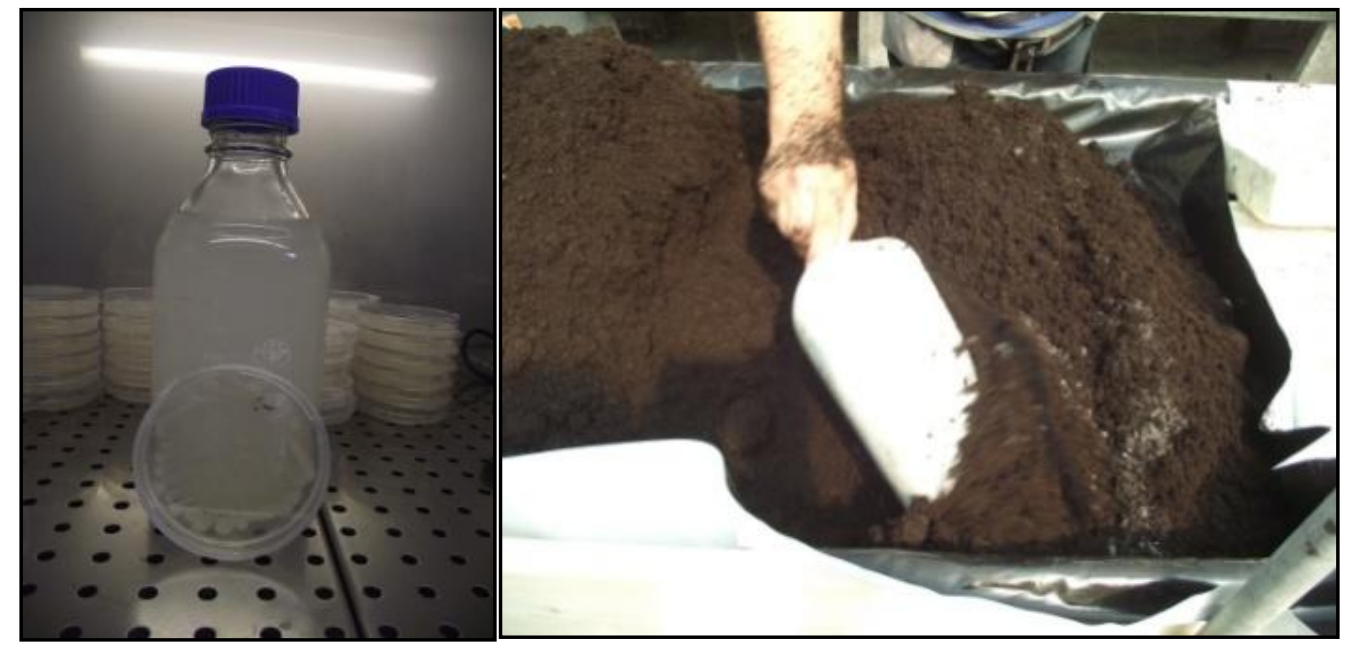

Picture 8: PCA with bacterial growth from Larminar®, bottle with B. subtilis suspension and inoculation of the substrate. 


\section{Biometrical measurements and phytochemicals analyses}

Whole plants were harvested and divided into aerial and root parts. The biometrical measurements recorded were: fresh and dry weight of the shoots (SFW and SDW, respectively) in 30 plants per treatment and per block; shoot height $(\mathrm{SH})$, leaf number (LN) per plant, leaf area (LA) using Image $1.47 \mathrm{v}$ pictures analyser developed at the National Institutes of Health (Bethesda, Maryland, USA), leaf colour (LC) using a CR10 colorimeter (Konica-Minolta Sensing Inc., Osaka, Japan), relative chlorophyll content (RCC) using a chlorophyllmeter (Minolta SPAD-502; Konica-Minolta Sensing Inc., Osaka, Japan) and fresh and dry weight of roots (RFW and RDW, respectively) in 12 plants per treatment and per block. These measurements enabled the following parameters to be calculated: specific leaf area (SLA), dry matter of shoot (SDM) and roots $(\mathrm{RDM})$, hue angle $\left(\mathrm{H}^{*}\right)$ as $\mathrm{H}^{*}=\tan ^{-1}\left(\mathrm{~b}^{*} / \mathrm{a}^{*}\right)(\mathrm{CIELAB})$ and Chroma $\left(C^{*}\right)$ as $C^{*}=\left(a^{* 2}+b^{*^{2}}\right)^{1 / 2}$. For yield and phytochemical content, all 12 trays per treatment and per block were used. The phytochemical analyses were conducted on the shoots. Ascorbic acid and dehydroascorbic acid were determined as described by Zapata and Dufour (1992) from $10 \mathrm{~g}$ of frozen tissue for each sample. The results were expressed as $\mathrm{mg}$ of vitamin $\mathrm{C}$ per $\mathrm{g}$ of fresh weight $(\mathrm{FW})$. Antioxidant capacity (AC) was performed following the procedures of Benzie and Strain (1996) using the ferric reducing ability of plasma (FRAP) assay as a measure of $\mathrm{AC}$ from $2 \mathrm{~g}$ of frozen tissue for each sample. The results were expressed as $\mu \mathrm{mol} \mathrm{Fe}^{2+} / \mathrm{g} \mathrm{FW}$. Total phenolics (TP) were determined using the Folin-Ciocalteu procedure based on the method of Singleton and Rossi (1965) from $2 \mathrm{~g}$ of frozen tissue for each sample. The results were expressed as $\mathrm{mg}$ gallic acid/g FW. Chlorophyll $a(\mathrm{Chl} a)$, chlorophyll $b(\mathrm{Chl} b)$ and carotenoids (Car) were determined according to the Lichtenthaler and Wellburn (1983) method from $1 \mathrm{~g}$ of frozen tissue for each sample. The results were expressed as $\mathrm{mg} / \mathrm{g}$ FW according to the formulas: $\mathrm{Chl} a=11.75 \times \mathrm{A}_{662 \mathrm{~nm}}-2.35 \times \mathrm{A}_{645 \mathrm{~nm}} ; \mathrm{Chl} b=$ $18.61 \times \mathrm{A}_{645 \mathrm{~nm}}-3.96 \times \mathrm{A}_{662 \mathrm{~nm}} ;$ Car $=\left(1000 \times \mathrm{A}_{470 \mathrm{~nm}}-2.27 \times \mathrm{Chl} a-81.4 \times \mathrm{Chl}\right.$ b)/227. Browning potential (BP) and soluble o-quinone (So-Q) were determined based on the method of Couture et al. (1993) and Loaiza-Velarde and Saltveit (2001) from $5 \mathrm{~g}$ of frozen tissue for each sample. The results were expressed as raw absorbance units ( $\mathrm{Abs}_{340} \mathrm{FW}$ and $\mathrm{Abs}_{437} \mathrm{FW}$ for $\mathrm{BP}$ and So-Q, respectively). Peroxidase (POD), polyphenol oxidase (PPO) and phenylalanine ammonia lyase 
(PAL) activities were determined from $0.5 \mathrm{~g}$ of frozen tissue for each sample. POD activity was determined as described by Nickel and Cunningham(1969) and the absorbance was spectrophotometrically determined at a wavelength of 470 $\mathrm{nm}$ at time 0 and after $1 \mathrm{~min}$. The results were expressed as $\Delta \mathrm{A}_{470} / \mathrm{min} \mathrm{g} \mathrm{FW}$. PPO activity was determined as described by Degl'Innocenti et al. (2005) at a wavelength of $480 \mathrm{~nm}$. The results were expressed as PPO Unit/g FW. PAL activity was determined as described by Campos et al. (2004) and Degl'Innocenti et al. (2005) at a wavelength of $290 \mathrm{~nm}$. The results were expressed as $\mu \mathrm{mol}$ cinnamic acid/h.g FW. Nitrate $\left(\mathrm{NO}_{3}{ }^{-}\right)$was determined on the shoots using a refractometric kit (Merck Reflectoquant RQflex $2^{\odot}$, Merck KGaA, Darmstadt, Germany), following the manufacturer's instructions. For each sample, $10 \mathrm{~g}$ of frozen tissue were stomached for $2 \mathrm{~min}$ at normal speed with $10 \mathrm{~mL}$ of deionized water, filtered and subsequently determined. The results were expressed as $\mathrm{mg} / \mathrm{g}$ FW.

\section{Microbiological analysis}

Total bacterial count (TBC) was determined by PCA, while the mould and yeast count ( $\mathrm{MC}$ and $\mathrm{YC}$, respectively) were determined using the Yeast Extract Glucose Chloramphenicol Agar (Fluka Analytical, Sigma-Aldrich S.r.l., Milan, Italy). For each sample $25 \mathrm{~g}$ of fresh tissue from the aerial part were used. The TBC was performed after incubation at $30{ }^{\circ} \mathrm{C}$ for $48 \mathrm{~h}$, while $\mathrm{YC}$ and $\mathrm{MC}$ were performed after incubation at $30^{\circ} \mathrm{C}$ for $5 \mathrm{~d}$. The results were expressed as the $\log$ colony-forming units per g (Log CFU/g FW).

\section{Statistical analysis}

Data were analysed using Statgraphics Plus. Analysis of variance was performed considering the factorial design substrate disinfection (DS and NDS) $\times$ bacterial inoculation (BI and NBI) in RCBD. When interactions were significant, they were included in the ANOVA, and the least significant difference (LSD) test was performed to separate means. 


\section{Results and discussion}

\section{Plant growth and yield}

The growth and development of watercress was considered adequate for all the treatments, although plants grown in BI had some minor post-emergence problems due to damping-off (data not shown). A significant interaction between the disinfection and inoculation was found for SH (Table 18). SH in the DS $\times$ NBI treatment was significantly higher than NDS $\times$ NBI (Fig. 11A). In addition, the disinfection also affected LN, RCC, SLA and C* (Table 18). Plants growing in DS conditions had a higher LN, RCC and SLA and a lower C* than those grown in NDS (Table 18), producing plants with greyish green leaves. The higher growth obtained in DS condition agree with the findings of Saubidet et al. (2002), who recorded higher growth for wheat plants grown in pots filled with disinfected substrate than in non-disinfected substrate, probably due to the release of nutrients such as $\mathrm{N}$ and $\mathrm{P}$ in the disinfected substrate after natural reinfection, which would increase yields in the short term (Paul and Clark,1989). As regards B. subtilis inoculation, no significant differences were found for any of the measured parameters with respect to the non-inoculated treatment. Similar results were obtained for B. subtilis by Balanza et al. (2012) and Corrêa et al. (2010) in a hydroponic lettuce crop. Nevertheless, some studies have found a positive effect of PGPR application on shoot growth in a hydroponic culture (Urashima and Hori, 2003), particularly when plants grown under stress conditions since PGPR application could have the function on abiotic stress relief (Liu et al. 2010).

\section{Mineral ion determinations.}

The disinfection of the substrate affected the shoot nitrate content, which significantly increased by $80.5 \%$ (Table 18). This result agrees with that observed by Saubidet et al. (2002) in wheat where the $\mathrm{NO}_{3}{ }^{-}$concentration in wheat tops was higher in plants grown in disinfected soil than in those grown of non-disinfected soil. There were no differences in the ion contents between BI and NBI (Table 18). Balanza et al. (2012) agrees with our study and found no difference in nitrate content between non-inoculated plants and plants inoculated with B. subtilis in a lettuce crop. However, gains in nutrition plants inoculated 
with rhizobacteria have been demonstrated as a benefit of the presence of this group of microorganisms in the rhizosphere (Barreto-Figuereido et al. 2010).

\section{Antioxidants and pigments}

The AC, TP, Chl $a, \mathrm{Chl} b$ and Car of plants growing in DS conditions increased by $36.4,19.3,20.5,18.7$ and $23.5 \%$ (Table 19), respectively, with respect to NDS plants. As regards inoculation, BI increased AC by $27.8 \%$ and decreased Chl $a$, Chl $b$ and Car by 20.4, 18.7 and $23.5 \%$, respectively, compared with NBI (Table 19). Not many studies have focused their attention on the effect of PGPR on the accumulation of antioxidants and pigments, while most of those that do exist look at the use of PGPR strains to alleviate the effect of abiotic stress. Thus, Heidari and Golpayegani (2012) demonstrated that the application of rhizobacteria improved the antioxidant and photosynthetic pigments of basil plants under water stress and Han and Lee (2005) showed that PGPR increased the chlorophyll content and decreased enzyme activity in plants under salinity stress.

\section{Enzymatic browning}

The measured parameters are related to the enzymatic activity produced by cuts or injury to plant tissues. Neither disinfection nor inoculation affected the reaction of watercress to the damage and cuts that occurred during harvest and no significant differences were observed for these factors in any parameter separately. The interaction of two factors was only observed in the PAL activity, when an antagonistic behaviour was evident (Table 20), the effect of BI depending on whether the substrate had been disinfected or not (Fig 1b). In DS conditions, BI plants showed a significantly higher PAL activity than NBI plants, whereas in NDS conditions NBI plants had significantly higher values for the activity of the enzyme than BI plants (Fig 11B). Vivekananthan et al. (2006) suggested that the preharvest application of biocontrol agents may help overcome pre and postharvest infection by increasing Levels of defence-related enzymes and phenolic substances. 


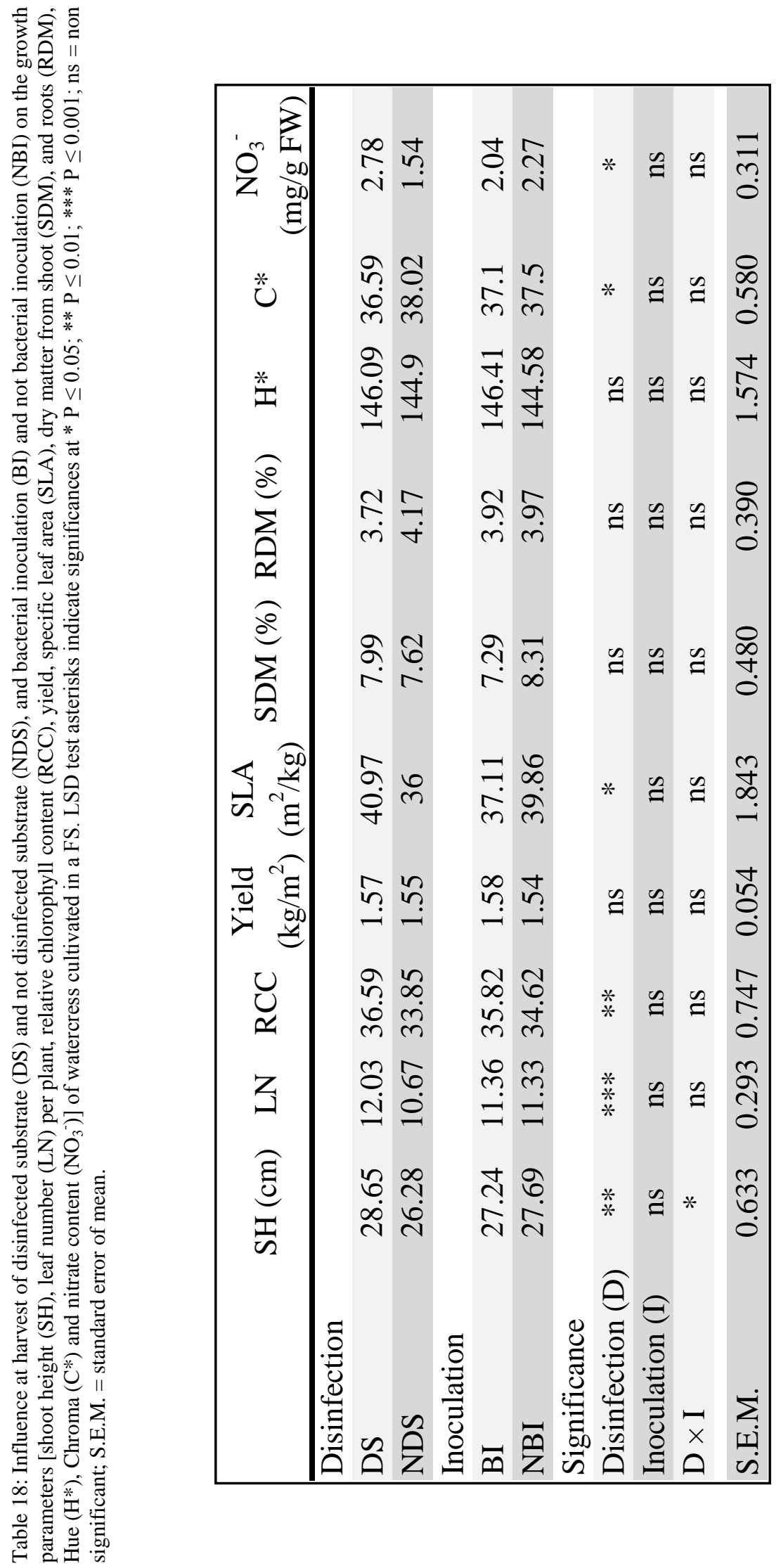




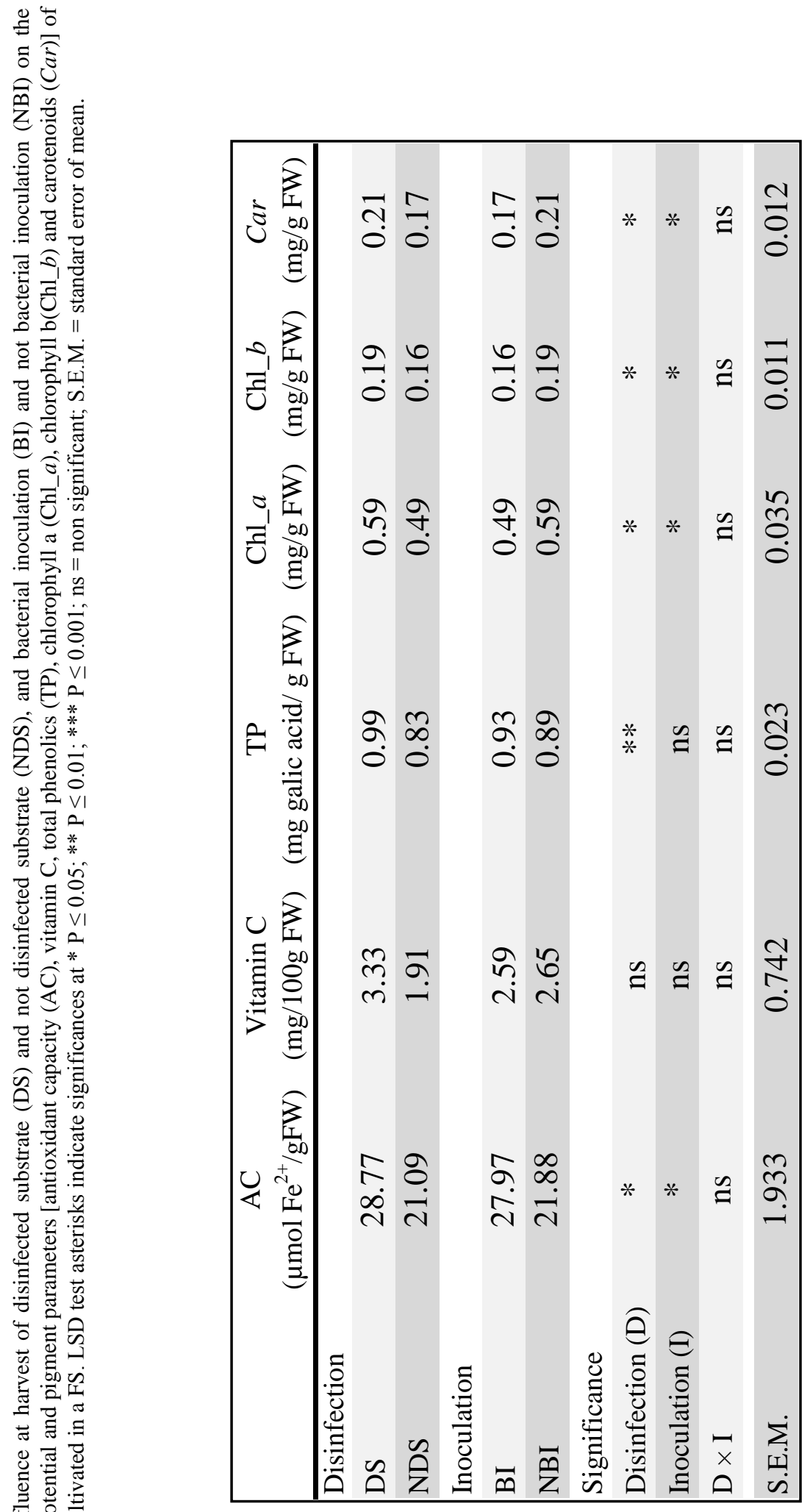



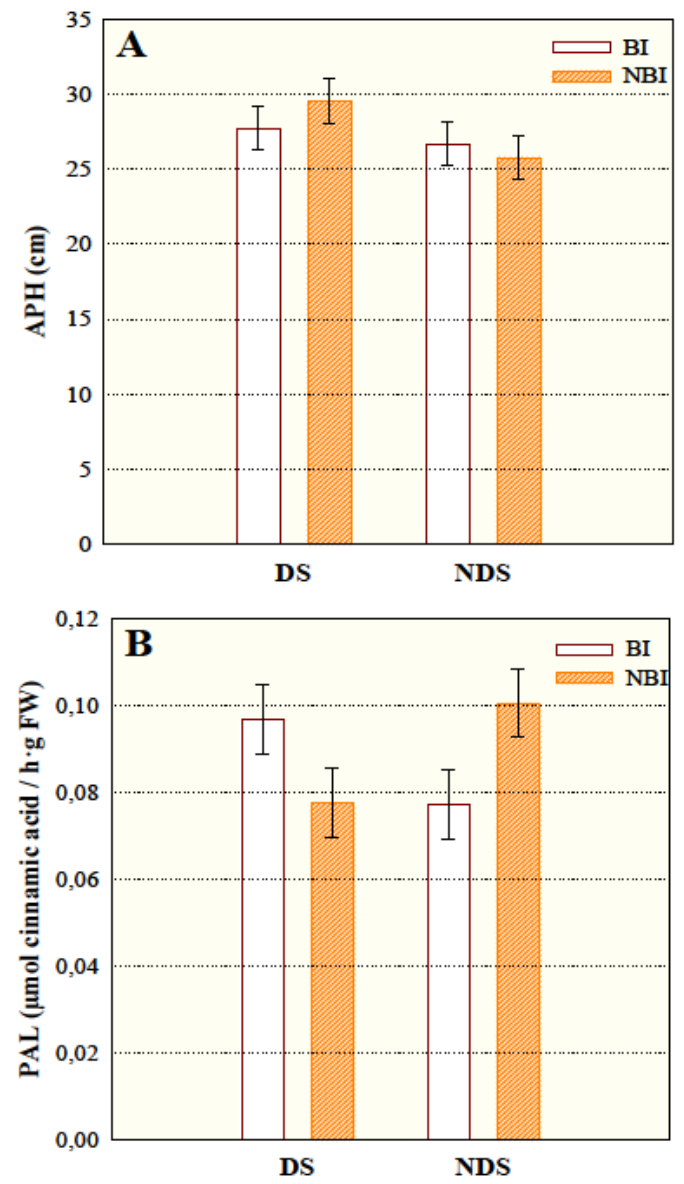

Figure 11: Effect of the disinfection of substrate - disinfected substrate (DS) and not disinfected substrate (NDS) - on shoot height (SPH) (A) and PAL (phenylalanine ammonia lyase) (B) in watercress cultivated in a floating system, either $B$. subtilis inoculation - bacterial inoculation (BI) and not bacterial inoculation (NBI) - Values are the mean of three replicates and vertical lines are the least significant difference (LSD) intervals at $\mathrm{P} \leq 0.05$.

Table 20: Influence at harvest of disinfected substrate (DS) and not disinfected substrate (NDS), and bacterial inoculation (BI) and not bacterial inoculation (NBI) on the phenolic oxidation parameters [browning potential (BP), soluble o-quinone (So-Q), peroxidase (POD), polyphenol oxidase (PPO) andphenylalanine ammonia lyase (PAL)] of watercress cultivated in a FS. LSD test asterisks indicate significances at $* \mathrm{P} \leq 0.05$; $* * \mathrm{P} \leq 0.01 ; * * * \mathrm{P} \leq 0.001$; ns $=$ non significant; $\mathrm{S}$.E.M. $=$ standard error of mean.

\begin{tabular}{|c|c|c|c|c|c|}
\hline & $\begin{array}{c}\text { PAL } \\
(\mu \text { molcinnamic acid/h g FW) }\end{array}$ & $\begin{array}{c}\text { PPO } \\
\left(\Delta \mathrm{A}_{470} / \mathrm{g} F W\right)\end{array}$ & $\begin{array}{c}\text { POD } \\
\text { (Unit/g FW) }\end{array}$ & $\begin{array}{c}\text { So-Q } \\
\left(\Delta \mathrm{A}_{437} / \mathrm{g} \mathrm{FW}\right)\end{array}$ & $\begin{array}{c}\mathrm{BP} \\
\left(\Delta \mathrm{A}_{340} / \mathrm{g} F W\right)\end{array}$ \\
\hline \multicolumn{6}{|l|}{ Disinfection } \\
\hline DS & 0.09 & 5.67 & 3.05 & 0.3 & 0.68 \\
\hline NDS & 0.09 & 7.42 & 3.26 & 0.55 & 0.8 \\
\hline \multicolumn{6}{|l|}{ Inoculation } \\
\hline BI & 0.09 & 5.8 & 3.21 & 0.34 & 0.7 \\
\hline NBI & 0.09 & 7.29 & 3.11 & 0.51 & 0.78 \\
\hline \multicolumn{6}{|l|}{ Significance } \\
\hline Disinfection (D) & $\mathrm{ns}$ & ns & ns & $\mathrm{ns}$ & $\mathrm{ns}$ \\
\hline Inoculation (I) & ns & ns & ns & ns & $\mathrm{ns}$ \\
\hline $\mathrm{D} \times \mathrm{I}$ & * & ns & ns & ns & ns \\
\hline S.E.M. & 0.008 & 1.360 & 0.158 & 0.146 & 0.095 \\
\hline
\end{tabular}


Table 21: Influence at harvest of disinfected substrate (DS) and not disinfected substrate (NDS), and bacterial inoculation (BI) and not bacterial inoculation (NBI) on the microbial growth [total bacterial count (TBC), yeast count (YC) and mould count (MC)] of watercress cultivated in a FS. LSD test asterisks indicate significances at $* \mathrm{P} \leq 0,05 ;{ }^{* *} \mathrm{P} \leq 0,01 ; * * * \mathrm{P} \leq 0,001 ; \mathrm{ns}=$ non significant; S.E.M. - standard error of mean

\begin{tabular}{|lccc|}
\hline & $\begin{array}{c}\text { TBC } \\
\text { (Log CFU/g FW) }\end{array}$ & $\begin{array}{c}\text { MC } \\
(\text { Log CFU/g FW) }\end{array}$ & $\begin{array}{c}\text { YC } \\
\text { Disinfection CFU/g FW) }\end{array}$ \\
\hline DS & 3.41 & 2.05 & 1.58 \\
NDS & 3.07 & 2.31 & 1.75 \\
Inoculation & & & \\
BI & 3.09 & 2.21 & 1.66 \\
NBI & 3.4 & 2.15 & 1.67 \\
Significance & & & \\
Disinfection (D) & $\mathrm{ns}$ & $*$ & $\mathrm{~ns}$ \\
Inoculation (I) & $\mathrm{ns}$ & $\mathrm{ns}$ & $\mathrm{ns}$ \\
D $\times$ I & $\mathrm{ns}$ & $\mathrm{ns}$ & $\mathrm{ns}$ \\
S.E.M. & 0.204 & 0.073 & 0.322 \\
\hline
\end{tabular}

\section{Microbial growth}

Disinfection of the substrate only affected mould CFU in watercress at harvest (Table 21). The MC was significantly higher under the NDS factor effect, demonstrating that disinfection provided a slight control of mould population. In addition, there were no differences in the TBC between BI and NBI (Table 21), meaning that neither inoculation of the seeds nor of the substrate would affect the microbiological quality of the final product.

In conclusion, disinfection of the substrate had a positive effect on the development of the watercress because it increased the shoot AC and general plant growth and decreased the CFU of moulds. Inoculation with B. subtilis had a less pronounced effect, since it increased the AC and decreased the content of Chl $a$, Chl $b$ and $C a r$. 


\section{GENERAL CONCLUSIONS}




\section{AERATION EXPERIMENTS}

\section{Chapter 1}

- Purslane plants showed little sensitivity to oxygen depletion in the root medium, and were able to adapt to a gradual reduction in level, creating an aerenchyma.

- However, aeration is advisable to increase yields, although the final quality of the product, in terms of nitrate levels, the concentrations of functional phytochemicals, and SPAD values, may be slightly lower.

\section{Chapter 2}

- For watercress the floating system is a very important preventive tool to obtain cleaner raw material due to, among other things, the low microbiological contamination.

- Spring season seemed to be more suitable than the winter season to reach high yield and quality, possibly as a result of high light and temperature conditions available. Thus, watercress plants from the spring cycle in general had higher yield, $\mathrm{AC}$, and $\mathrm{Ca}^{2+}$ and $\mathrm{K}^{+}$ contents and lower oxalate content.

- A lack of aeration has slightly improved the quality of the final product, which was richer in vitamin $\mathrm{C}$ and antioxidants and had lower nitrate content.

\section{Chapter 3}

- Red lettuce cultivated in floating system is tolerant to the lack of aeration of the nutrient solution.

- Aeration did not affect yield, reaching the higher productivity in autumn.

- The effect of aeration in the majority of the quality parameters measured was determinate by the growing cycle.

The sensibility to oxygen depletion depends on the species and on the growing cycle. In general, lack of oxygen reduces nitrate content and increases the phytochemical compounds. For this reason, it is necessary to look for a 
compromise situation in which the quality of the product as a ready to eat could increase without affecting the yield.

\section{PGPR EXPERIMENTS}

\section{Chapter 4}

- The use of the lower doses of $\mathrm{N}$ in the nutrient solution reduced the nitrate content in leaves lettuce.

- The application of $B$. velezensis in nutrient solution provoked a decrease of nitrate content in leaves respect to control, mainly in red lettuce plants, probably due to the use of nitrates by bacterium in an anaerobic respiration process.

- The level of $\mathrm{N}$ and the PGPRs application did not influence the root growth in any crop cycle.

\section{Chapter 5}

- The disinfection of the substrate had a positive effect on the development of the watercress because it increased the shoot $\mathrm{AC}$ and general plant growth and decreased the CFU of moulds.

- Inoculation with $B$. subtilis had a less pronounced effect, since it increased the $\mathrm{AC}$ and decreased the content of $\mathrm{Chl} a, \mathrm{Chl} b$ and Car.

The use of PGPR studied not significantly affect the growth of plants grown in floating system although its activity can reduce nitrate accumulation and increase functional phytochemicals. 


\section{REFERENCES}


REFERENCES

Abadias, M., Usall, J., Anguera, M., Solsona, C., Viñas, I., 2008. Microbiological quality of fresh, minimally-processed fruit and vegetables and sprouts from retail establishments. International Journal of Food Microbiology, 123: 121-129.

Aberoumand, A. 2011. Major antinutrients and phytochemical investigation found in an iranian edible plant source. Journal of Natural Product and Plant Resources, 1 (2):56-61.

Acidoascórbico. Mecanismo antioxidante del ácido ascórbico. http://www.acidoascorbico.com/mecanismo_antioxidante_del_cido_ascrbico

Ahemad, M., Kibret, M. 2014. Mechanisms and applications of plant growth promoting rhizobacteria: Current perspective. Journal of King Saud University - Science, 26: $1-20$.

Ainiadisal. Diseño en el sector agroalimentario. Diseño hortofrutícola. http://www.ainiadisal.es/publico/docs/Prospecci\%C3\%B3n\%20y\%20tendencias $\% 20 I V \% 20$ gama.pdf

Ala, F., Ismail, S., Ahmad, R., Shaheen, R. 1995. Effects of salinity and waterlogging on physiological processes and ionic regulation in Atriplex amnicola. Pakistan Journal Of Botany, 27, 283-295.

Alwi, S.S., Cavell, B.E. , Telag, U. 2010. In vivo modulation of 4E binding protein I (4EBPI) phosphorylation by watercress: A pilot study. British Journal of Nutrition, 104: 1288-1296.

Andriolo, J.L. 1999. Fisiologia da produção de hortaliças em ambiente protegido. Horticultura Brasileira, 18: 26-33.

Armstrong, W. 1979. Aeration in higher plants. Advances in Botanical Research, 7: 225332.

Armstrong, W., Webb, T., Darwent, M., Beckett, P. M. 2009. Measuring and interpreting respiratory critical oxygen pressures in roots. Annals Of Botany, 103: 281-293.

Artés, F., Artés-Hernández, F. 2000. Innovaciones industriales en el procesado mínimo de frutas y hortalizas. CTC. Revista Agroalimentación e Industrias Afines, 7: 2933.

Artés-Hernández, F., Artés, F. 2005. Concepción y ejecución de instalaciones industriales para el procesado mínimo en fresco de productos vegetales. Nuevas tecnologías de conservación de productos vegetales frescos cortados. Gonzalez- 
REFERENCES

Aguilar, G., Gardea, A. A., Cuamea, F. (eds). CIAD-CYTED-CONACYT: 456472 .

Avis T.J., Gravel V., Antoun H., Tweddell R.J. 2008. Multifaceted beneficial effects of rhizosphere microorganisms on plant health and productivity. Soil Biology \& Biochemistry,40: 1733-1740.

Bailey-Serres, J., Chang, R. 2005. Sensing and signalling in response to oxygen deprivation in plants and other organisms. Annals of Botany, 96 (4): 507-518.

Baixauli, C., Aguilar J.M. 2002. Cultivo sin Suelo de Hortalizas: Aspectos Prácticos y Experiencias. Consellería d'Agricultura, Peixca i Alimentació. Generalitat Valenciana. Sèrie Divulgació Técnica, 53: 110.

Balanza, V., Martínez, J.A., Conesa, E., Egea-Gilabert, C., Niñirola, D., López-Marín, J., González, A., Fernández, J.A. 2012. Effect of PGPR application and nitrogen doses on baby leaf lettuce grown in a floating system. Acta Horticulturae, 952: 679-687.

Balsano, C., Alisi, A. 2009. Antioxidant effects of natural bioactive compounds. Current Pharmaceutical Design, 15(26): 63-73.

Barreto-Figuereido, M.V., Seldin, L., Araujo, F.F., Ramos, R.L. 2010. Plant growth promoting rhizobacteria: Fundamentals and applications. D.K. Maheshwari (ed.), Plant Growth and Health Promoting Bacteria, Microbiology Monographs 18. Springer Verlag Berlin Heidelberg: 21-43.

Barrett-Lennard, E. G. 2003. The interaction between waterlogging and salinity in higher plants: causes, consequences and implications. Plant Soil, 253: 35-54.

Beaudry, R.M. 2007. MAP as a basis for active packaging. In: Wilson C.L. (ed.), Intelligent and active packaging of fruits and vegetables. Boca Raton, FL: CRC Press: 31-55.

Beaulieu, J.C. 2011. Factors affecting sensory quality of fresh-cut produce. Advances in fresh-cut fruits and vegetables processing. Taylor and Francis Group: 115-143.

Beauregard, P. B., Chai, Y., Vlamakis, H., Losick, R., Kolter, R. 2013. Bacillus subtilis biofilm induction by plant polysaccharides. Proceedings of the National Academy of Sciences, 110 (17): 21-30.

Benavides-Mendoza, A., Ramírez, H. Robledo-Torres, V. Fuentes-Lara, L.O. 2009. Antioxidantes en las plantas: algunos factores edáficos y ambientales que los 
REFERENCES

modifican. En: A. Benavides-Mendoza (Compilador). Temas Modernos de Nutrición Vegetal, A.C.. Sociedad Mexicana de la Ciencia del Suelo, A.C. Texcoco, México: 13-26.

Benzie, I. F.F., Strain, J. J. 1996.The ferric reducing ability of plasma (FRAP) as a measure of "antioxidant power": The FRAP assay. Analytical Biochemistry, 239: 70-76.

Bianco, V. 1990. Lattuga ( Lactuca sativa L.). En: Orticoltura. Ed.: Patron, Bologna, Italia: 270-319.

Bianco, V.V., Santamaria, P., Elia, A., Rubatzky, V.E. (ed.), Hang, C. (ed.), Peron J.Y. 1998. Nutritional value and nitrate content in edible wild species used in southern Italy. Acta Horticulturae, 467: 71-87.

Bielmelt, S., Keetman, U., Albrecht, G. 1998. Re-aeration following hypoxia or anoxia leads to activation of the antioxidative defense system in roots of wheat seeding. Plant Physiology, 116: 651-658.

Blokhina, O., Virolainen, E. And Fagerstedt, K. V., 2003 antioxidants, oxidative damage and oxygen deprivation stress: A review. Annals Of Botany, 91: 179-194.

Bojović, M., Stojanović, J. 2005. Chlorophyll and carotenoid content in wheat cultivars as a function of mineral nutrition. Archives of Biological Sciences, 57 (4): 283290.

Bonasia, A., Conversa G., Lazzizera, C., Elia, A. 2013. Pre-harvest nitrogen and Azoxystrobin application enhances postharvest shelf-life in butterhead lettuce. Postharvest Biology and Technology, 85: 67-76.

Brand-Williams, W., Cuvelier, M.E., Berset, C. 1995. Use of a free radical method to evaluate antioxidant activity. Lebensmittel-Wissenschaft und-Technologie, 28: 25-30.

Burns, I.G., Zhang, K., Turner, M.K., Meacham, M., Al-Redhiman, K., Lynn, J., Broadley, M.R., Hand, P., Pink, D. 2011. Screening for genotype and environment effects on nitrate accumulation in 24 species of young Lettuce. Journal of the Science of Food and Agriculture, 91: 553-562.

Buwalda, F., Barrett-Lennard, E. G., Greenway, H., Davies, B.A. 1988. Effects of growing wheat in hypoxic nutrient solutions and of subsequent transfer to aerated 
solutions. II. Concentrations and uptake of nutrients and sodium in shoots and roots. Australian Journal of Plant Physiology, 15: 599-612.

Campbell Scientific, CS512 Oxyguard Type III. Dissolved Oxygen Probe, 2006. http://s.campbellsci.com/documents/us/manuals/cs512-1.pdf

Campos, R., Nonogaki, H., Suslow, T., Saltveit, M. E. 2004. Isolation and characterization of a wound inducible phenylalanine ammonia-lyase gene (LsPAL1) from Romaine lettuce leaves. Physiologia Plantarum, 121: 429 -438.

Carrasco, G., Gajardo, J.M., Álvaro, J.E., Urrestarazu, M. 2011. Rocket production (Eruca sativa Mill.) in a floating system using peracetic acid as oxygen source compared with substrate culture. Journal of Plant Nutrition, 34: 1397-1401.

Chapman, J., Stewart R.B., Yarnell R.A. 1974. Archaeological evidence for preColumbian introduction of Portulaca oleracea and Mullugo verticillata into eastern North America. Economic Botany, 28: 411-412

Clarkson, G.J.J., O’Byrne, E.E., Rothwell, S.D., Taylor, G. 2003. Identifying traits to improve postharvest processability in baby leaf salad. Postharvest Biology and Technology, 30: 287-298.

Colmer, T.D., Voesenek, L.A.C.J. 2009. Flooding tolerance: Suites of plant traits in variable environments. Functional Plant Biology, 36: 665-681.

Conesa, E., Lara, L.J., Niñirola, D., Ochoa, J., Fernández, J.A. 2009a. Efecto de la dosis de nitrógeno sobre el desarrollo y el contenido de nitratos y oxalatos en colleja cultivada en bandejas flotantes. III Jornadas del Grupo de Fertilización de la SECH. El Ejido (Almería).

Conesa, E., Niñirola, D., Vicente, M. J., Ochoa, J., Bañón, S., Fernández, J. A. 2009b. The influence of nitrate/ammonium ratio on yield quality and nitrate, oxalate and vitamin c content of baby leaf spinach and bladder campion plants grown in a floating system. Acta Horticulturae, 843: 269-274.

Conte, A., Conversa, G., Scrocco, C. , Brescia, I. , Laverse, J. , Elia, A., Del Nobile, M.A. 2008. Influence of growing periods on the quality of baby spinach leaves at harvest and during storage as minimally processed produce. Postharvest Biology and Technology, 50: 190-196.

Corrêa, E.B., Bettiol, W., Sutton, J.C. 2010. Biocontrol of root rot (Pythium aphanidermatum) and growth promotion with Pseudomonas chlororaphis 63-28 
REFERENCES

and Bacillus subtilis GB03 in hydroponic lettuce. Summa Phytopathologica, 36 (4): $275-281$.

Couture, R, Cantwell, M.I., Ke, D., Saltveit, M.E. 1993. Physiological attributes related to quality attributes and storage life of minimally processed lettuce. Hortscience 28(7): 723-725.

Cros, V., Martínez-Sánchez, J. J. And Franco, J. A. 2007. Good Yield Of Common Purslane With High Fatty Acid Content Can Be Obtained In A Peat-Based Floating System. HortTechnology, 17: 14-20.

Cros, V., Nicola, S., Fernández, J. A., Martínez, J. J., Carreño, S. 2003. Cultivo de hortalizas en bandejas flotantes: Sistema de riego y control de la solución nutritiva. Revista Agrícola Vergel, 268: 20-26.

Degl'Innocenti, E., Guidi, L., Pardossi, A., Tognoni, F. 2005. Biochemical study of leaf browning in minimally processed leaves of lettuce (Lactuca sativa L. Var. Acephala). Journal of Agricultural and Food Chemistry, 53: 80-84

Dere, S., Günes, T., Sivaci, R. 1998. Spectrophotometric determination of chlorophyll $\mathrm{a}, \mathrm{b}$ and total carotenoid contents of some algae species using different solvents. Trends Journal of Botany, 22: 13-17.

Doğan, S., Salman, Ü. 2007. Partial characterization of lettuce (Lactuca sativa L.) polyphenol oxidase. European Food Research and Technology, 226 (1-2): 93103.

Du, G., Li, M., Ma, F., Liang, D. 2009. Antioxidant capacity and the relationship with polyphenol and Vitamin C in Actinidia fruits. Food Chemistry, 113 (2): 557-562.

EC (European Commission), 2004. Commission Regulation (EU) No 852/2004 of 29 April 2004 amended Regulation (EC) No. 1019/2008 of 17 October 2008 and Regulation (EC) No. 219/2009 of 11 March 2009. Official Journal of the European Union. L139: 1-12.

EC (European Commission), 2007. Commission Regulation (EU) No 1441/2007 of 5 December 2007 amending Regulation (EC) No. 2073/2005. of 15 November 2005 on microbiological criteria for foodstuffs. Official Journal of the European Union. L322: 12-29.

EC (European Commission), 2011. Commission Regulation (EU) No 1258/2011 of 2 December 2011 amending Regulation (EC) No 1881/2006 as regards maximum 
levels for nitrates in foodstuffs. Official Journal of the European Union. L320: 15-17.

Egea-Gilabert, C., Fernández, J.A., Migliaro, D., Martínez-Sánchez, J.J., Vicente, M.J. 2009. Genetic variability in wild vs. cultivated Eruca vesicaria populations as assessed by morphological, agronomical and molecular analyses. Scientia Horticulturae, 121: 260-266.

Escaff, M., Saavedra, G., Blanco, C. 2006. La demanda de alimentos funcionales fuente de nutracéuticos. Tierra Adentro Nov-Dic 2006: 12 - 14.

Evans, D. 2003.Aerenchyma formation. New Phytologist, 161: 35-49.

FAOSTAT. Organización de las Naciones Unidas para la Alimentación y la Agricultura. Dirección de Estadística. http://faostat3.fao.org/browse/Q/*/S (Accessed January 2014).

Favela, E., Preciado, P., Benavides, A. 2006. Manual para la preparación de soluciones nutritivas. Departamento de Horticultura. Universidad Autónoma Agraria Antonio Narro. http://www.nutricaodeplantas.agr.br.

Fernández, J.A., Esteban, A., Conesa, E., Ochoa, J., Álvarez-Rogel, J. 2012. Nitrate evolution in soil, leaching water, and lettuce plant crops using different fertilization strategies. Communications in Soil Science and Plant, 43: 24672483.

Fernández, J.A., Niñirola, D., Vicente, M.J., Conesa, E., López, J, González, A. 2007. Efecto de la densidad de plantación y del tipo de sustrato sobre la producción de verdolaga (Portulaca oleracea L.) en un cultivo hidropónico de bandejas. XXXVII Seminario de Técnicos y Especialistas en Horticultura en Almería: 707714.

Ferrante, A., Incrocci, L., Maggini, R., Tognoni, F. 2003. Preharvest and postharvest strategies for reducing nitrate content in rocket (Eruca sativa). Acta Horticulturae, 628: 153-159.

Fontana, E., Nicola, S. 2004. Producing garden cress (Lepidium sativum L.) for the freshcut chain using a soilless culture system. The Journal of Horticultural Science and Biotechnology, 83: 23-32. 
REFERENCES

Fontana, E., Nicola, S., Hoeberechts, J., Saglietti, D. 2003. Soilless culture systems produce ready-to-eat corn salad (Valerianella olitoria L.) of high quality. Acta Horticulturae, 604: 505-509.

Franco, J. A., Cros, V., Vicente M. J., Martínez-Sánchez, J. J. 2011. Effects of salinity on the germination, growth, and nitrate contents of purslane (Portulaca oleracea L.) Cultivated under different climatic conditions. Journal Of Horticultural Science \& Biotechnology, 86: 1-6.

Fu, Q., Liu, Ch., Ding, N., Lin, Y. and Guo, B. 2010. Ameliorative effects of inoculation with the plant growth-promoting rhizobacterium Pseudomonas sp. DW1 on growth of eggplant (Solanum melongena L.) seedlings under salt stress. Agricultural Water Management, 97: 1994-2000.

Fukao, T., Bailey-Serres, J. 2004. Plant responses to hypoxia is survival a balancing act? Trends in Plant Science, 9: 449-456.

Galloway, B.A., Monks, D.W., Schultheis, J.R. 2000. Effect of herbicides on pepper (Capsicum annuum) stand establishment and yield from transplants produced using various irrigation systems. Weed Technology, 14: 241-245.

Garcia-Macias, P., Ordidge, M., Vysini, E., Waroonphan, S., Battey, N.H., Gordon, M.H., Hadley, P., John, P., Lovegrove, J.A., Wagstaffe, A. 2007. Changes in the flavonoid and phenolic acid contents and antioxidant activity of red leaf lettuce (Lollo Rosso) due to cultivation under plastic films varying in ultraviolet transparency. Journal of Agricultural and Food Chemistry, 55: 68-72.

Garcia-Novo, F., Crawford, R. M. M. 1973. Soil aeration, nitrate reduction and flooding tolerance in higher plants. New Phytologist, 72: 31-39.

Garrett, E.H. 1998 . Fresh-cut produce. Principles and applications of M.A.P. of food. Aspen publication. 2nd edition: 125-131.

Garti, N., Slavin, Y., Aserin, A. 1999. Surface and emulsification properties of a new gum extracted from Portulaca oleracea L. Food Hydrocolloids, 13(2): 145-155.

Gaudreau, L., Charbonneau, J., Vezina, L.P., Gosselin, A. 1995. Effects of photoperiod and photosynthet1c photon flux on nitrate content and nitrate reductase activity in greenhouse- grown lettuce. Journal of Plant Nutrition, 18: 437-453.

Gazula, A., Kleinhenz, M.D., Scheerens, J.C., Ling, P.P. 2007. Anthocyanin levels in nine lettuce (Lactuca sativa) cultivars: influence of planting date and relations 
among analytic, instrumented, and visual assessments of colour. Hortscience, 42:232-238.

Gimeno, C. E. 2004. Compuestos fenólicos. Un análisis de sus beneficios para la salud. Nutrición, 23(6): 80-84.

Going, B., Simpson, J., Even, T. 2008. The influence of light on the growth of watercress (Nasturtium officinale R. Br.). Hydrobiologia, 607: 75-85.

Gökmen, V., Kahraman, N., Demir, N., Acar, J. 2000. Enzymatically validated liquid chromatographic method for the determination of ascorbic and dehydroascorbic acids in fruit and vegetables. Journal of Chromatography A, 881: 309-316.

Gonnella, M., Charfeddine, M., Conversa, G., Elia, A., Santamaria, P. 2002. Riduzione del contenuto di nitrato in floating system Colture Prottete, 12: 38-41.

Gonnella, M., Charfeddine, M., Conversa, G., Santamaria, P. 2010. Purslane: A review of its potential for health and agricultural aspects. The European Journal Of Plant Science And Biotechnology.

Gonnella, M., Conversa, G., Santamaria, P., Serio, F. 2004. Production and nitrate content in lamb's lettuce grown in floating system. Acta Horticulturae, 644: 6168.

González, A., Abellán, M.A., López, J. and Fernández, J.A. 2004. Aprovechamiento de especies de hoja pequeña, "baby leaf", para IV gama, en cultivo en invernadero. Agrícola Vergel, 272:399-408.

Goto, E. 1996. Effect of dissolved oxygen concentration on lettuce growth in floating hydroponics. Proc. Int. Sym. Plant Production in Closed Ecosystems. Acta Horticulturae, 440: 205-210.

Grieve, C.M., Suarez, D.L. 1997. Purslane (Portulaca oleracea L.): A halophytic crop for drainage water reuse systems. Plant and Soil, 192(2): 277-283.

Gruda, N. 2005. Impact of environmental factors on product quality of greenhouse vegetables for fresh consumption. Critical Reviews in Plant Sciences, 24: $227-$ 247.

Gül, A., Kidoglu, F., Tüzel, Y., Tüzel, I.H. 2008. Effects of nutrition and Bacillus amyloliquefaciens on tomato (Solanum lycopersicum L.) growing in perlite. Spanish Journal of Agricultural Research, 6: 422-429. 
REFERENCES

Han, H.S., Lee K.D. 2005. Plant growth promoting rhizobacteria effect on antioxidant status, photosynthesis, mineral uptake and growth of lettuce under soil salinity. Research Journal of Agriculture and Biological Sciences, 1 (3): 210-215

Hardenburg, R.E., Watada, A.E., Wang, C.Y. 1986. The commercial storage of fruits, vegetables, and florist and nursery stocks. United States Department of Agriculture Agricultural Research Service. Handbook, 66: 12-62.

Harwood, R. R., Bantilan, R.T. 1974. Integrated weed management. 2. Shifts in composition of the weed community on intensive cropping systems. Philippines Weed Science Bulletin, 1: 37-59.

He, Q., Luo, Y. 2007. Enzymatic browning and its control in fresh-cut produce. Stewart Postharvest Review, 3 (6): 1-7.

Heidari, M., Golpayegani, A. 2012. Effects of water stress and inoculation with plant growth promoting rhizobacteria (PGPR) on antioxidant status and photosynthetic pigments in basil (Ocimum basilicum L.). Journal of the Saudi Society of Agricultural Sciences, 11: 57-61

Hernández, J.E., León, J. 1994. Neglected Crops 1492 from a different perspective. J.E. Bermejo y J. León, eds. FAO Plant Production and protection series, 26.

Hinojosa, A., Silveira, A.C., Ospina, M., Char, C. , Sáenz, C., Escalona, V. 2013. Safety of ready-to-eat watercress using environmentally friendly sanitization methodsJournal of Food Quality, 36: 66-76.

http://www2.inia.cl/medios/biblioteca/ta/NR34013.pdf

Igamberdiev, A. U., Hill, R. D. 2004. Nitrate, NO and haemoglobin in plant adaptation to hypoxia: an alternative to classic fermentation pathways. Journal of Experimental Botany, 55: 73-82.

Jackson, M. B. 2008. Ethylene-promoted elongation: An adaptation to submergence stress. Annals Of Botany, 101: 229-248.

Jain, A.K., Nessler, C.L. 2000. Metabolic engineering of an alternative pathway for ascorbic acid biosynthesis in plants. Molecular Breeding. Kluwer Academic Publishers, 6(1): 73-78.

Jampeetong, A., Brix, H. 2009. Oxygen stress in Salvinia natans: Interactive effects of oxygen availability and nitrogen source. Environmental and Experimental Botany, 66: 153-159. 
Kader, A.A. and Saltveit, M.E. 2003. Respiration and gas exchange. In Bartz, J. \& Brecht, J., eds. Post-harvest physiology and pathology of vegetables. 2nd edition. Marcel Dekker Inc, New York, NY.

Kader, A.A., Zagory, D., Kerbel, E.L. 1989. Modified atmosphere packaging of fruits and vegetables. Critical Reviews in Food Science and Nutrition, 28 (1): 1-30.

Kara, Y. 2006. Bioaccumulation of $\mathrm{Cu}, \mathrm{Zn}$ and $\mathrm{Ni}$ from the wastewater by treated Nasturtium officinale. International Journal of Environment Science and Technology, 2 (1): 63-67.

Karimi, S. H., Ungar, I. A. 1986. Oxalate and inorganic ion concentrations in Atriplex triangularis Willd. Organs in response to salinity, light level, and aeration. Botanical Gazette, 147: 65-70.

Kaşkar, C., Fernández, J. A., Ochoa, J., Niñirola, D., Conesa, E., Tüzel, Y. 2009. Agronomic behaviour and oxalate and nitrate content of different purslane cultivars (Portulaca Oleracea) grown in a hydroponic floating system. Acta Horticulturae, 807: 521-526.

Kaskey, J.B.,Tindall, D.R. 1979. Physiological aspects of growth and heteroblastic development of Nasturtium officinale under natural conditions. Aquatic Botany, 7: 209-229.

Kleinhenz, M.D., D.G. French, A. Gazula, and J.C. Scheerens. 2003. Variety, shading and growth stage effects on pigment concentrations in lettuce grown under contrasting temperature regimens. HortTechnology, 13:677-683.

Kloepper, J.W., Hume, D.J., Scher, F.M., Singleton, C., Tipping, B., Laliberte, M., Frauley, K., Kutchaw, T., Simonson, C., Lifshitz, R., Zaleska, I., Lee, L. 1988. Plant growth-promoting rhizobacteria on canola (rapeseed). Plant Disease, 72: 42-46.

Konstantopoulou, E., Kapotis, G., Salachas, G., Petropoulos, S.A., Karapanos, I.C., Passam, H.C. 2010. Nutritional quality of greenhouse lettuce at harvest and after storage in relation to $\mathrm{N}$ application and cultivation season. Scientia Horticulturae, 125: 93.e1-93.e5

Kumar A., Prakash A., Johri B.N. 2011. Bacillus as PGPR in crop ecosystem. In: Maheshwari D.K. (ed.), Bacteria in Agrobiology: Crop Ecosystems. Berlin, Heidelberg, Springer-Verlag: 37-59. 
REFERENCES

Lara, L., Egea-Gilabert, C., Niñirola, D., Conesa, E., Fernández, J.A. 2011. Effect of aeration of the nutrient solution on the growth and quality of purslane (Portulaca oleracea). The Journal of Horticultural Science and Biotechnology, 86: 603-610.

Latham, M.C. 2002. Nutrición humana en el mundo en desarrollo. Organización de las Naciones Unidas para la Agricultura y la Alimentación. Capítulo 11. http://www.fao.org/docrep/006/w0073s/w0073s0f.htm

Lau, M., Swanson, B. 2000. Kinetics of textural and colour changes in green asparagus during thermal treatments. Journal of Food Engineering, 45: 231-236.

Lazof, D.B., Bernstein, N. 1999. Effects of salinization on nutrient transport to lettuce leaves: consideration of leaf developmental stage. New Phytologist, 144: 85-94.

Lee, S.K., Kader, A.A. 2000. Preharvest and postharvest factors influencing vitamin C content of horticultural crops. Postharvest Biology and Technology, 20: 207-220.

Lester, G.E., Jifon, J.L., Makus, D.J. 2010. Impact of potassium nutrition on postharvest fruit quality: Melon (Cucumis melo L) case study. Plant and Soil, 335 (1-2); $117-$ 131.

Libert, B., Franceschi, V. R. 1987. Oxalate in crop plants. Journal of Agricultural and Food Chemistry, 35(6): 926-938.

Lichtenthaler, H.K., Wellburn, A.R. 1983. Determinations of total carotenoids and chlorophylls $a$ and $b$ of leaf extracts in different solvents. Biochemical Society Transactions 11: 591-592.

Lind, O.T. 1974. Handbook of common methods in limnology. C.V. Mosby, Saint Louis, Missouri.

Liu, W., Chen, D. 2010. Bacillus subtilis for salt stress relief in vegetable cultivation. Acta Horticulturae, 856: 237-242.

Liu, X., Ardo, S., Bunning, M., Parry, J., Zhou, K., Stushnoff, C., Stoniker, F., Yu, L., Kendall, P. 2007. Total phenolic content and DPPH radical scavenging activity of lettuce (Lactuca sativa L.) grown in Colorado. LWT - Food Science and Technology, 40 (3): 552-557.

Llorach, R., Martínez-Sánchez, A., Tomás-Barberán, F.A., Gil, M.I. , Ferreres, F. 2008. Characterisation of polyphenols and antioxidant properties of five lettuce varieties and escarole. Food Chemistry, 108: 1028-1038. 
Loaiza-Velarde, J.G., Saltveit, M.E., 2001. Heat shocks applied either before or after wounding reduce browning of lettuce leaf tissue. Journal of the American Society for Horticultural Science, 126: 227-234.

Lobo, M.G., González, M. 2006. Estado actual de los productos mínimamente procesados en España. En: Actas del IV Congreso Nacional sobre Procesamiento Mínimo de Frutas y Hortalizas. I Simposio Iberoamericano de Vegetales Frescos Cortados. pp. 77-80.

Løkke, M.M., Fast Seefeldt, H., Skov, T., Edelenbos, M. 2013. Colour and textural quality of packaged wild rocket measured by multispectral imaging. Postharvest Biology and Technology, 75: 86-95.

Maathuis, F. J. 2014. Sodium in plants: Perception, signalling, and regulation of sodium fluxes. Journal of Experimental Botany, 65(3): 849-858.

Mallar, A. 1978. La lechuga. Temas de Agricultura,14. Ed.: Hemisferio Sur, Buenos Aires, Argentina, 61.

Manzocco, L., Foschia, M., Tomasi, M., Maifreni, M. 2011. Influence of hydroponic and soil cultivation on quality and shelf life of ready-to-eat lamb's lettuce (Valerianella locusta L. Laterr). Journal of the Science of Food and Agriculture, 91: 1373-1380.

Martínez-Sánchez, A., Allende, A., Cortés- Galera, Y., Gil, M.I. 2008. Respiration rate response of four baby Brassica species to cutting at harvest and fresh-cut washing. Postharvest Biology and Technology, 47: 382-388.

Martínez-Sánchez, A., Luna M.C., Selma M.V., Tudela J.A., Abad J., Gil M.I. 2012. Baby-leaf and multi-leaf of green and red lettuces are suitable raw materials for the fresh-cut industry. Postharvest Biology and Technology, 63: 1-10.

Martínez-Valverde, I., Periago, M.J., Ros, G. 2000. Unidad Docente de Bromatología e Inspección de Alimentos, Facultad de Veterinaria, Universidad de Murcia, España. Archivos Latinoamericanos de Nutricion, 50 (1): 5-18.

Mattheis, J.P., Fellman, J.K. 1999. Preharvest factors influencing flavor of fresh fruit and vegetables. Postharvest Biology and Technology, 15: 227- 232.

Meletti,1 N. 2006. L'innovazione di prodotto in orticoltura: il caso della IV gamma. Tesis doctoral. http://www.tesionline.com. 
REFERENCES

Michalsky, F., Hanke, A., Schnitzler, W.H. 1997. Ertrag und qualität von brunnenkresseim ebbe/flut-system. Gemüse, 33: 575-578.

Mohamed, A. I., Hussein, A. S. 1994. Chemical Composition Of Purslane (Portulaca oleracea). Plant Foods For Human Nutrition, 45: 1-9.

Morard, P., Silvestre, J. 1996. Plant injury to oxygen deficiency in the root environment of soilless culture: A review. Plant And Soil, 184: 243-254.

Morard, P., Silvestre, J., Lacoste, L., Caumes, E., Lamaze, T. 2004. Nitrate uptake and nitrite release by tomato roots in response to anoxia. Journal Of Plant Physiology, 161: 855-865.

Mousavizadeh, S.J., Sedaghathoor, S. 2011. Peroxidase activity in response to applying natural antioxidant of essential oils in some leafy vegetables Australian Journal of Crop Science, 5(4): 494-499.

Nickel, R.S., Cunningham, B.A. 1969. Improved peroxidase assay method using Leuco 2, 3', 6 trichloroendophenol and application to comparative measurements of peroxidase catalysis. Annals of Biochemistry, 27: 292-299.

Nicola, S., Tibaldi, G., Fontana, E. 2009. Freshcut produce quality: Implications for a systems approach. In: Florkowski, W.J., R.L. Shewfelt, B. Brueckner, and S.E. Prussia (eds.). Postharvest handling. 2nd Ed. Elsevier Inc. and Academic Press, Amsterdam, The Netherlands: 247-282.

Niñirola, D., Fernández, J.A., Conesa, E., Martínez, J.A., Egea-gilabert, C. 2014. Combined effects of growth cycle and different levels of aeration in nutrient solution on productivity, quality and shelf life of watercress (Nasturtium officinale R. Br.) plants. HortScience,49: 567-573.

Niranjan Raj, S., Shetty, H.S., Reddy, M.S. 2005. Plant growth promoting rhizobacteria: potential green alternative for plant productivity. In: Siddiqui Z.A. (ed.), PGPR: Biocontrol and Biofertilization. Dordrecht, Springer: 197-216.

Noctor, G., Foyer, C.H. 1998. Ascorbate and glutathione: Keeping active oxygen under control. Annual Review of Plant Physiology and Plant Molecular Biology, 49: 249-279. 
Noonan, S. C., Savage, G. P. 1999. Oxalate content of foods and its effect on humans. Asia Pacific Journal Of Clinical Nutrition, 8: 64-74.

Oh, M., Carey, E.E., Rajashekar, C.B. 2009. Environmental stresses induce healthpromoting phytochemicals in lettuce. Plant Physiology and Biochemistry, 47: $578-583$.

Olalde-Portugal, V., Mena-Violante, H.G. 2008. Rhizosphere microorganisms and their effect on fruit quality. In: Paliyath G., Murr D.P., Handa A.K., Lurie S. (eds.), Postharvest Biology and Technology of fruits, vegetables and flowers. Singapore, Wiley-Black Well: 360-372

Oliveira, I., Valentão, P., Lopes, R., Andrade, P. B., Bento, A., Pereira, J. A. 2009. Phytochemical characterization and radical scavenging activity of Portulaca oleraceae L. leaves and stems. Microchemical Journal, 92: 129-134.

Oliveira, M., Usall, J., Solsona, C., Alegre, I., Viñas, I., Abadias, M. 2010. Effects of packaging type and storage temperature on the growth of foodborne pathogens on shredded 'Romaine' lettuce. Food Microbiology, 27(3): 375-380.

Ozturk, F., Duman, F., Leblebici, Z., Temizgul, R. 2010. Arsenic accumulation and biological responses of watercress (Nasturtium officinale $\mathrm{R}$. Br.) exposed to arsenite. Environmental and Experimental Botany, 69(2): 167-174.

Padh, H. 1990. Cellular functions of ascorbic acid. Biochemistry and Cell Biology, 68 (10): 1166-1173.

Palaniswamy U.R., Bible B.B., McAvoy R.J. 2004. Oxalic acid concentrations in Purslane (Portulaca oleracea L.) is altered by the stage of harvest and the nitrate to ammonium ratios in hydroponics. Scientia Horticulturae, 102: 267-275.

Palaniswamy, U., R.J. McAvoy, Bible, B. 2000. Omega-3-fatty acid concentration in Portulaca oleracea L. is altered by nitrogen source in hydroponic solution. Journal of the American Society for Horticultural Science, 125: 190-194.

Palaniswamy, U.R., Bible, B.B., McAvoy, R.J. 2002. Effect of nitrate: ammonium nitrogen ratio on oxalate levels of purslane. Trends in new crops and new uses: 453-455. 
REFERENCES

Palaniswamy, U.R., McAvoy, R.J., Bible, B. 1997. Supplemental lighting before harvest increases phenethyl isothiocyanate in watercress under 8-hour photoperiod. HortScience, 31: 222-223.

Pardo, J.M., Quintero F.J. 2002. Plants and sodium ions: Keeping company with the enemy. Genome Biology, 3(6).

Pascual, M.R., Calderón, V. 2000. Microbiología alimentaria. Metodología analítica para alimentos y bebidas. Ed. Díaz de Santos: 13-16.

Paul, E.A., Clark, F.E. 1989. Soil Microbiology and Biochemistry. San Diego, Academic Press: 275.

Peiper, H. 2007. New hope for serious diseases. Safe goods publishing: 41-48.

Pellegrini, N., Serafini, M, Colombi, B., Del Rio, D., Salvatore, S., Bianchi, M., Brighenti, F. 2003. Total antioxidant capacity of plant foods, beverages and oils consumed in Italy assessed by three different in vitro assays. Journal of Nutrition, 133: 2812-2819.

Pimpini, F., Gianini, M. and Lazzarin, R. 2005. Ortaggi da foglia da taglio. Veneto Agricoltura. Legnaro.

Pimpini, F., Sambo, P. And Lunardi, G. 2000. Effects of nutritive solution electric conductibility $(\mathrm{Ec})$ on quality and yield of floating system cultivated rocket (Eruca Sativa Mill.). Atti V Giornate Scientifiche S.O.I., 1: 255-256.

Podile, A.R., Kishore, G.K. 2006. Plant growth-promoting rhizobacteria. In: Gnanamanickam S.S. (ed.), Plant-Associated Bacteria. Dordrecht, Springer: 195230.

Pompella, A; Visvikis, A; Paolicchi, A; Tata, V; Casini, A.F. 2003. The changing faces of glutathione, a cellular protagonist. Biochemical Pharmacology, 66 (8): 499503.

Poovaiah, B.W. 1986. Role of calcium in prolonging storage life of fruits and vegetables. Food Technology: 86-89.

Rajapakse, N., He, C., Cisneros-Zevallos, L., Davies Jr. F. T. 2009. Hypobaria and hypoxia affects growth and phytochemical contents of lettuce. Scientia Horticulturae, 122: 171-178. 
Reddy, M. S.; Ilao, R. I.; Faylon, P. S.; Dar, W. D.; Sayyed, R.; Sudini, H.; Kumar, K. V. K.; Armanda, A. 2013. Recent advances in biofertilizers and biofungicides (PGPR) for sustainable agriculture. Proceedings of 3rd Asian Conference on Plant Growth-Promoting Rhizobacteria (PGPR) and other Microbials, Manila, Philippines, 21-24 April, 2013: 568.

Rice-Evans, C. A., Miller, N. J., Paganga, G. 1997. Antioxidant properties of phenolic compounds. Trends In Plant Sciences, 2: 152-159.

Rodríguez-Hidalgo, S., Artés-Hernández, F., Gómez, P., Artés, F., Fernández, J.A. 2010a. Quality changes on minimally processed purslane baby leaves growth under floating trays system. Acta Horticulturae, 877: 641-648.

Rodríguez-Hidalgo, S., Artés-Hernández, F., Gómez, P., Fernández, J.A., Artés, F. 2010b. Quality of fresh-cut baby spinach grown under a floating trays system as affected by nitrogen fertilization and innovative packaging treatments. Journal of the Science of Food and Agriculture, 90: 1089-1097.

Rose, P., Faulkner, K., Williamson, G., Mithen, R. 2000. 7-Methylsulfinylheptyl and 8methylsulfinyloctyl isothiocyanates from watercress are potent inducers of phase II enzymes. Carcinogenesis, 21: 1983-1988.

Saltveit, M.E. 2000. Wound induced changes in phenolic metabolism and tissue browing are alterad by heat shock. Postharvest Biology and Technology, 21, 61-69.

Santamaria, P. 2006. Nitrate in vegetables: Toxicity, content, intake and EC regulation. Journal of the Science of Food and Agriculture, 86: 10-17.

Santamaria, P., Elia, A., Gonnella, M., Serio, F., Todazo, E. 1997. I fattori che influenza nol'accumulo dei nitrati negli ortaggi. L'Informatore agrario, 40: 117-121.

Santamaria, P., Valenzano, V. 2001. La qualità degli ortaggi allevati senza suolo. Italus Hortus, 8: 31-38.

Saubidet M. I., Fatta N., Barneix A.J. 2002. The effect of inoculation with Azospirillum brasilense on growth and nitrogen utilization by wheat plants. Plant and Soil, 245 (2): $215-222$

Seelig, R.A. 1974. Fruit and vegetable facts and pointers. United Fresh Fruit and Vegetable Association, Washington, D.C.

Selma, M.V., Luna, M.C., Martínez-Sánchez, A., Tudela J.A., David Beltrán, D., Carlos Baixauli, C., Gil M.I. 2012. Sensory quality, bioactive constituents and 
REFERENCES

microbiological quality of green and red fresh-cut lettuces (Lactuca sativa L.) are influenced by soil and soilless agricultural production systems. Postharvest Biology and Technology, 63: 16-24.

Shao, H.B., Chu, L.Y., Lu, Z.H., Kang, C.M. 2008. Primary antioxidant free radical scavenging and redox signaling pathways in higher plant cells. International Journal of Biological Sciences, 4: 8-14.

Shibghatallah, M.A.H., Khotimah, S.N., Suhandono, S., Viridi, S., Kesuma, T. 2013. Measuring Leaf chlorophyll concentration from its colour: A way in monitoring environment change to plantations. Padjadjaran International Physics Symposium, 7-8 May 2013, Jatinangor, Indonesia.

Simonne, A., Simonne, E., Eitenmiller, R., Coker, C.H. 2002. Bitterness and composition of lettuce varieties grown in the southeastern United States. HortTechnology, 12:721-726.

Singleton, V. L., Rossi J. A. 1965. Colorimetry of total phenolics with phosphomolybdic-phosphotungstic acid reagents. American Journal Of Enology And Viticulture, 16: 144-158.

Sivasakthi, S., Kanchana, D., Usharani G., Saranraj, P. 2013. Production of plant growth promoting substance by Pseudomonas fluorescens and Bacillus subtilis isolates from paddy rhizosphere soil of Cuddalore District, Tamil Nadu, India. International Journal of Microbiological Research, 4 (3): 227-233.

Smith, E.N., 2007. Watercress (Nasturtium officinale) Production utilizing brook trout (Salvelinus fontinalis) flow-through aquaculture effluent. Thesis submitted to the Davis College of Agriculture, Forestry, and Consumer Sciences at West Virginia University.

Souci, S., Fachmann, W., Kraut, H. 2008. Food composition and nutrition tables. Medpharm Scientific Publishers, Stuttgart, Germany.

Spinu, V.C., Albright, L.D., Langhans, R.W. 1997. Electrochemical pH control in hydroponic systems. Acta Horticulturae, 456: 275-282.

Steiner, A.A. 1961. A universal method for preparing nutrient solutions of a certain desired composition. Plant Soil, 15: 134-154.

Subbarao, G. V., Ito, O., Berry, W. L., Wheeler, R. M. 2003. Sodium: A functional plant nutrient. Critical Reviews in Plant Sciences, 22(5): 391-416. 
Tarakcioglu, C., Inal, A. 2002. Changes induced by salinity, demarcating specific ion ratio $(\mathrm{Na} / \mathrm{Cl})$ and osmolarity in ion and praline accumulation, nitrate reductase activity, and growth performance of lettuce. Journal of Plant Nutrition, 25: 27-41.

Tarazona-Díaz, M. P., Viegas, J. Moldao-Martins, M., Aguayo, E. 2011. Bioactive compounds from flesh and by-product of fresh-cut watermelon cultivars. Journal of the Science of Food and Agriculture, 91: 805-812.

Tardelli, F., Guidi, L., Massai, R., Toivonen, P.M.A. 2013. Effects of 1methylcyclopropene and post-controlled atmosphere air storage treatments on fresh-cut Ambrosia apple slices. Journal of the Science of Food and Agriculture, 93: $262-270$.

Tesi, R., Lenzi, A., Lombardi, P. 2003a. Effect of different $\mathrm{O}_{2}$ levels on spinach (Spinacia oleracea L.) grown in a floating system. Acta Horticulturae, 614: 631637.

Tesi, R., Lenzi, A., Lombardi, P. 2003b. Effect of salinity and oxygen level on lettuce grown in a floating system. Acta Horticulturae, 609: 383-387.

Toivonen, P.M.A., Brummell, D.A. 2008. Biochemical bases of appearance and texture changes in fresh-cut fruit and vegetables. Postharvest Biology and Technology, 48: $1-14$.

Tomás-Callejas, A., Martínez-Hernández, G.B., Artés, F. , Artés-Hernández, F. 2011. Neutral and acidic electrolyzed water as novel sanitizers on fresh-cut mizuna baby leaves. Effects on safety and quality attributes. Postharvest Biology and Technology, 59: 298-306.

Trejo-Téllez, L.I., Gómez-Merino, F.C. 2012. Nutrient Solutions for Hydroponic Systems, Hydroponics - A Standard Methodology for Plant Biological Researches, Dr. Toshiki Asao (Ed.), In Tech, Available from: http://www.intechopen.com/books/hydroponics-a-standardmethodology-forplant-biological-researches/nutrient-solutions-for-hydroponic-systems.

Trought, M.C.T., Drew, C. 1980. The development of water logging damage in young wheat plants in anaerobic solution cultures. Journal of Experimental Botany, 31: 1573-1585.

Tucker, M.R. 1999. Essential plant nutrients: their presence in North Carolina soils and role in plant nutrition. http://www.ncagr.gov/. 
REFERENCES

Urashima, Y., Hori, K. 2003. Selection of PGPR which promotes the growth of spinach. Journal of Soil Science and Plant Nutrition, 74:157-162.

USDA, United States Department of Agriculture. Agricultural Research Service. National Nutrient Database for Standard Reference Release 26, NBD: 11591, 11253, 11427, 11257. Available in: http://ndb.nal.usda.gov/ndb/foods (Accessed January 2014).

Valdés, F. 2006. Vitamina C. Actas Dermo-Sifiliográficas, 97 (9): 557-68.

Vartapetian, B.B. 2006. Plant anaerobic stress as a novel trend in ecological physiology, biochemistry, and molecular biology: further development of the problem. Russian Journal of Plant Physiology, 53 (6): 711-738.

Veen, B. W. 1988. Influence of oxygen deficiency on growth and function of plant roots. Plant And Soil, 111: 259-266.

Vicent, W.F., Downes, M.T. 1980. Variation in nutrient removal from a stream by watercress (Nasturtium officinale R. Br.). Aquatic Botany, 9: 221-235.

Visser, E.J.W., Colmer, T.D., Blom, C.W.P.M., Voesenek, L.A.C.J. 2000. Changes in growth, porosity, and radial oxygen loss from adventitious roots of selected mono- and dicotyledonous wetland species with contrasting types of aerenchyma. Plant, Cell \& Environment, 23: 1237-1245.

Visser, E.J.W., Nabben, R.H.M., Blom, C.W.P.M. and Voesenek L.A.C.J. 1997. Elongation by primary lateral roots and adventitious roots during conditions of hypoxia and high ethylene concentrations. Plant, Cell \& Environment, 20: 647653.

Vivekananthan, R., Ravi, M., Ramanathan, A., Kumar, N., Samiyappan, R. 2006. Preharvest application of a new biocontrol formulation induces resistance to postharvest anthracnose and enhances fruit yield in mango. Phytopathologia Mediterranea, 45: 126-138.

Vodnik, D., Strajnar, P., Jemc, S., Macek, I. 2009. Respiratory potential of maize (Zea Mays L.) Roots exposed to hypoxia. Environmental And Experimental Botany, 65: $107-110$ 
Watada, A. E., Qi, L. 1998. Quality of fresh-cut produce. Postharvest Biology and Technology, 15(3): 201-205.

Wellburn, A. R. 1994. The spectral determination of chlorophyll $a$ and $b$, as well as total carotenoids, using various solvents with spectrophotometers of different resolution. Journal of Plant Physiology, 144: 307-313.

Weston, L.A., Barth, M.M. 1997. Preharvest factors affecting postharvest quality of vegetables. HortScience, 32: 812-816.

Whipps, J.M. 2001. Microbial interactions and biocontrol in the rhizosphere. Journal of Experimental Botany, Roots Special Issue, 52: 487-511.

Williams ,D.J., Critchleya ,C., Punb ,S., Chalihab, M., O’Harec, T.J. 2009. Differing mechanisms of simple nitrile formation on glucosinolate degradation in Lepidium sativum and Nasturtium officinale seeds. Phytochemistry, 70: 1401-1409.

Wilson, P.C. 2009. Water quality notes: Dissolved oxygen. U.S. Department of Agriculture, UF/IFAS Extension Service, University of Florida.

Woitke, M, Hanafi, A., Schnitzler, W.H. 2004. Effect of salinity and Bacillus subtilis on white fly (Trialeurodes vaporariorum, Westwood) in hydroponically grown tomatoes (Lycopersicon esculentum Mill.). Acta Horticulturae, 659: 323-329.

Wolff, X.Y., Coltman, R.R. 1990. Productivity of eight leafy vegetable crops grown under shade in Hawaii. Journal of the American Society for Horticultural Science, 115:182-188.

Workneh, T.S., Osthoff, G. 2010. A review on integrated agro-technology of vegetables. African Journal of Biotechnology, 9: 307-327.

Yan, Z., Reddy M.S., Kloepper, J.W. 2003. Survival and colonization of rhizobacteria in a tomato transplant system. Canadian Journal of Microbiology, 49: 383-389.

Yasufumi, U., Kaneaki, H. 2003. Selection of PGPR which promotes the growth of spinach. Japanese Journal Of Soil Science And Plant Nutrition, 74: 157-162.

Yazdanparast R, Bahramikia S, Ardestani A. 2008. Nasturtium officinale reduces oxidative stress and enhances antioxidant capacity in hypercholesterolaemic rats. Chemico-Biological Interactions: 176-184.

Zapata, S., Dufour, J., 1992. Ascorbic, dehydroascorbic and isoascorbic acid simultaneous determinations by reverse phase ion interaction HPLC. Journal of Food Science, 57: 506-511. 
REFERENCES

Zea, J. 2014. Chinese and Japanese growers increasingly interested in floating raft systems. http://www.hortidaily.com/article/9071/Chinese-and-Japanese-growersincreasingly-interested-in-floating-raft-systems.

Zehnder, G.W., Yao, C., Murphy, J.F., Sikora, E.J., Kloepper, J.W. 2000. Induction of resistance in tomato against cucumber mosaic virus by plant growth-promoting rhizobacteria. Biological Control, 45: 127-137.

Zhan, L. J., Fontana, E., Tibaldi, G., Nicola, S. 2009. Qualitative and physiological response of minimally processed garden cress (Lepidium sativum L.) to harvest handling and storage conditions. Journal of Food, Agriculture and Environment, 7: $43-50$.

Zheng, Y., Wang, L., Dixon, M. 2007. An upper limit for elevated root zone dissolved oxygen concentration for tomato. Scientia Horticulturae: 62-165. 


\section{FIGURE INDEX}

Figure 1: Explanation of treatments in PGPR assay. .37

Figure 2: Evolution of dissolved oxygen (DO) and temperature of the nutrient solution in different crops cycles (1-autumn, 2-spring, 3 and 4-summer). DAS: days after sowing. 48

Figure 3: Evolution of dissolved oxygen (DO) and temperature (Ta) of the nutrient solution under different levels of aeration - no aeration (NA), low aeration (LA), high aeration (HA) - in two different crop cycles. Each datum point for each day after sowing (DAS) is the average of 24 hourly measurements $(\mathrm{n}=3)$.

Figure 4: Effect of the aeration level of the nutrient solution - no aeration (NA), low aeration (LA), high aeration (HA) —on mesophilic (A) and psychrophilic (B) microorganisms in watercress, cultivated in a floating system, either in spring or winter cycles; and the effect on psychrophilic microorganisms (C) at harvest or $7 \mathrm{~d}$ at $5{ }^{\circ} \mathrm{C}$. Values are the mean of three replicates and vertical lines are the least significant difference (LSD) intervals at $\mathrm{P} \leq 0,05$. Different letters indicate significant differences $(\mathrm{P}<$ $0,05)$

Figure 5: Influence of the aeration level of the nutrient solution-no aeration (NA), low aeration (LA), high aeration (HA) — on the headspace partial pressure of $\mathrm{O} 2$ and $\mathrm{CO} 2$ within the polypropylene basket of fresh-cut watercress cultivated in two cycles (spring and winter) and stored for $7 \mathrm{~d}$ at $5{ }^{\circ} \mathrm{C}$. Values are the mean of three replicates \pm SD. .72

Figure 6: Evolution of dissolved oxygen (DO) and temperature ( $\mathrm{T}^{\mathrm{a}}$ ) of the nutrient solution under different levels of aeration (no aeration -NA-, low LA-, high aeration -HA-) in three different crops cycles. Each datum point for each day after sowing (D.A.S.) is the average of 24 hourly measurements. Autumn cycle (A), Winter (B) and summer cycle(C).

Figure 7: Evolution of dissolved oxygen (DO) and temperature $\left(\mathrm{T}^{\mathrm{a}}\right)$ of the nutrient solution under different levels of aeration (no aeration -NA-, low 
FIGURE INDEX

aeration-LA-, high aeration -HA-) in three different growing cycles (autumn -A-, winter -B-, summer -C-). Each datum point for each day after sowing (Das) is the average of 24 hourly measurements $(n=3)$.

Figure 8: Effect on \% of dry matter (A) and nitrate content (B) of the aeration level of the nutrient solution (no aeration -NA-, low aeration -LA-, high aeration -HA-) in red lettuce cultivated in floating system, either in autumn, winter or summer and, the effect on total phenolics (C) and mesophilic microorganism (D) at harvest or $7 \mathrm{~d}$ at $5^{\circ} \mathrm{C}$. Values are the mean of three replicates and vertical lines are the least significant difference (LSD) intervals at $\mathrm{P} \leq 0.05$. Different letters indicate significant differences $(\mathrm{P}<$ $0.05)$

Figure 9: Leaf area of lettuce 'Diveria' for the combination of nitrogen concentration in the nutrient solution and bacterial inoculation in two experiments.

Figure 10: Number of leaves of lettuce 'Ganeria' for the combination of nitrogen concentration in the nutrient solution and bacterial inoculant in two experiments.

Figure 11: Effect of the disinfection of substrate — disinfected substrate (DS) and not disinfected substrate (NDS) - on shoot height (SPH) (A) and PAL (phenylalanine ammonia lyase) (B) in watercress cultivated in a floating system, either B. subtilis inoculation - bacterial inoculation (BI) and not bacterial inoculation (NBI) - Values are the mean of three replicates and vertical lines are the least significant difference (LSD) intervals at $\mathrm{P} \leq 0,05 \ldots . .114$ 


\section{TABLE INDEX}

Table 1: Nutritional content of purslane. Source: Purslane raw. USDA National Nutrient Database for Standard Reference (2015).

Table 2: Nutritional content of red and green lettuce. Source: Lettuce green and red leaf raw. USDA National Nutrient Database for Standard Reference (2015).

Table 3: Nutritional content of watercress. Source: Watercress raw. USDA National Nutrient Database for Standard Reference (2015).

Table 4: Vegetative growth parameters of the shoots and relative chlorophyll contents (RCC; SPAD values) of purslane 'Golden Purslane' and C-215 plants grown in nutrient solutions with different levels of aeration $\ddagger$ The four growth cycles studied were: Experiment 1,Autumn; Experiment 2, Spring; Experiment 3 and Experiment 4, Summer. Data are means \pm SE. $(n=20)$. $\dagger$ Values within the same column followed by a different lower-case letter are significantly different (LSD test) at $\mathrm{P} \leq 0.05$. TThe interaction between aeration and cultivar was not significant. All values are the means of pooled data for both cultivars.

Table 5: Vegetative growth parameters of the roots of purslane 'Golden Purslane' and C-215 plants grown in nutrient solutions with different levels of aeration. \$The four growth cycles studied were: Experiment 1,Autumn; Experiment 2, Spring; Experiment 3 and Experiment 4, Summer. Data are means \pm SE. $(n=$ 20). $\uparrow$ Values within the same column followed by a different lower-case letter are significantly different (LSD test) at $\mathrm{P} \leq 0.05$. TThe interaction between aeration and cultivar was not significant. All values are the means of pooled data for both cultivars.

Table 6: Nitrate, oxalate, $\mathrm{Na}+, \mathrm{K}+$, glutathione, and total phenolics contents, and anti-oxidant capacities of the shoots of 'Golden Purslane' and C-215 purslane plants grown in nutrient solutions with different levels of aeration. $\ddagger$ The four growth cycles studied were: Experiment 1,Autumn; Experiment 2, Spring; Experiment 3 and Experiment 4, Summer. Data are means \pm SE. $(n=20)$. 
$\uparrow$ Values within the same column followed by a different lower-case letter are significantly different (LSD test) at $\mathrm{P} \leq 0.05$. TThe interaction between aeration and cultivar was not significant. All values are the means of pooled data for both cultivars

Table 7: Influence of aeration of the nutrient solution-no aeration (NA), low aeration (LA), high aeration (HA) - at harvest on the growth parameters [specific leaf area (SLA), dry matter content, yield, total root length, root diameter, length of 0 to 0.5 diameter root] of watercress cultivated in spring and winter cycles in a floating system. zValues within the same column followed by a different lower-case letter are significantly different (least significant difference test) at $\mathrm{P} \# 0.05$. yAsterisks indicate significances at $* \mathrm{P}$ $\leq 0.05 ; * * \mathrm{P} \leq 0.01 ; * * * \mathrm{P} \leq 0.001 ; \mathrm{ns}=$ non significant.

Table 8: Influence of aeration of the nutrient solution-no aeration (NA), low aeration (LA), high aeration (HA) — on the biochemical parameters at harvest (total phenolics, antioxidant capacity, vitamin $\mathrm{C}$, nitrate, oxalate, $\mathrm{Ca}^{2+}$ and $\mathrm{K}^{+}$ contents) of watercress cultivated in spring and winter cycles in a floating system. Values within the same column followed by a different lower-case letter are significantly different (least significant difference test) at $\mathrm{P} \leq 0,05$. Asterisk indicates significant differences between spring and winter cycles. ns $=$ non significant. $\mathrm{CAE}=$ chlorogenic acid equivalent; $\mathrm{FW}=$ fresh weight; $\mathrm{AAE}=$ ascorbic acid equivalent. 68

Table 9: Analysis of variance (in percentage of the total sum of squares and probability) of microbial growth (mesophilic and psychrophilic microorganisms) and leaf colour parameters [hue angle, chromaticity $\left(\mathrm{C}^{*}\right)$ and lightness $\left.\left(\mathrm{L}^{*}\right)\right]$ of watercress either at harvest or $7 \mathrm{~d}$ at $5{ }^{\circ} \mathrm{C}$. Asterisks indicate significances at $* \mathrm{P} \leq 0.05 ; * * \mathrm{P} \leq 0.01 ; * * * \mathrm{P} \leq 0.001 ; \mathrm{NS}=$ non significant. .70

Table 10: Interaction (cycle $\cdot$ aeration $\bullet$ storage time) in the parameters of colour [chromaticity $\left(\mathrm{C}^{*}\right)$ and lightness $\left(\mathrm{L}^{*}\right)$ ] of watercress, cultivated in a floating system, with different levels of aeration of the nutrient solution, no aeration (NA), low aeration (LA), high aeration (HA), in two crop cycles (spring and 
winter) stored at $5^{\circ} \mathrm{C}$ for up to 7 days. $\mathrm{zSEM}=0.77$; $\mathrm{LSD}=1.79 . \mathrm{ySEM}=$ $0.81 ; \mathrm{LSD}=1.88 . \mathrm{LSD}=$ least significant difference .74

Table 11: Influence of aeration of the nutrient solution (no aeration -NA-, low aeration -LA-, high aeration -HA-) at harvest on the vegetative plant growth parameters (\% dry matter, specific leaf area (SLA), yield, total root length, root diameter and length of 0 to $1.5 \mathrm{~mm}$ diameter roots) of baby leaf red lettuce cultivated in floating system in autumn, winter and summer cycles * Significant at $\mathrm{P} \leq 0.05$. ** Significant at $\mathrm{P} \leq 0.01$.*** Significant at $\mathrm{P} \leq$ 0.001. Values in each row which do not have any letter in common are significantly different as described by LSD test $(\mathrm{P} \leq 0.05)$.

Table 12: Influence of growing cycle (autumn, winter and summer ) and aeration of the nutrient solution (no aeration -NA-, low aeration -LA-, high aeration HA-) on nitrate content, total phenolics, antioxidant capacity, vitamin $\mathrm{C}$, leaf colour parameters(lightness - $\mathrm{L}_{-}^{*_{-}}$, Hue angle and chromaticity - $\mathrm{C}_{-}$) and microbial growth (mesophilic and psychrophilic microorganisms) of baby leaf red lettuce cultivated in floating system, at harvesting time and after 7 days of storage at $5{ }^{\circ} \mathrm{C}$. ns: non-significant. * Significant at $\mathrm{P} \leq 0.05$. ** Significant at $\mathrm{P} \leq 0.01$.*** Significant at $\mathrm{P} \leq 0.001$. Values in each row which do not have any letter in common are significantly different as described by LSD test $(\mathrm{P} \leq$ $0.05)$.

Table 13: Interaction (cycle $\mathrm{x}$ aeration $\mathrm{x}$ storage time) in the parameters of antioxidant capacity, vitamin $\mathrm{C}$, lightness $\left(\mathrm{L}^{*}\right)$ and psychrophilic microorganisms of red lettuce cultivated in floating system, with different levels of aeration of the nutrient solution (no aeration -NA-, low aeration LA-, high aeration -HA-) in three growing cycles (autumn, winter and summer), stored at $5^{\circ} \mathrm{C}$ for up to 7 days.

Table 14: Vegetative growth parameters of the shoots, and relative chlorophyll content (RCC in SPAD values) and nitrate content of lettuce 'Diveria' grown in two different nutrient solutions with different bacterial inoculants. n.s, *,**,** no significant or significant at $\mathrm{P} \leq 0.05, \mathrm{P} \leq 0.01$ or $\mathrm{P} \leq 0.001$, respectively. 
Table 15: Vegetative growth parameters of the shoots, and relative chlorophyll content (RCC in SPAD values) and nitrate content of lettuce 'Ganeria' grown in two different nutrient solutions with different bacterial inoculants. n.s, $*, * *, * *$ no significant or significant at $\mathrm{P} \leq 0.05, \mathrm{P} \leq 0.01$ or $\mathrm{P} \leq 0.001$, respectively.

Table 16: Vegetative growth parameters of the roots of lettuce 'Ganeria' grown in two different nutrient solutions with different bacteria inoculants. n.s, $*$,**,** no significant or significant at $\mathrm{P} \leq 0.05, \mathrm{P} \leq 0.01$ or $\mathrm{P} \leq 0.001$, respectively.

Table 17: Vegetative growth parameters of the roots of lettuce 'Diveria' grown in two different nutrient solutions with different bacterial inoculants. n.s, $*$,**,*** no significant or significant at $\mathrm{P} \leq 0.05, \mathrm{P} \leq 0.01$ or $\mathrm{P} \leq 0.001$, respectively.

Table 18: Influence at harvest of disinfected substrate (DS) and not disinfected substrate (NDS), and bacterial inoculation (BI) and not bacterial inoculation (NBI) on the growth parameters [shoot height (SH), leaf number (LN) per plant, relative chlorophyll content (RCC), yield, specific leaf area (SLA), dry matter from shoot $(\mathrm{SDM})$, and roots $(\mathrm{RDM})$, Hue $\left(\mathrm{H}^{*}\right)$, Chroma $\left(\mathrm{C}^{*}\right)$ and nitrate content $\left(\mathrm{NO}_{3}^{-}\right)$] of watercress cultivated in a FS. LSD test asterisks indicate significances at $* \mathrm{P} \leq 0.05 ; * * \mathrm{P} \leq 0.01$; *** $\mathrm{P} \leq 0.001$; ns $=$ non significant; S.E.M. = standard error of mean.

Table 19. Influence at harvest of disinfected substrate (DS) and not disinfected substrate (NDS), and bacterial inoculation (BI) and not bacterial inoculation (NBI) on the antioxidant potential and pigment parameters [antioxidant capacity (AC), vitamin $\mathrm{C}$, total phenolics (TP), chlorophyll a (Chl_a), chlorophyll $\mathrm{b}\left(\mathrm{Chl} \_b\right)$ and carotenoids $\left.(C a r)\right]$ of watercress cultivated in a FS. LSD test asterisks indicate significances at $* \mathrm{P} \leq 0.05 ; * * \mathrm{P} \leq 0.01 ; * * * \mathrm{P} \leq$ 0.001; ns = non significant; S.E.M. = standard error of mean. 113

Table 20: Influence at harvest of disinfected substrate (DS) and not disinfected substrate (NDS), and bacterial inoculation (BI) and not bacterial inoculation (NBI) on the phenolic oxidation parameters [browning potential (BP), soluble o-quinone (So-Q), peroxidase (POD), polyphenol oxidase (PPO) 
andphenylalanine ammonia lyase (PAL)] of watercress cultivated in a FS. LSD test asterisks indicate significances at * $\mathrm{P} \leq 0.05 ; * * \mathrm{P} \leq 0.01 ; * * * \mathrm{P} \leq$ 0.001; ns = non significant; S.E.M. = standard error of mean.

Table 21: Influence at harvest of disinfected substrate (DS) and not disinfected substrate (NDS), and bacterial inoculation (BI) and not bacterial inoculation (NBI) on the microbial growth [total bacterial count (TBC), yeast count (YC) and mould count (MC)] of watercress cultivated in a FS. LSD test asterisks indicate significances at $* \mathrm{P} \leq 0,05 ; * * \mathrm{P} \leq 0,01 ; * * * \mathrm{P} \leq 0,001 ; \mathrm{ns}=$ non significant; S.E.M. - standard error of mean .115 


\section{PICTURE INDEX}

Picture 1: Floating raft system. (Source: www.hortidaily.com) ...........................5

Picture 2: Purslane cultivars grown in floating system. .................................... 42

Picture 3 Root aerenchyma tissue in transverse sections of the roots of 'Golden Purslane' grown under different levels of aeration: no aeration (Panel A), low aeration (Panel B), or high aeration (Panel C); and of C-215 purslane grown under different levels of aeration: no aeration (Panel D), low aeration (Panel E), or high aeration (Panel F). Samples represent roots at harvest time in the Summer cycle (Experiment 4). Arrows indicate aerenchyma air spaces. All

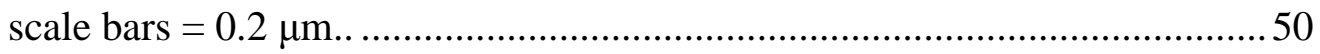

Picture 4: Watercress plant grown in floating system. ......................................57

Picture 5: Red lettuce at the end of the experience............................................. 76

Picture 6: 'Ganeria' and 'Diveria' lettuce growing floating system..................... 92

Picture 7: Watercress experience in the glasshouse in Torino. ......................... 104

Picture 8: PCA with bacterial growth from Larminar ${ }^{\circledR}$, bottle with B. subtilis suspension and inoculation of the substrate 107 